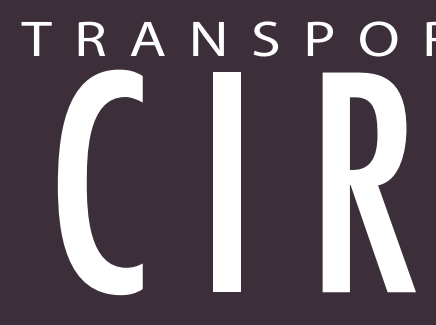

Number E-C134

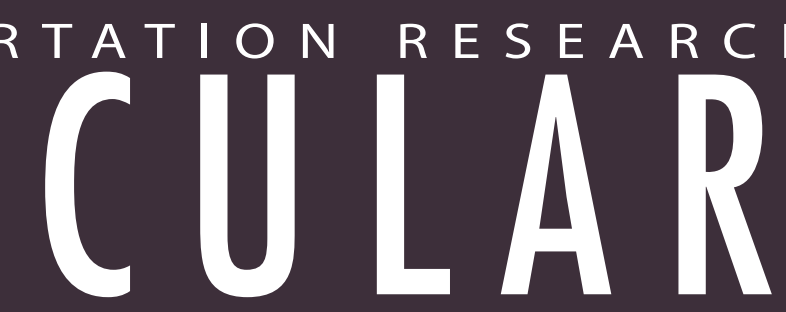

May 2009

\title{
Influence of \\ Roadway Surface \\ Discontinuities \\ on Safety
}

State of the Art Report

TRANSPORTATION RESEARCH BOARD

OF THE NATIONAL ACADEMIES 


\section{TRANSPORTATION RESEARCH BOARD 2009 EXECUTIVE COMMITTEE OFFICERS}

Chair: Adib K. Kanafani, Cahill Professor of Civil Engineering, University of California, Berkeley

Vice Chair: Michael R. Morris, Director of Transportation, North Central Texas Council of Governments, Arlington

Division Chair for NRC Oversight: C. Michael Walton, Ernest H. Cockrell Centennial Chair in Engineering, University of Texas, Austin

Executive Director: Robert E. Skinner, Jr., Transportation Research Board

\section{TRANSPORTATION RESEARCH BOARD} 2009-2010 TECHNICAL ACTIVITIES COUNCIL

Chair: Robert C. Johns, Director, Center for Transportation Studies, University of Minnesota, Minneapolis

Technical Activities Director: Mark R. Norman, Transportation Research Board

Jeannie G. Beckett, Director of Operations, Port of Tacoma, Washington, Marine Group Chair

Paul H. Bingham, Principal, Global Insight, Inc., Washington, D.C., Freight Systems Group Chair

Cindy J. Burbank, National Planning and Environment Practice Leader, PB, Washington, D.C., Policy and Organization Group Chair

James M. Crites, Executive Vice President, Operations, Dallas-Fort Worth International Airport, Texas, Aviation Group Chair

Leanna Depue, Director, Highway Safety Division, Missouri Department of Transportation, Jefferson City, System Users Group Chair

Robert M. Dorer, Deputy Director, Office of Surface Transportation Programs, Volpe National Transportation Systems Center, Research and Innovative Technology Administration, Cambridge, Massachusetts, Rail Group Chair

Karla H. Karash, Vice President, TranSystems Corporation, Medford, Massachusetts, Public Transportation Group Chair

Edward V. A. Kussy, Partner, Nossaman, LLP, Washington, D.C., Legal Resources Group Chair

Mary Lou Ralls, Principal, Ralls Newman, LLC, Austin, Texas, Design and Construction Group Chair

Katherine F. Turnbull, Associate Director, Texas Transportation Institute, Texas A\&M University, College Station, Planning and Environment Group Chair

Daniel S. Turner, Professor, University of Alabama, and Director, University Transportation Center for Alabama, Tuscaloosa, Operations and Maintenance Group Chair 


\title{
Influence of Roadway Surface Discontinuities on Safety
}

\author{
State of the Art Report
}

\author{
Sponsored by the \\ Surface Properties-Vehicle Interaction Committee \\ Transportation Research Board
}

May 2009

Transportation Research Board

500 Fifth Street, NW

Washington, DC 20001

WWW.TRB.org 


\title{
TRANSPORTATION RESEARCH CIRCULAR E-C134
}

ISSN 0097-8515

The Transportation Research Board is one of six major divisions of the National Research Council, which serves as an independent adviser to the federal government and others on scientific and technical questions of national importance. The National Research Council is jointly administered by the National Academy of Sciences, the National Academy of Engineering, and the Institute of Medicine. The mission of the Transportation Research Board is to provide leadership in transportation innovation and progress through research and information exchange, conducted within a setting that is objective, interdisciplinary, and multimodal.

The Transportation Research Board is distributing this Circular to make the information contained herein available for use by individual practitioners in state and local transportation agencies, researchers in academic institutions, and other members of the transportation research community. The information in this Circular was taken directly from the submission of the authors. This document is not a report of the National Research Council or of the National Academy of Sciences.

Design and Construction Group

Mary Lou Ralls, Chair

Pavement Management Section

Thomas J. Kazmierowski, Chair

Surface Properties-Vehicle Interaction Committee
Kevin K. McGhee, Chair
Don L. Ivey, Task Group Leader
Betsy Preston Hamilton, Task Group Secretary

Forrest M. Council Bob Gallaway

Thomas D. Gillespie John J. Henry

\author{
Jack Humphreys \\ Fran Julian \\ Francesca La Torre \\ Kevin K. McGhee
}

Dean L. Sicking
James C. Wambold
Thomas J. Yager
Richard Z. Zimmer

Stephen Maher, TRB Staff Representative

Michael DeCarmine, Senior Program Assistant

\author{
Transportation Research Board \\ 500 Fifth Street, NW \\ Washington, DC 20001 \\ www.TRB.org
}

Glenda J. Beal, Production Editor; Deborah Uffelman, Proofreader; and Joanne Endres, Grammarians, Inc., Layout 


\section{Contents}

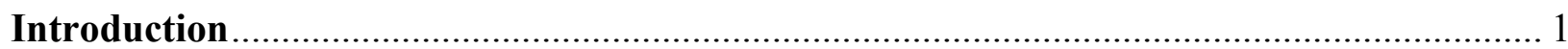

Don L. Ivey and Francesca La Torre

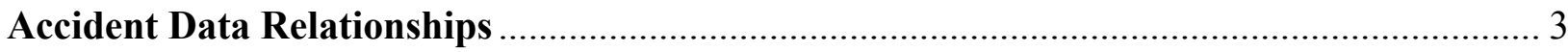

Forrest M. Council, Lindsay I. Griffin III, S. L. Hallmark, and Jack Humphreys

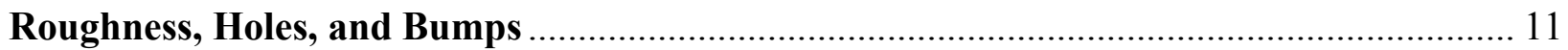

James C. Wambold, Richard A. Zimmer, Don L. Ivey, and Dean L. Sicking

Positive Effects of Road Surface Discontinuities.............................................................. 25

Francesca La Torre

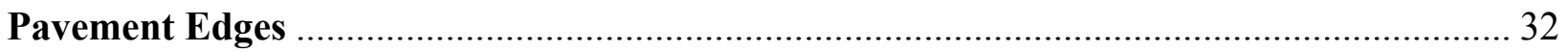

Don L. Ivey, Richard A. Zimmer, Frank Julian, Dean L. Sicking, Walter A. Johnson, and

Eric F. Nordlin

Friction Variations.

John C. Burns, Wolfgang E. Meyer, Gordon F. Hayhoe, J. J. Henry, and Don L. Ivey

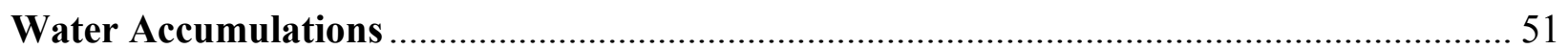

Thomas Yager, Bob Gallaway, Don L. Ivey, and John M. Mounce

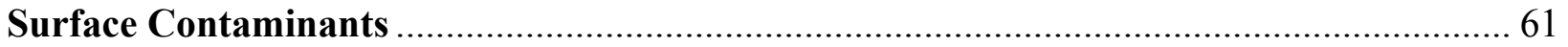

E. A. Whitehurst, Don L. Ivey, and J. J. Henry

Small and Large Vehicles

Lindsay I. Griffin III and Thomas D. Gillespie

Summary

Forrest M. Council and Don L. Ivey 



\title{
Introduction
}

\author{
DON L. IVEY \\ FranCESCA LA TORRE
}

$\mathrm{A}_{\text {s the commitment to improve highway safety emerged in the late 1960s and the philosophy }}$ challenged the highway engineer to find a practical solution. Prominent among these issues were (a) tire-pavement available friction, (b) influence of potholes and road surface roughness, (c) water accumulations, and (d) influence of pavement edge drop-offs.

These issues were important because these conditions can never be completely eliminated in all roadways all the time. Thus it was important to be able to prioritize treatment of these conditions so that with limited funds the highest influence on safety could be achieved. This need was addressed by the Transportation Research Board (TRB) Surface Properties-Vehicle Interaction (AFD90) Committee. This committee set up a task group on Roadway Surface Discontinuities and Safety. That group was active from 1980 until the publication of TRB's first state of the art report in 1983. That report, "The Influence of Roadway Surface Discontinuities on Safety," was the culmination of the task group's work.

In subsequent years many of the members of the original task group remained active in the various areas of relevant study. In so doing, they were acutely aware that by 2003 TRB's first state of the art report no longer reflected the state of the art and that revision was needed in areas where new information obtained through both research and experience had become available.

The TRB Surface Properties-Vehicle Interaction (AFD90) Committee set up a new task group to update the 1983 State of the Art Report 1 (SOAR 1) in 2003. That new group is composed of members of the original task group plus others enlisted to provide expertise in various areas.

Members of the new task group have rewritten sections of SOAR 1 (1983), retaining that information still viable and changing and adding new information. The result is this report.

The most important changes since SOAR 1 was published are

1. Hydroplaning. It was found, contrary to common engineering understanding in 1983, that large tractor/trailer rigs (18 wheelers) were also subject to hydroplaning at usual highway speeds when in an unloaded condition. Further advances were made in predicting hydroplaning critical speeds.

2. Holes and Bumps. Research was completed in defining road roughness frequencies that are most influential in affecting tire-pavement friction. Due to the style changes initiated by automobile manufacturers that make 17 to 20 inch rims available, these modern rims are more susceptible to damage and thus to air-outs due to interaction with holes, bumps, and edges.

3. Edge Conditions. In $1983 \mathrm{few}$ tests of edge conditions above $55 \mathrm{mph}$ had been conducted. Speed limits of $70 \mathrm{mph}$ are now common. Recent research has shown some pavement edges to be of more concern at elevated speeds resulting in changes in some maintenance and construction recommendations. Research on certain edge shapes has shown safety improvements that can be made during construction and maintenance. These improved methods are gaining acceptance through a combination of research and positive experience. 
4. Positive Effects of Road Surface Discontinuities has been added. It deals with positive influences of discontinuities such as rumble lines, rumble strips, rumble zones, and speed bumps.

These innovations, powerfully cost effective, are expected to become widespread in use. The current objectives of TRB Committee AFD90 in preparing this report are consistent with those originally stated in 1983. The writers trust that this document will be useful to practicing highway engineers in making evaluations of maintenance guidelines and priorities. 


\title{
Accident Data Relationships
}

\author{
FORREST M. COUNCIL \\ LINDSAY I. GRIFFIN III \\ S. L. HALLMARK \\ JACK HUMPHREYS
}

\begin{abstract}
$\mathrm{T}$ raffic accidents can be complex events. To assume that traffic accidents or a given subset of traffic accidents (e.g., accidents that result from inadequate surface friction) can be accurately predicted on the basis of one antecedent condition such as skid number is wishful thinking.

Making the situation even more difficult is the fact that accidents are rarely categorized as resulting from inadequate surface friction. Instead, some surrogate for inadequate friction must be found. The usual candidate is wet surface accidents. The tacit assumption in choosing this surrogate is that an accident that occurs on a wet surface is the result of inadequate friction. As Hegmon (1) points out, accidents that occur on wet surfaces may or may not be associated with inadequate friction. It follows that it is extremely difficult to predict wet surface accidents solely on the basis of skid number.
\end{abstract}

\section{SURFACE FRICTION AND TRAFFIC ACCIDENTS}

In a review of the literature on the association between wet surface accident rate and skid number, an unsatisfactory association between the two measures was demonstrated (2). In that review a simple linear regression of wet accident rate on skid number (SN70) was calculated for data contained in Rizenbergs et al. (3). The resulting equation was

$\mathrm{AR}=31.80-0.55 \mathrm{SN}$

where AR is the wet accident rate (wet accidents per 100 million vehicle miles), and $\mathrm{SN}$ is the skid number (SN70) predicted for a speed of $70 \mathrm{mph}$. This equation accounted for 8.7 percent of the variance in wet accident rate.

This same regression procedure was then applied to a second set of data provided by Rizenbergs et al. (4). In this case, the resulting equation was

$\mathrm{AR}=101.58-1.51 \mathrm{SN}$

(Note that for this second data set skid numbers were recorded at $40 \mathrm{mph}$.) This second regression equation accounted for 9.6 percent of the variance in the wet accident rate.

Equation 1 was based on data for rural, four-lane, controlled-access highways. Equation 2 was based on rural, two-lane roads. The low values of 8.7 and 9.6 percent indicate that skid number alone is not extremely helpful in predicting wet weather accident rates.

A 1998 study by Jayawickrama and Thomas (5) provided some understanding concerning why measured skid numbers do not correlate well with accident rates. In that study, repeated measures of skid resistance data were collected on the same six pavement sections over 18 months. The authors found that the measured skid numbers varied as much as 10 to 12 skid 
numbers for the same location, depending on temperature and precipitation. Thus, a single measured number is a questionable indication of true skid resistance.

In addition it should be recognized that the frictional properties of a road surface are not inherently adequate or inadequate. Rather, those surface properties are adequate or inadequate in terms of specific vehicle maneuvers - stopping, turning, accelerating (i.e., vehicle demand for friction). This fact has been recognized directly or indirectly in a number of studies (6-11).

In the study by Ivey and Griffin (6), wet weather accidents were used as a surrogate for accidents that result from inadequate friction. Several variables were used as surrogates for vehicle demand for friction:

$\mathrm{ADT}=$ average daily traffic,

$\mathrm{ACC}=$ access (a standardized subjective scale of roadway congestion),

$\mathrm{SN}=$ skid number at $40 \mathrm{mph}$,

$\mathrm{TW}=$ proportion of time wet,

$\mathrm{VM}=$ mean traffic speed,

$V=$ variation in traffic speed (one standard deviation from the mean), and

$\mathrm{LN}=$ lanes of traffic.

For 32 segments of highway on high-speed roads $(55 \mathrm{mph})$, wet accident rates (WARS) ranged from 0 to 6.56. Approximately 58 percent of the variance in WAR could be accounted for by the following standard multiple linear-regression equation:

$$
\begin{aligned}
\mathrm{WAR}= & 21.7+0.0009 \mathrm{ADT}+2.34 \mathrm{ACC}-0.40 \mathrm{SN} \\
& +286 \mathrm{TW}+1.32 \mathrm{LN}
\end{aligned}
$$

(Note that the units of WAR are wet pavement accidents per mile per year.)

For 36 segments of highway on low-speed roads $(<55 \mathrm{mph})$, the WARs ranged from 0 to 40.41. Approximately 46 percent of the variance in WAR could be accounted for by the following standard multiple linear-regression equation:

$$
\begin{aligned}
\mathrm{WAR}= & -0.75+0.0001 \mathrm{ADT}-0.053 \mathrm{VM}+0.54 \mathrm{~V} \\
& +069 \mathrm{ACC}-0.025 \mathrm{SN}
\end{aligned}
$$

Although Equations 3 and 4 still leave a large portion of the variation in the dependent variable unaccounted for, note that by tacitly taking demand for friction into account in these equations, much greater accuracy is achieved in predicting WAR than would have been possible on the basis of SN alone. This is emphasized by comparing the values of 58 and 46 percent (which roughly account for half the variation) to the values of 8.7 and 9.6 percent (which account for roughly one-tenth of the variation).

In a more recent study, Xiao et al. (12) attempted to predict wet pavement accidents using a fuzzy logic model, an alternative to traditional regression models such as the one noted above. The authors concluded that while more developmental work is necessary, the fuzzy logic models appear to be more accurate and reliable than nonlinear regression models. Their models indicated a relationship between wet-weather accidents per mile and skid number, posted speed, average daily traffic, pavement wet time, and driving difficulty. The latter is a high, medium, low rating 
for a section of roadway based on horizontal and vertical alignment, signalization, presence of turn lanes, number of access points, and surrounding land use.

That combining measurements of skid resistance with wet pavement data is predictive of wet weather crashes is further supported by the results of New York State DOT's Skid Accident Reduction Program (SKARP) (13). Since they could not obtain accurate and timely data on rainfall for every pavement section on the state system, the DOT compared the proportion of wet weather crashes at each site with the proportion for similar roads in the same county. The assumption here is that rainfall (and thus wet pavement exposure) would be similar across a county, a reasonable assumption. If a location has a wet weather crash rate that is 50 percent or more higher than the wet weather crash proportion for all roads in the same county for two years, and if it has a low skid number, it is treated with an overlay or microsurfacing as part of the maintenance program. Preliminary analysis of before and after data indicates reductions of 50 percent for wet road accidents and 20 percent for total accidents. While these results could be somewhat inflated due to possible regression-to-the-mean bias, there is fairly clear indication that the site selection or treatment program is effective. Again, the results further support the finding that skid numbers need to be used in combination with rainfall or other similar data if they are used to predict safety.

During the study of truck tire hydroplaning in 1984 Chira-Chavala (14) analyzed wet single-vehicle accidents of commercial vehicles compared to dry accidents. It was found that empty rigs were three times more likely to be involved in losses of control than were loaded rigs. This was considered to be strong circumstantial evidence that empty rigs were going out of control due to sensitivity to hydroplaning at common highway speeds. This overrepresentation is illustrated by Figure 1 .

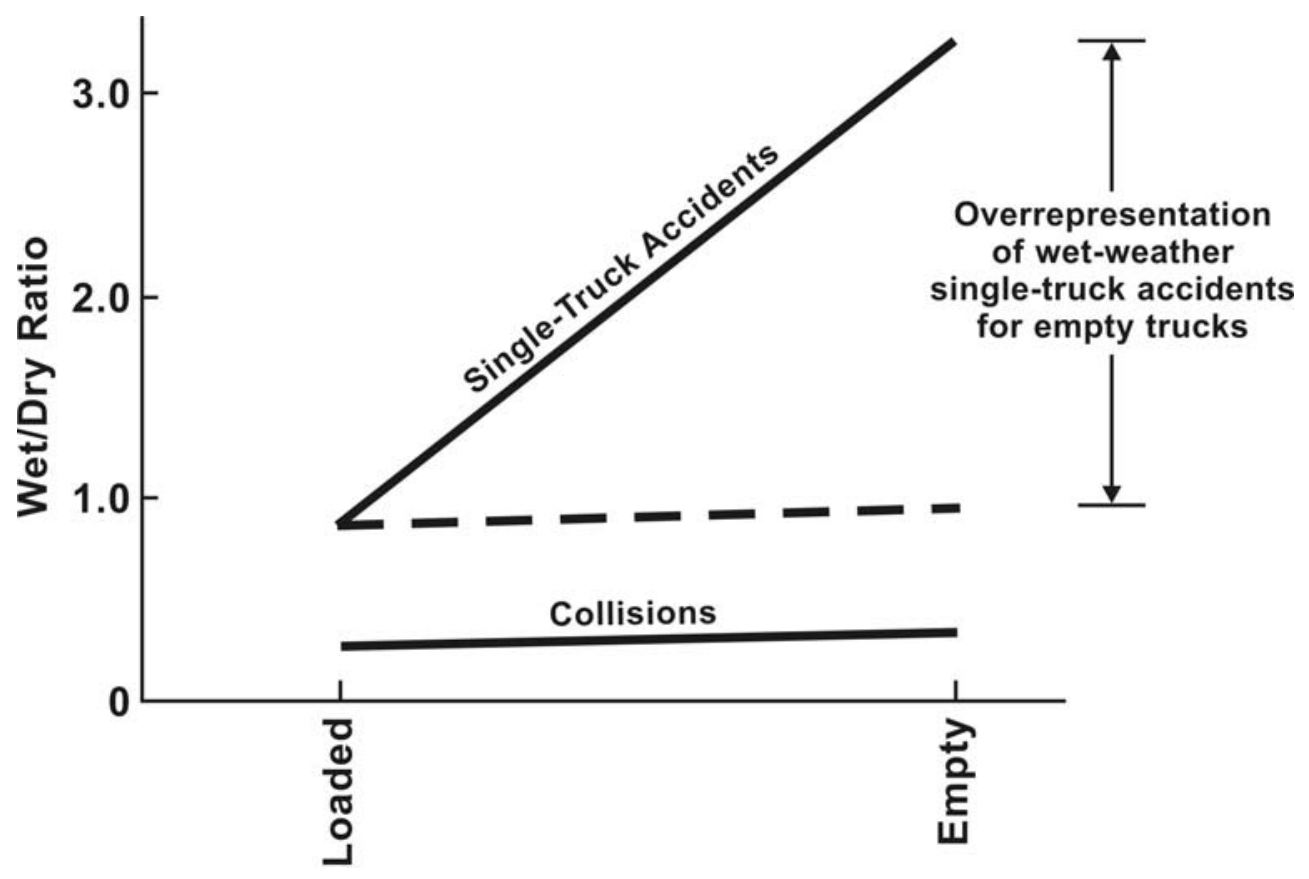

FIGURE 1 Means of wet to dry ratios for single-truck accidents and collisions. 


\section{SURFACE DISCONTINUITIES AND TRAFFIC ACCIDENTS}

The literature on the relationship between roadway discontinuities and traffic accidents is limited. If discontinuities are related to crash risk, then a significant problem could exist, particularly on two-lane rural roads. As reported by Neuman et al. (13), approximately 39 percent of the fatal crashes occurring annually - approximately 15,000 fatal crashes - involve a vehicle departing the roadway. Of these roadway departure fatal crashes, approximately 50 percent occur on rural two-lane roads. An additional 14 percent of fatal crashes are head-on crashes, some of which could be unsuccessful recoveries from roadway departures. Studies which have attempted to look at both the extent of roadway discontinuities (e.g., pavement edge drops, pavement ruts, potholes, etc.) and the relationship of these discontinuities to crashes include the following.

A 2006 study by Hallmark et al. (15) examined the frequency and magnitude of pavement edge drop on rural two-lane roads with ADT of 400 vehicles per day (vpd) or greater in two midwestern states. Randomly sampling sections of these roadways, the researchers found that 22 percent of the total sampled mileage in one state and 31 percent in the second state had edge drops of no greater than 1.0 inches. Edge drops of 2.5 inches or greater were found on 3.3 percent and 7.1 percent of the sampled mileage in the two states. Note that the sampled roads were all state-system roads, and edge drops may be found more often on non-state-system roads (i.e., county or local roads) where maintenance funding may be more limited. These two states are believed to have very good shoulder maintenance programs, and thus it is perhaps unlikely that these statistics represent state systems in other states.

Unfortunatley, no other studies of edge drop extent or on the extent of other roadway discontinuities were found.

With respect to roadway discontinuities and crashes, Ivey and Griffin (16) examined 15,968 single-vehicle accidents that occurred in North Carolina in 1974. Police officers' narratives for all 15,968 accidents were read by automated means. Any narrative that contained 1 of 19 key words (e.g., dip, rocks, rut, edge) was printed out and reviewed by the authors to determine if that accident resulted from, or was aggravated by, a roadway discontinuity. Approximately 566 (3.5 percent) of the 15,968 accidents were associated with roadway disturbances.

The data in Table 1 are adapted from the original report. Note that police accident reports are not always correct in indicating the elements that contribute to a specific accident because of a wide variation in officer experience and capability. Nevertheless, even with this known shortcoming, the keyword-narrative data-retrieval system developed by the North Carolina Highway Safety Research Center is a powerful tool.

The authors inferred that approximately half of the accidents reported in Table 1 resulted from a disturbance off of the traveled surface (e.g., "which dropped off the pavement," "vehicle hit curb and overturned") and half resulted from disturbances in the lane of travel (e.g., "vehicle hit bump in road," "ruts in road caused loss of control").

Klein et al. (17) reviewed accident data from three sources: California accident data (police level data), collision performance and injury report (CPIR) data provided by the Highway Safety Research Institute of the University of Michigan, and Indiana accident data (levels II and III) provided by Indiana University. Their findings were based on 23 hard copies from the California files, 26 from the Michigan files, and 22 from the Indiana files. The authors concluded that the most significant roadway disturbance is shoulder drop-off, closely followed by loose material on roadway. Lesser disturbances included potholes, rough roads, dips, and roadway design faults. 
TABLE 1 Number of Accidents from Discontinuity (Keyword)

\begin{tabular}{|l|c|l|c|}
\hline Disturbance & Frequency & Disturbance & Frequency \\
\hline Water & 143 & Patch & 11 \\
\hline Dropped & 173 & Bump & 9 \\
\hline Soft & 71 & Dip & 9 \\
\hline Curb & 62 & Rocks & 4 \\
\hline Edge & 59 & Ruts & 4 \\
\hline Hole & 34 & Track & 3 \\
\hline Rail & 24 & Rut & 2 \\
\hline Drop & 23 & Manhole & 2 \\
\hline Rock & 19 & Bumps & 2 \\
\hline Surface & 12 & Total & 566 \\
\hline
\end{tabular}

In a more recent (2005) study, Dixon (18) examined the extent to which roadway factors including pavement edge drop were possible causal factors in rural two-lane road fatal crashes. The authors randomly selected 150 fatal crashes on both state-system and non-state-system roads in Georgia, visited the crash locations, and recorded roadway characteristics. Although they were not initially looking for drop-off, it was noted at a number of locations investigated. The researchers estimated that in 38 of the 69 non-state-system fatal crashes ( 55 percent), edge rutting or edge drop-off was present. In 21 of the 38 sites where drop-off was present, the authors determined that it appeared to be one of the crash causal factors. The researchers also felt that edge drop was more likely to have been present when they investigated crashes on non-statesystem roads than on state-system roads.

In the 2006 study referenced above, Hallmark et al. (15) conducted a comprehensive examination of pavement edge drop-offs (EDOs) which include reviewing of national and state guidelines on maximum acceptable drop-offs on existing roadways and during construction or repaving, sampling the frequency of drop-offs in two states, determining what roadway characteristics were correlated with higher incidence of EDOs, estimating the numbers of crashes related to EDO in four states, and developing a model predicting EDO crashes as a function of measured drop-off and other roadway factors in two states. With respect to estimation of EDO crashes on two-lane rural roads, the extent of the problem, police narratives and sketches on samples of crash report forms from four states (North Carolina, Illinois, Iowa, and Missouri) were examined by researchers who made judgments on whether each crash was a "probably" or "possible" drop-off related crash. Although the judgments were made by different researchers, while the amount of detail on the state crash forms differed from state to state, and while the sampling was from state-system roads in two states but all rural two-lane roads in the other two, an attempt was made to use the same methodology. In general, a "probably" drop-off crash was one where the police sketch indicated the possibility of tire scrubbing (i.e., the vehicle was drawn parallel to and near the pavement edge during the crash sequence) and the shoulder condition indicating the presence of an edge drop. A "possible" drop-off crash again included some indication of a tire-scrubbing condition, but was unclear on shoulder condition. Obviously, since tire scrubbing is not routinely investigated or recorded by the police, these were researcher judgments based on the data available. The results for the samples of crash report forms reviewed were then extrapolated to estimate the proportion of total crashes and the proportion of 
single-vehicle run-off-road crashes involving "probably" and "possible" drop-offs in each state. The results indicated that the percent of two-lane rural road crashes which were "probable" EDO crashes ranged from 0.01 percent to 0.12 percent across the four states. The percent of two-lane rural road crashes that were "possible" EDO crashes ranged from 0.57 percent to 1.24 percent. For these same roads, the percent of single-vehicle run-off-road crashes that were "probably" EDO crashes ranged from 0.14 percent to 1.24 percent, and those that were "possible" EDO crashes ranged from 1.89 percent to 12.44 percent.

Finally, using data from Iowa and Missouri, the research team attempted to explore the issue of critical height of EDO by developing negative-binomial regression models where potential EDO crashes per mile were modeled as a function of AADT, lane width, shoulder width, and a specific fraction of drop-off measurements above a given height or within a given height interval. The height intervals examined were all 2.0 inches or greater. Note that the crashes being modeled here were not the same as in the "problem-size" analysis, since it was not possible to manually examine the report form for each crash. These potential EDO crashes included five different crash types (e.g., head-on crashes into opposing vehicles after running off the road), but the largest component was all run-off-road right crashes. The Iowa results indicated that the fraction of edge drops above 2.5 inches for a roadway segment was a statistically significant predictor of these potential EDO crashes. The Missouri results, based on a much smaller sample, did not show any of the EDO variables to be significant predictors.

In summary, although most authorities would agree that road surface discontinuities may precipitate or aggravate accidents, the magnitude of the problem still remains in question for many such discontinuities. The 2006 research effort provided some information on edge drops. It appears that while the number and proportion of total crashes that are EDO related is small, it is large enough to continue to warrant attention, particularly given that there are existing repaving techniques that can be used to eliminate the problem (e.g., see FHWA's "safety edge" at http://safety.fhwa.dot.gov/roadway_dept/docs/sa05003.htm).

Unfortunately, however, even this somewhat limited available knowledge from accident data of the relationship between the magnitude and shape of the drop-off itself and the hazard presented has not resulted in reasonably uniform warning or remedial action among various highway agencies. The Hallmark et al. (15) report lends credibility to this concern in that during construction activity, one state reported that a $3 / 4$ inch drop-off required warning signing, while another state requires signing only when the drop-off equals or exceeds 3 inches. That latter state, interestingly, also reports that "any" drop-off is considered hazardous. Such widespread admissions of hazard and lack of agreement among various governmental agencies as to how to address those hazards are frequently difficult to overcome by defendants in tort claims litigation. The fact that resurfacing contracts in some counties and municipalities are still being funded without a requirement that shoulders be brought up to pavement level is indicative of the need for the most recent information reaching those entities.

\section{REFERENCES}

1. Hegmon, R. R. Wet Weather Accidents and Pavement Skid Resistance. Public Roads, Vol. 54, No. 2, Sept. 1981, pp. 68-74.

2. McFarland, W. F., L. I. Griffin, III, J. B. Rollins, W. R. Stockton, D. T. Phillips, and C. L. Dudek. Assessment of Techniques for Cost-Effectiveness of Highway Accident Countermeasures. Final Report. Texas Transportation Institute, Texas A\&M University, College Station, 1979.

3. Rizenbergs, R. L., J. L. Burchett, and C. T. Napier. Accidents on Rural Interstate and Parkway Roads and Their Relation to Pavement Friction. Kentucky Bureau of Highways, Lexington, 1973. 
4. Rizenbergs, R. L., J. L. Burchett, and L. A. Warren. Accidents on Rural, Two-Lane Roads and Their Relation to Pavement Friction. Kentucky Bureau of Highways, Lexington, 1976.

5. Jayawickrama, P. W., and B. Thomas. Correlations of Field Skid Measurements for Seasonal Variations in Texas. In Transportation Research Record 1639, TRB, National Research Council, Washington, D.C., 1998, pp. 147-154.

6. Ivey, D. L., and L. I. Griffin, III. Development of a Wet Weather Safety Index. Texas Transportation Institute, Texas A\&M University, College Station, 1977.

7. Weaver, G. D., K. D. Hankins, and D. L. Ivey. Factors Affecting Vehicle Skids: A Basis for Wet Weather Speed Zoning. Texas Transportation Institute, Texas A\&M University, College Station, 1973.

8. Dunlap, D. F., P. S. Fancher, R. E. Scott, C. C. MacAdam, and L. Segel. Influence of Combined Highway Grade and Horizontal Alignment on Skidding. Vol.1, Final Report. Highway Safety Research Institute, Institute of Science and Technology, University of Michigan, Ann Arbor, 1974.

9. Blackburn, R. R., D. W. Harwood, A. D. St. John, and M. C. Sharp. Effectiveness of Alternative Skid Reduction Measures. Volume 1: Evaluation of Accident Rate-Skid Number Relationships. Midwest Research Institute, Kansas City, Mo., 1978.

10. Schulze, K. H., A. Gerbaldi, and J. Chavet. Skidding Accidents, Friction Numbers, and the Legal Aspects Involved: Report of the PIARC Technical Committee on Slipperiness and Evenness. In Transportation Research Record 623, TRB, National Research Council, Washington, D.C., 1977, pp. 1-10.

11. Burchett, J. L., and R. L. Rizenbergs. Frictional Performance of Pavements and Estimates of Accident Probability. Presented at ASTM Symposium on Surface Characteristics and Materials, Orlando, Fla., December $11,1980$.

12. Xiao, J., B. T. Kulakowski, and M. El-Gindy. Prediction of Wet-Pavement Accidents: Fuzzy Logic Model. In Transportation Research Record: Journal of the Transportation Research Board, No. 1717, TRB, National Research Council, Washington, D.C., 2000, pp. 28-36.

13. Neuman, T. R., R. Phefer, K. L. Slack, K. K. Hardy, F. M. Council, H. McGee, L. Prothe, and K. Eccles. NCHRP Report 500. Guidance for Implementation of the AASHTO Strategic Highway Safety Plan, Vol. 6: A Guide for Addressing Run-Off-Road Collisions. Transportation Research Board of the National Academies, Washington, D.C., 2003, pp V29-30.

14. Chira-Chavala, T. Study of Accident Experience of Large Trucks and Combination Vehicles. Unpublished Ph.D. dissertation, pp. 181-230. Department of Civil Engineering, University of Michigan, Ann Arbor, Aug. 1984.

15. Hallmark, S. L., D. Veneziano, T. McDonald, J. Graham, K. Bauer, R. Patel and F. Council. Safety Impacts of Pavement Edge Drop-offs. AAA Foundation for Traffic Safety, Washington, D.C., 2006.

16. Ivey, D. L., and L. I. Griffin, III. Driver/Vehicle Reaction to Road Surface Discontinuities and Failures-The Hidden Trigger to Accidents. Presented at 16th International Congress of the International Federation of the Societies of Automotive Engineers, Tokyo, May 1976.

17. Klein, R. H., W. A. Johnson, and H. T. Szostak. Influence of Roadway Disturbances on Vehicle Handling. Final Report. Systems Technology, Inc., Hawthorne, Calif., Oct. 1976.

18. Dixon, K. The Pavement Edge Drop-off Crash Problem in Georgia. Paper presented at the Federal Highway Administration Workshop, February 11, 2004. 



\title{
Roughness, Holes, and Bumps
}

\author{
JAMES C. WAMBOLD \\ RICHARD A. ZIMMER \\ DON L. IVEY \\ DEAN L. SICKING
}

\begin{abstract}
$\mathrm{M}$ ost people are aware of extreme cases of roughness, such as the potholes and severe bumps. The effect of these surface irregularities on safety is widely recognized. The hazard of a washboard road where a driver can lose control of a vehicle at inappropriate speeds is readily understood. The transition of a roadway from a smooth surface to a rough one, however, may give a driver difficulty in controlling his vehicle and can be more subtle in its influence on safety. By violating driver expectancy, a road that is differentially rough may be less safe than a uniformly rough road. See Figures 1 and 2.
\end{abstract}

\section{ROUGHNESS}

Studies of the effects of roughness on vehicle handling characteristics were conducted in 1972 by Quinn and Hildebrand (1, 2), by Brickman et al. (3), and by Wambold et al. (4). These studies demonstrate that pavement roughness had an effect on the tire-pavement friction available to the vehicle. The Quinn and Hildebrand study demonstrated the effect of pavement roughness on steering, and the study by Wambold et al. demonstrated the effect of pavement roughness on traction.

The relationship between road roughness and accident risk was reported by Parr in 1973 (5). In 1975 Hutchinson et al. (6) reported that traction is highly dependent on the speed at which a driver traverses a rough road; thus when frictional measurements are made at speeds other than the test speed, road profile data should be considered. Therefore, frictional predictions without profile considerations can result in gross errors. In 1976 Ivey and Griffin (7) reported on the

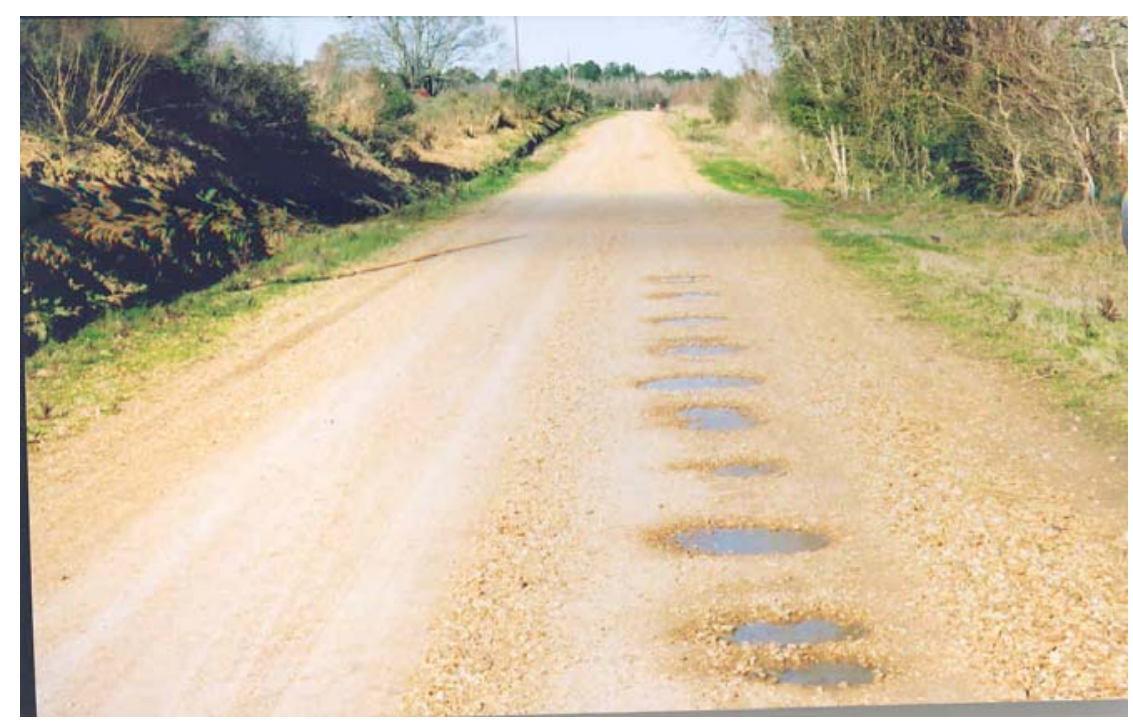

FIGURE 1 Critical roughness on gravel farm road. 


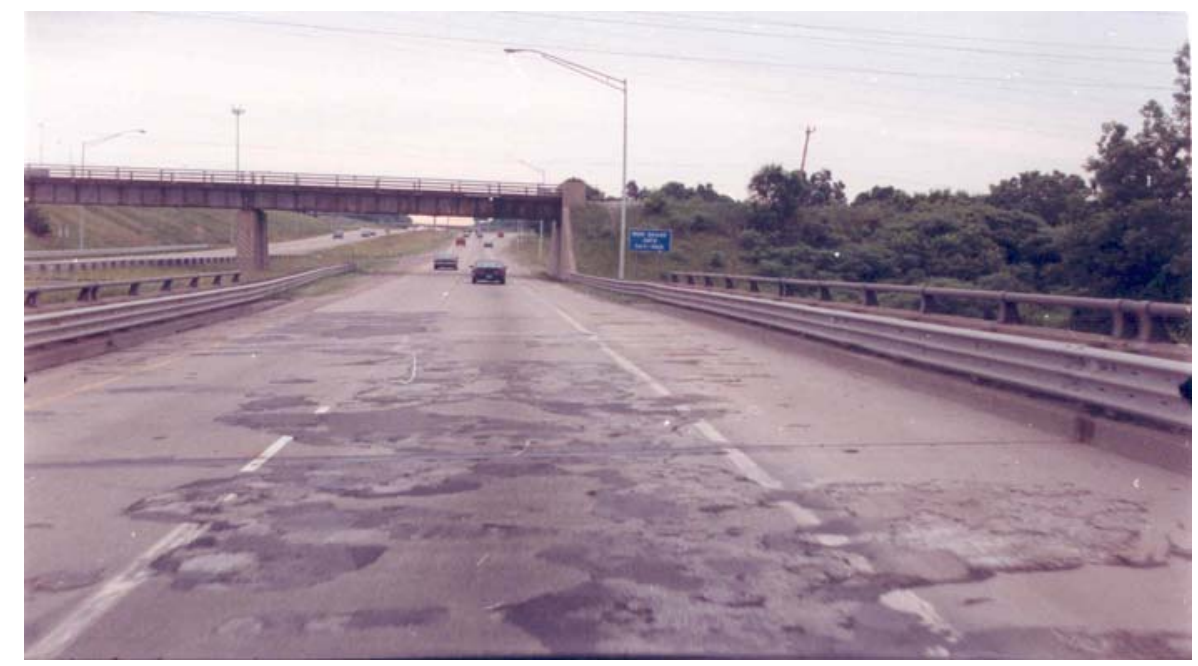

FIGURE 2 Repairs of critical roughness on a concrete bridge deck.

relationship between road surface failures and accident causation. In that paper a group of engineers ranked a number of surface conditions in relation to safety, based on their understanding of vehicle dynamics, potential surface conditions, and experience. According to that ranking, washboarding, or corrugated surfaces, was a leading condition pertaining to the pavement surface that affected safety.

In 1977 Magnusson and Arnberg (8) reported that road roughness affects a driver's ability to collect information and carry out intended maneuvers. They also reported that a person's ability to perform motor tasks has been shown to be reduced by vibrations, but it is not known to what degree the findings are applicable to vibrations encountered on a rough roadway. In 1977 Bohn and Dunkle (9) and in 1980 Kuehne and Bohn (10) simulated the effects of road roughness on pavement loading and traction. Although the way roughness reduces available pavement friction was illustrated, it was determined that a better tire road model would be required to achieve accurate quantitative results. In a more recent paper Burns (11) concluded that roughness affects safety in many ways, and it needs to be considered in any evaluation of pavement safety. He noted that roughness can reduce the steering and braking force and can significantly affect the controllability of a vehicle. Washboarding surfaces and repeated cycling undulations of the surface can cause significant control problems and can shake a vehicle, thus causing it to lose part of its load. In another paper Molenaar and Sweere (12) concluded that roughness appears to have a marked effect on road user safety.

A study at the Pennsylvania Transportation Institute makes use of a circular track developed by R. R. Hegmon. This track has been modified so that roughness of a known amplitude and wavelength can be inserted in a wheel track. Testing was reported at TRB (13) and showed a 30\% loss of traction between 8 and $12 \mathrm{~Hz}$. Figure 3 shows the wavelengths that need to be avoided as a function of speed.

In a paper by Bester (14), a study is described in which the effect of the riding quality of the road surface on the accident rate was investigated. This was done for a network of paved roads in two of the provinces in South Africa. Data on various road features were collected from the KwaZulu-Natal and Western Cape Provincial Road Departments. Road sections with constant cross sections were identified. For each of these, the average traffic volume, the terrain 


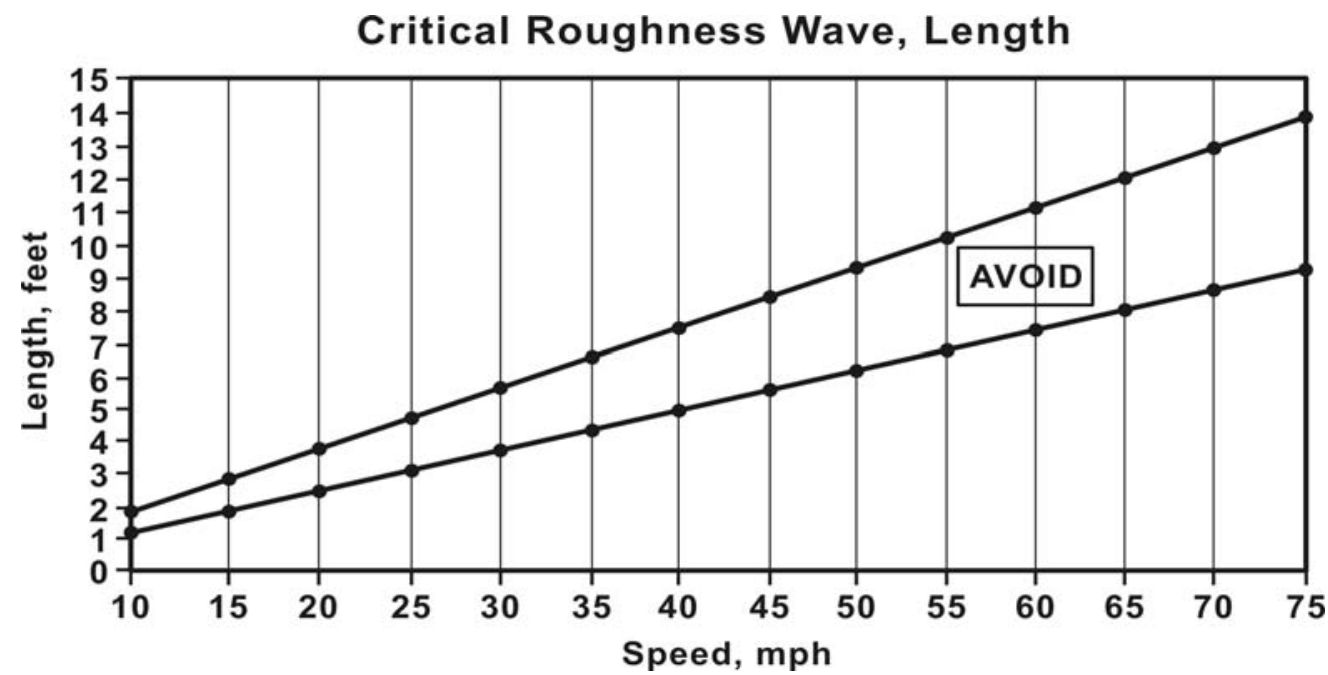

FIGURE 3 Wavelengths to avoid as a function of speed.

type, riding quality, and the different types of accidents were obtained. Correlation matrices, direct comparisons, and regression analyses were used to determine the effect of the different road features on the occurrence of the different types of accidents. The road and its environment alone contribute only about seven percent to the occurrence of accidents. However, when the combination of human error and the road is considered, research has shown that more than 20 percent of accidents can be ascribed to this combination of factors. Improving the Pavement Serviceability Index (PSI) from 2.0 to 3.5 leads to a $34 \%$ lowering of the total accident rate in rolling terrain and by $39 \%$ in mountainous terrain.

One factor that is probably the least understood is the effect of vehicle vibration induced by road roughness on driver performance. It has been reported by human factors researchers that continuous exposure to vibration may induce fatigue, which may in turn be a factor that contributes to accidents. To date, no direct relationship between road roughness and fatiguerelated accidents has been clearly established, although the International Standards Organization (ISO) provides an arguable link between vibrations and fatigue.

The International Roughness Index (IRI) has in recent years become the standard for assessing pavement surface roughness. It is based on a quarter-car model traveling the pavement surface at a constant speed. The pavement surface is represented by true geometric data; i.e., the longitudinal profile represents the pavement surface. IRI has been proven to satisfactorily explain phenomena such as pavement performance and pavement deterioration. However, vertical motion frequencies and amplitudes affecting humans the most are different from those used in the model. Humans are also affected by side motion, which is not accounted for at all. At a road test with instrumented vehicles (15) it was found that the index did not properly indicate rough road sections. Thus the IRI was less suitable for this time of road. A laser profiler commonly adapted to road surface surveying was also used for assessing the IRI. Raw data were stored so that other models could be tried, including horizontal acceleration. A comparison was then made to the instrumented vehicle test data. Some suggestions are made for a ride quality index adjusted to human aspects. 


\section{POTHOLES}

Holes in the pavement have to be a foot or more long and wider than a tire to be hazardous. If a driver claims his vehicle was thrown out of control by a small hole, treat this statement with suspicion and look for driver actions which may be contributing factors, such as cutting back into lane after overtaking. A vehicle can be turned over by hitting a chuck hole without signs on either the tire or the hole, especially when the edges of the hole are rounded.

With this statement Baker (16) gave credence to the danger of holes - a major example of discontinuities. Whether called pothole, chuck hole, or any other colloquialism, the nature of such a hole is to be hard on tires, vehicles, and drivers' tempers. But are they a significant direct threat to safety? This alleged influence on safety may be highly inflated by many accident reports that reflect driver frustrations and excuses.

Accident reports state that holes are a causative factor in many accidents. In 1976 Ivey and Griffin (7) reported a rank ordering of roadway disturbances based on 15,968 accidents in North Carolina. Hole was mentioned in 34 reports that ranked hole sixth out of 19 disturbances behind the key words water, dropped, soft, curb, and edge. In a Delphi ordering developed by the same authors, holes ranked eighteenth out of 20 disturbances.

In 1977 Klein et al. (17) completed a study of the influence of roadway disturbances on vehicle handling. The accident data cited were difficult to interpret because of the extremely small sample size from each source. As part of this study a questionnaire was sent to the membership of the Automobile Club of Southern California. Twenty-eight percent $(1,412$ individuals) responded. Holes ranked third out of 13 identified disturbances in terms of a driver's perception of hazard. It appears that, whether justified or not, holes are clearly perceived to be a significant threat to safety. It is also clear that this public perception is not shared by many engineers who have significant knowledge of vehicle handling and stability characteristics.

To clarify this apparent difference in opinions, Zimmer and Ivey (18) conducted a series of controlled vehicle-hole interaction experiments. With holes as large as 3 feet long (diameter) and 7 inches deep, the stability of vehicles was not affected. That is, the trajectory, or vehicle path, was not changed. The only safety-related influence of holes identified was damage to tires and rims, with the associated potential for an air-out. Figure 4 shows one of the tests conducted on naturally occurring holes. By controlled experiments and computer modeling, the drop rates of various automobile suspension systems were determined. The information was then combined with observed tire deformation effects to determine the limits of safety (see Figure 4).

As illustrated in Figure 4, the critical point for a particular vehicle and speed combination is first located by determining how long it takes for a tire to descend to a critical level in a hole. A line is extended up and to the right from that point. The area cut off by the two arrows (i.e., the area of the chart above and to the right of the intersection of arrows) represents those combinations of hole length and depth that could produce a potentially hazardous condition. Conversely, the area to the left and below the intersection of arrows indicates relatively safe hole sizes for the indicated speed.

Figure 4 is still applicable for vehicles with conventional size rims and tires, that is vehicles rim-tire combinations with rim ground clearance, $\mathrm{RGC}$, equal or greater than 3 inches.

Styling changes of modern automobiles, SUVs, and pickups have rendered Figure 4 obsolete for those pretentious recipients of rim-tire combinations with rim ground clearances significantly less than 3 inches; e.g., rims up to 22 inches in diameter sometimes have ground 


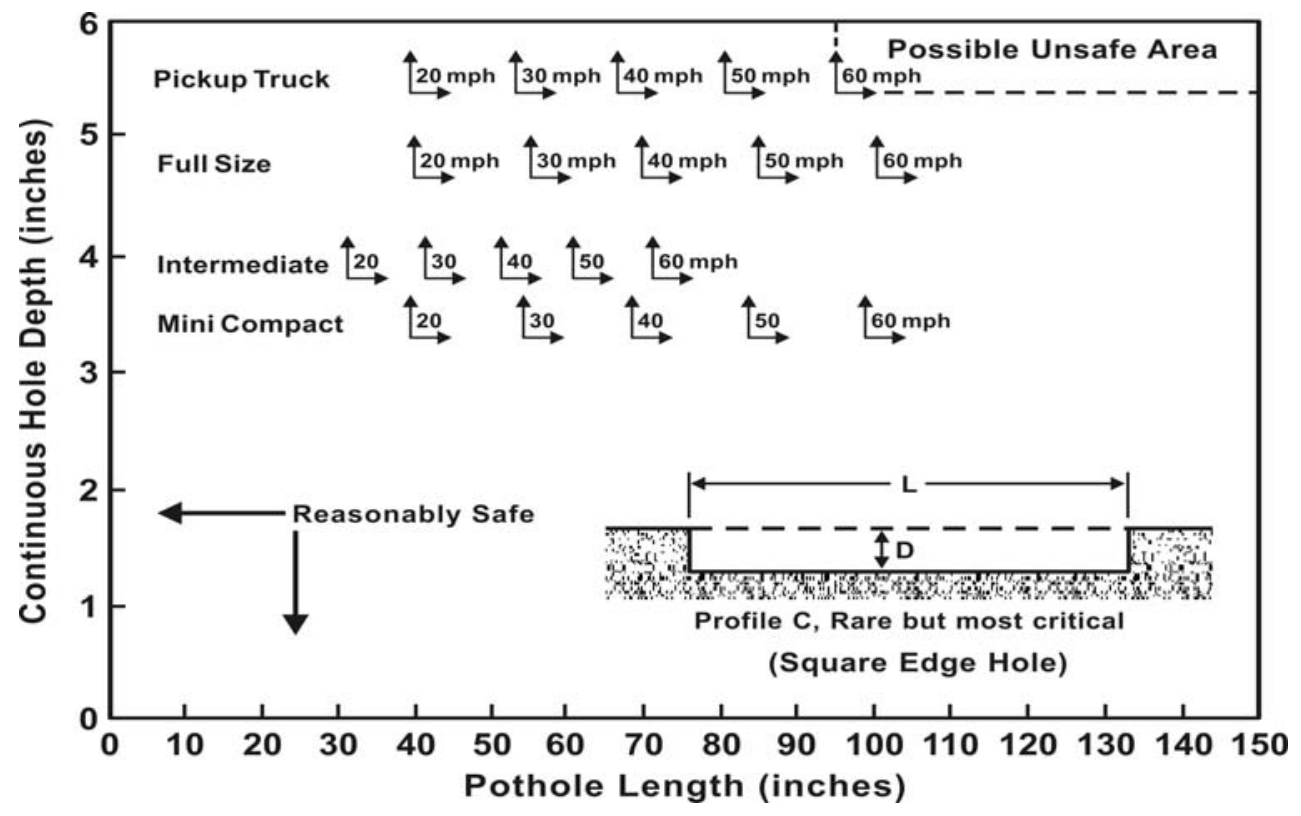

\section{FIGURE 4 Critical Combinations of hole length and depth for various speed and vehicle situations (1983).}

clearances of as little as $1 \frac{1}{2}$ inches. ${ }^{1}$ While little actual full-scale dynamic testing of these rimtire combinations is available at this time it is highly probable that they are significantly more susceptible to damage from holes and bumps than are conventional combinations having rim ground clearance greater than 3 inches. See Figure 5 for example of a plus-sized tire-rim with less than 2 inches of ground clearance (RGC). The coin is a quarter.

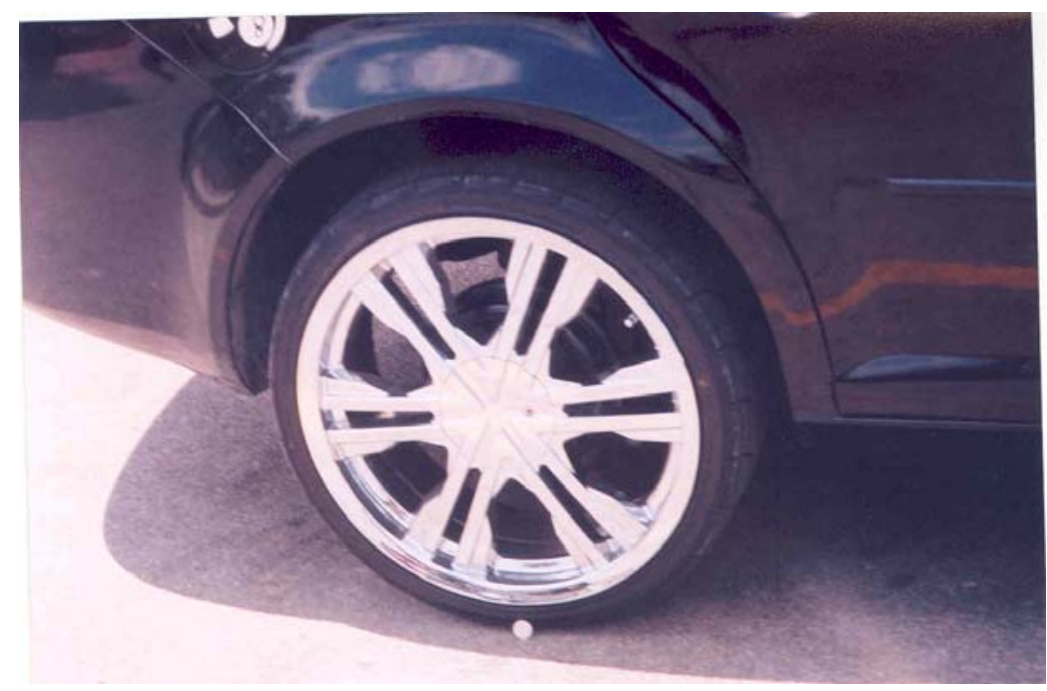

FIGURE 5 Plus-sized rim-tire (reference quarter is 0.92 inches in diameter or 23 millimeters).

\footnotetext{
${ }^{1}$ The auto industry calls this "plus sizing."
} 
Walter (19) states:

Plus-sizing seems to be reversing these long-term developmental trends in tire-wheel technology. While the functional benefits include improved vehicle handling and high speed capability as well as the potential to increase brake diameter, the principal disadvantages are many and include cost, weight, fuel economy, ride quality and wet grip/snow traction, as well as indicate hydroplaning resistance. Perhaps more serious downsides include reduced load-carrying capacity at extremely low aspect ratio, a shift in the handling balance toward oversteer and a slight increase in rollover propensity.

A further disadvantage is that the increased vertical stiffness of low aspect ratio tires means they act as shock transmitters rather than shock absorbers. Safety implications arise when a motorist will agree to replace a bent wheel that is no longer able to hold air, but will continue to use an injured tire since the damage is internal and not visible to the naked eye.

It was found in pre-1983 research by Zimmer that the threshold for damage to rims was closely approximated by hole depth or bump height equal to or greater than the rim ground clearance (RGC). A conservative approach would be to estimate that this will hold true for modern style, low clearance rims. In that case Figure 6 illustrates significant difference in sensitivity of the new rims.

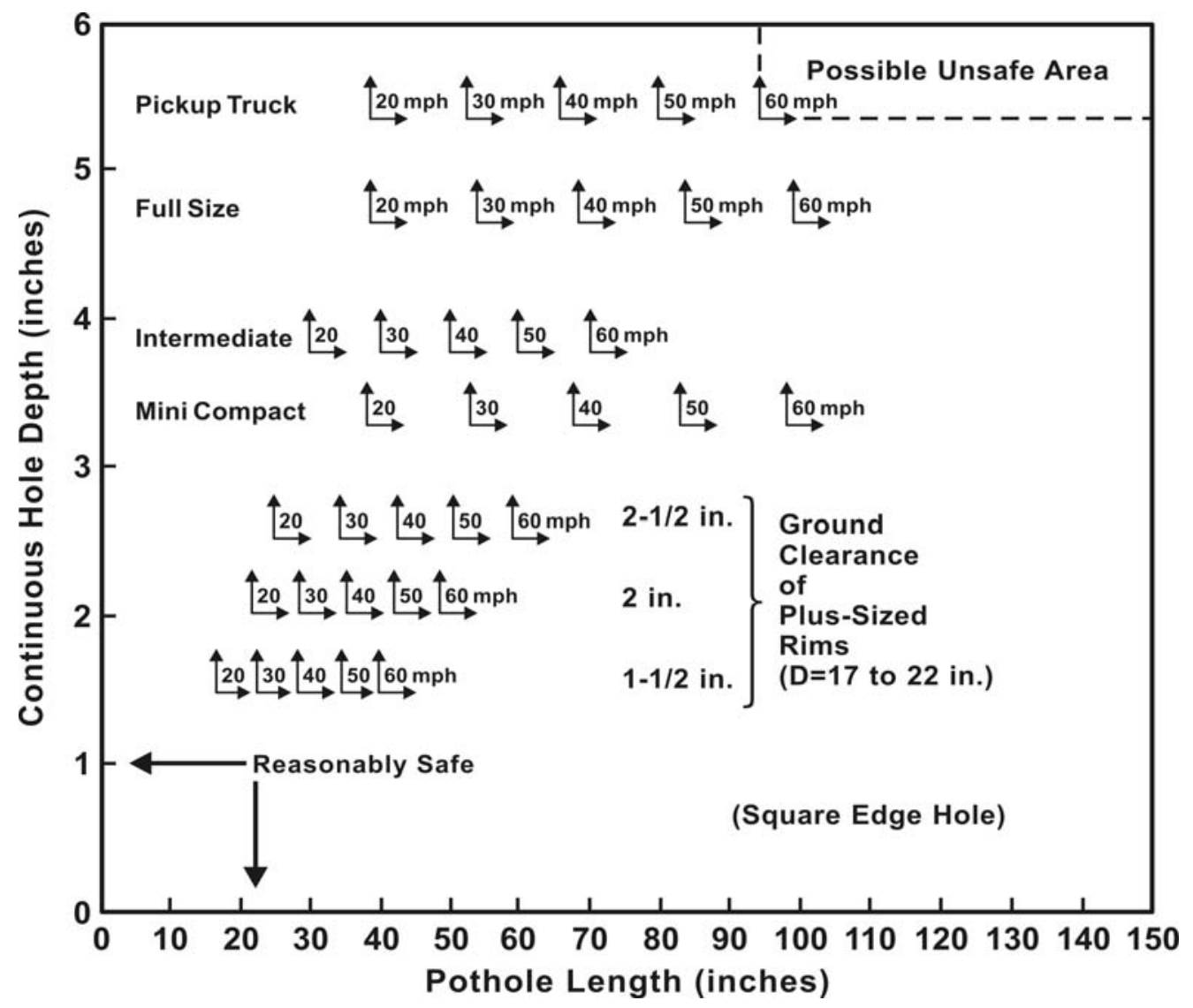

FIGURE 6 Changes suggested by plus-sized rims (for definitions of depth, D, and length, L, see Figure 4). 
The bottom series of arrow indicators defining "Reasonably Safe" and "Possibly Unsafe" areas is far removed from the areas defined in Figure 4 in 1983. Figure 7 also indicates this major change in sensitivity.

While in 1983 a pothole would need to be over 3 inches in depth and over 30 inches in length to pose a rim damage threat to even a mini-compact vehicle, in 2006 holes as shallow as $1 \frac{1}{2}$ inches no more than 16 inches long could, in theory, cause rim damage. It may be, however, that this overstates the problem, since the angle the tire circumferential surface makes with the

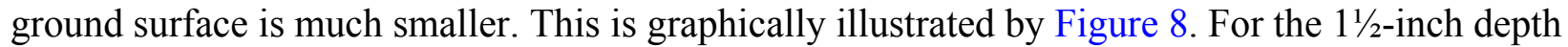
in comparison with a 3-inch depth see Figures 7 and 8.

Damage to tires and rims, with the associated potential for an air-out, is the only significant influence of holes on safety identified in the study by Zimmer and Ivey (18). Holes are atypical of most highway surface discontinuities in that they have a greater potential to cause

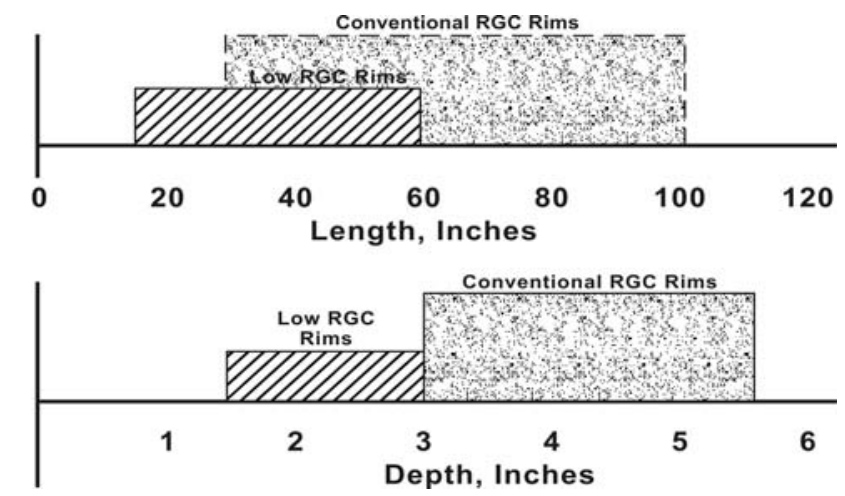

FIGURE 7 Theoretical change in sensitivity of (low values of RGC) rims with low clearance values.
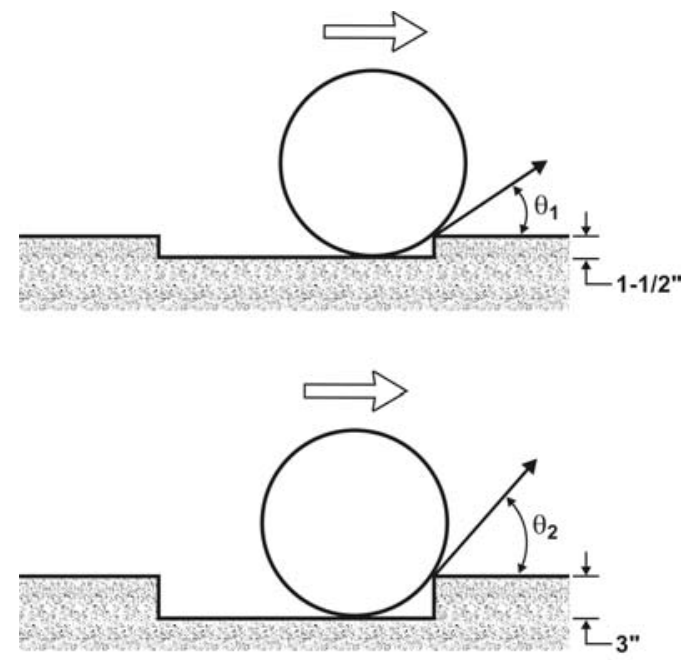

$\theta_{2}>45^{\circ}>\theta_{1}<45^{\circ}$

FIGURE 8 Illustration of contact angle. 
damage at lower vehicle speeds. A vehicle with an air-out is obviously much easier to cope with at $30 \mathrm{mph}$ than at $60 \mathrm{mph}$. The result of these two effects is that the usual size hole a driver encounters is not likely to be a major problem when struck directly.

Problems can arise if a driver reacts to a hole inappropriately. For example, it is usually counterproductive to react with braking or extreme cornering to a hole in the vehicle's path. In general, a given size hole is more likely to cause damage if speed is reduced. Losses of control can occur if extreme braking is produced at highway speed. Extreme cornering can have two results. First, if a driver reacts with a large steering input to avoid a hole, he may produce a loss of control on a low friction surface. Second, he may put his vehicle in a hazardous position with respect to other traffic. In the authors' opinion, it is sometimes the latter maneuver that accounts for some of the accidents where holes are identified as having an influence on driver safety.

The influence of holes encountered when cornering deserves further attention. A cornering (turning) vehicle transfers weight from the wheels on the inside of the turn to the outside wheels. The springs on the heavily loaded side are compressed. When one of these tires encounters a hole it goes down faster because of the acceleration of the higher spring force. Thus it is in position to be damaged more quickly (down farther in a given length of hole for a specific speed) than is represented in Figure 8. A second and potentially more hazardous situation is if a tire is moving laterally and encounters the side of a hole. A trip and roll could possibly occur in this situation, but it would require the car to be in an extreme lateral drift (skid). This lateral drift would need to be so extreme that it would be associated with intemperate vehicle control or a loss of control that preceded contact with the hole. It could be that first-hand knowledge of an event such as this, even though it is likely to be rare, led Baker (16) to say that "a vehicle can be turned over by hitting a chuck hole."

This work does not indicate that holes in highway surfaces should be tolerated. The many disadvantages of these flaws dictate their elimination within the bounds of financial constraints. In this day of highways that are "past maturity and in future shock" (20), it is unlikely that the public will choose to fund the maintenance required to make holes an endangered species. The purpose of this work is to put the influence of holes on safety into perspective so that maintenance activities can be appropriately prioritized.

It appears improbable that any but the largest holes cause significant control problems for tire-rim combinations with RGC values of 3 or more inches. Exceptions may be a large number of holes in a small area that cause extreme roughness, especially where maneuvers such as braking or cornering are required. Under some highway conditions, the slower the speed is of a vehicle, the larger is the impact force for a given size hole. Although tire or rim damage may be more probable at lower speeds for deep holes, the result of such damage will be easier for the driver to accommodate. The greatest influence of holes on safety may be the hazard caused by drivers trying to avoid them.

\section{CURBS}

Curbs and gutters were used to facilitate the ingress and egress of carriage riders and later automobile passengers, to control roadway drainage, to help delineate the edge of the travelway, and to afford protection for pedestrians. As paved roadways branched out into the rural areas, so did the use of curbs. Early standards and guidelines published by federal and state agencies promoted their use on rural highways and urban streets.

Two basic types of curbs have been used for many years. Barrier curbs, which were designed to prohibit or discourage encroachments, are relatively high and steep faced. Mountable 
curbs, which were designed to enable vehicles to cross them readily, are relatively low, with flat sloping faces. Details of widely used curbs of each type can be found in the AASHO Blue Book (21).

Studies in the 1950s by Benton and Peterson (22) and Benton and Field (23) were some of the first to note the potential safety problems with curbs. Vehicle jump subsequent to impact with the curb was observed, and recommendations were made regarding barrier height as a function of barrier setback from the curb. In 1964 the Highway Research Board Special Report 81 (24) alluded to possible problems if high curbs are used in front of guardrails.

The first Yellow Book published by AASHO in 1967 (25) stated that "a dike or curb should not be used in front of guardrail where it may result in a dynamic jump by the vehicle before it strikes the barrier." NCHRP reports by Michie and Calcote (26) and Michie and Bronstad (27) recommended that curbs be placed behind guardrail. The Red Book published by AASHO in 1973 (28) pointed out the need for relatively flat surfaces in front of barriers. It stated that barrier curbs should not be used on freeways and high-speed arterials. The second Yellow Book published in 1974 (29) reflected these recommendations.

As shown in Figure 9, studies by Olson et al. (30) overstated the direction capability of curbs, probably due to an inaccurate tire model in versions of HVOSM used to simulate vehicle tests. Also shown on Figure 9 is a boundary reported by Navin (31) and a boundary derived by Ivey that compare favorably. These curves illustrate the modest redirection capabilities of the most common curb design.

The AASHTO barrier guide of 1977 (32) concluded that a curb should not be used as a redirective device, and if it is used with a barrier, the face of the curb should be no closer to the traveled way than the face of the barrier.
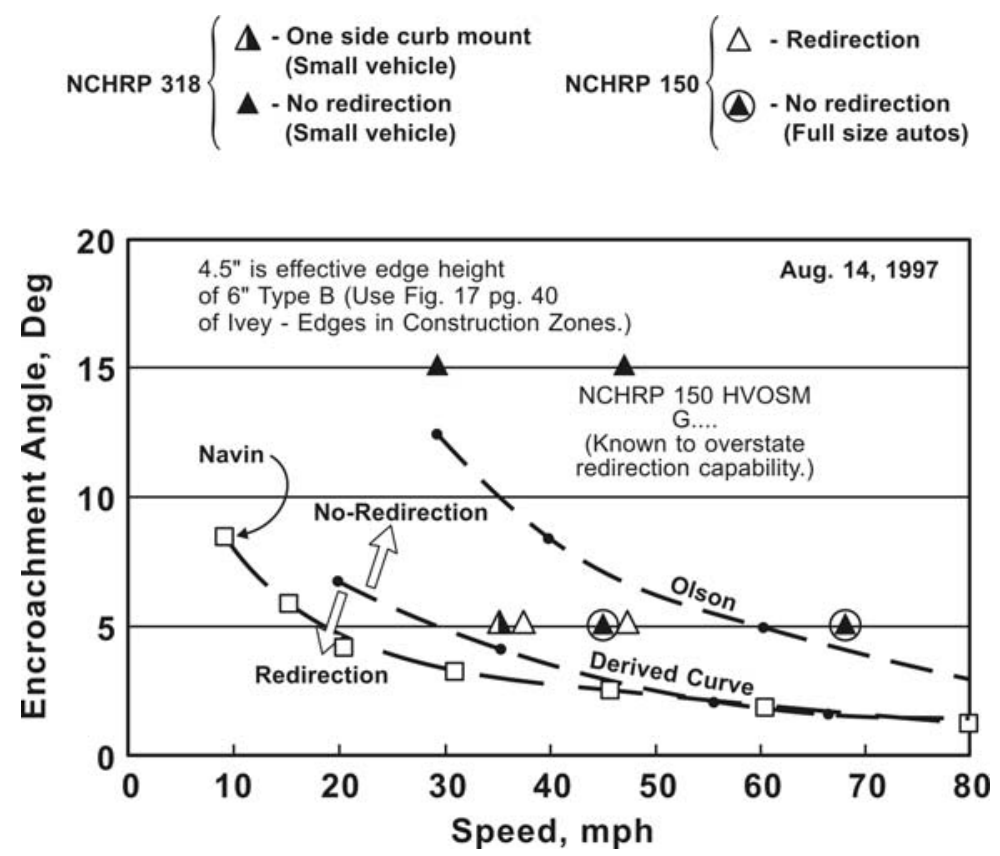

FIGURE 9 Type B curb redirection. [From AASHO (21).] 


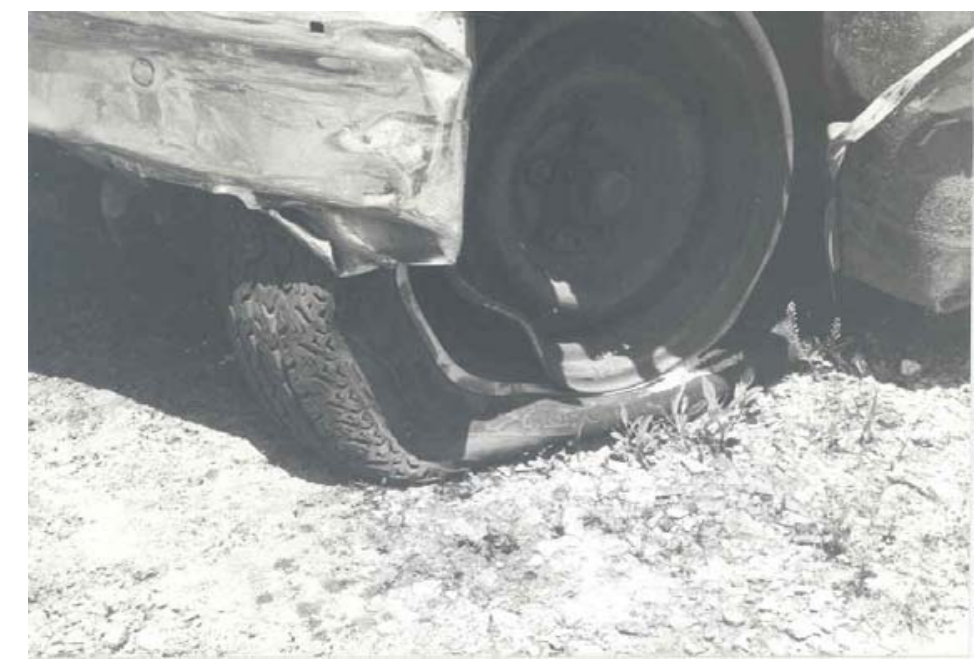

FIGURE 10 Rim damage and air out from high speed curb impact.

A recent study by Griffin (33) indicated that small cars are more likely to be involved in curb accidents than are large cars. This appears to be a logical consequence, because handling and stability problems associated with car-curb involvements should be inversely related to wheel size. Figure 10 shows an extreme example of the damage a curb can cause when struck at high speed.

The literature and data in the report by Griffin strongly suggest that the hazards curbs present to errant motorists on high-speed facilities in terms of potential loss of vehicle control, potential overturning, and incompatibility with barrier performance outweigh those benefits that may accrue as a result of improved delineation, drainage, and traffic control. On most high-speed facilities, delineation, drainage, and traffic control can be treated better by other means.

In lower speed urban areas 6 inch curbs have traditionally been considered "barrier curbs." (REF) This misnomer may have had influence in allowing utilities to place poles directly behind a curb. This practice, placing poles in a position clearly hazardous to traffic, is still not totally discarded.

\section{QUESTIONABLE INFLUENCES}

Roughness has a traditionally negative connotation to highway engineers. In 1983, when TRB's first State of the Art Report was published that was still true. That report was titled "The Influence of Road Surface Discontinuities on Safety." Every example of roughness given was either shown or assumed to have a negative safety influence. Examples were

- Travel surface roughness,

- Holes,

- Bumps,

- Rutting, and

- Edge drops.

The presumed negative influence of these characteristics is not always valid. The budding philosophy of traffic calming lends credence to some heretofore unexplained positive influences. 
This "traffic calming" approach follows an idea expressed by Gallaway in the 1980's "If you make the road bad enough speeds will go down and injury rates will plummet." In a nation addicted to mobility, this is not an acceptable solution. It might be of consideration, however, when developing maintenance priorities.

For example, there is research by Kamplade (34) that shows accident rates reduced as wheel path depression (WTD) increases. This is seemingly contrary to conventional wisdom and to other research studies, such as Start et al. (35). Depressed wheel paths, pond water, and ponded water leads to hydroplaning losses of control.

The explanation may be in the experimental design of those two studies. In the case of the Kamplade data analysis, both wheel track depressions and tire-pavement friction were measured. By separation of these variables, as shown by Figure 11, it is seen that higher WTD values are a positive influence on reducing accidents while lower values of friction have a comparatively negative influence on accident rate (i.e., accident rates increase). When Start et al. analyzed simply the one variable influence of WTD values compared to accident rate, they found WTD to be a negative influence. (See Figure 12.) These studies might not conflict if there is a codependence between friction and WTD. This seems likely, since normally it would be older pavements that have significant WTD and these are also the surfaces which would have greater traffic polishing.

It is difficult to explain the indication from Kamplade that larger WTDs result in lower accident rates. The only explanation that is straightforward enough to seem reasonable is Gallaway's reasoning: to wit, "As WTDs increase and the water depths get deeper under rainfall conditions, most drivers slow down." The exception to this would be when a restricted zone of higher WTDs is a surprise on an otherwise low WTD roadway, i.e., driver expectance is violated.

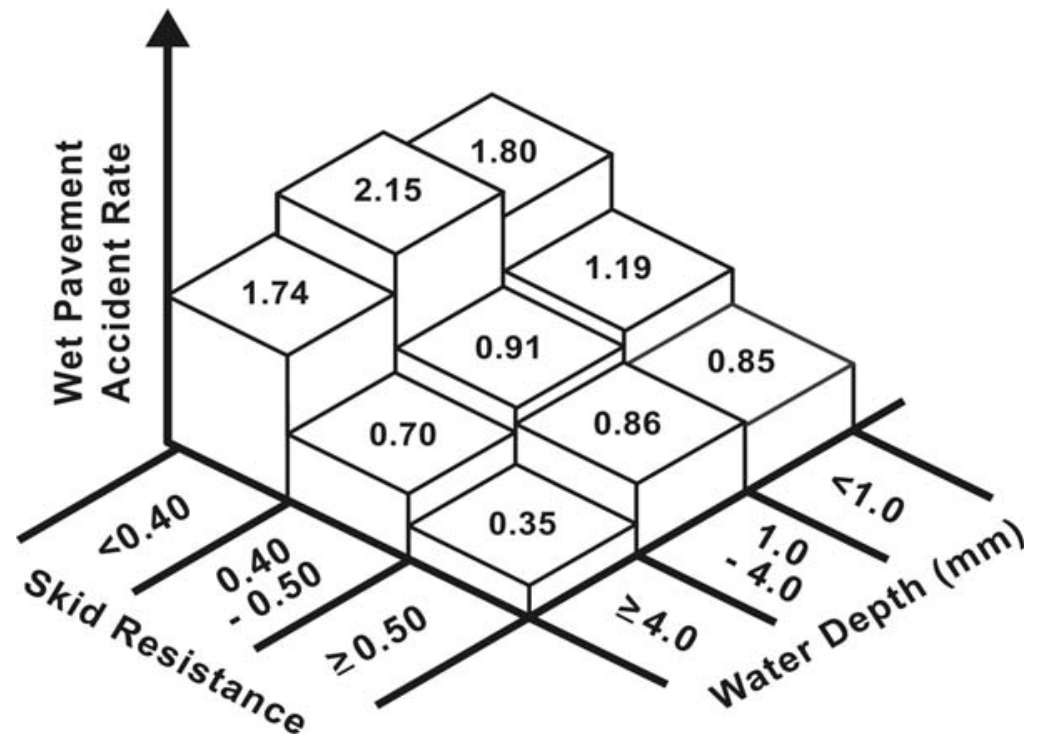

FIGURE 11 Wet pavement accident rate as a function of water depth (WTD post depth) and skid resistance. [After Kamplade (34).] 


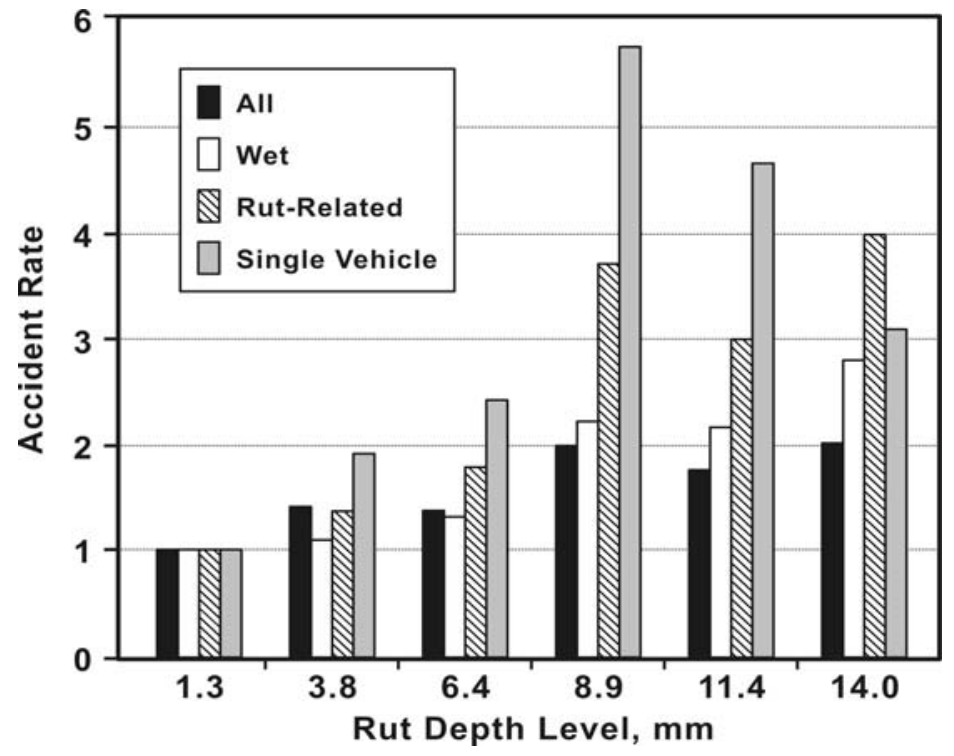

FIGURE 12 Relative accident rates.

Also considered should be the fact that the Kamplade data only had rut depths up to about $6 \mathrm{~mm}$ compared to Start's data that included rut depth up to $14 \mathrm{~mm}$. Although not counterintuitive in influencing accident rate, the rate is quite insensitive in the 0 -to- $6 \mathrm{~mm}$ zone in the Start observations. The accident rate according to Figure 12 increases precipitously at rut depths greater than $6 \mathrm{~mm}$. If heavy traffic polishing or asphaltic concrete bleeding is associated with the rut depths in excess of $6 \mathrm{~mm}$, greatly reduced tire-pavement friction might account for much of the increase.

On dry pavements the observations of the AASHTO task force on rutting are

Rutting affects vehicle handling. Handling for smaller vehicles is impaired when they drive in a rut pattern that has been established by trucks. There is also concern that the wider 102-inch trucks are having steering consistency problems because of rut patterns formed by the more common 96 -inch wide trucks. (36)

There are also examples of pavement roughness cited that seem to decrease accident rates. Perhaps one conclusion might be: While pavement roughness is clearly a hindrance to mobility and transportation economy, the existence of modest roughness does not necessarily equate to an increase in accident rates. Some types or degrees of roughness may lead to overall traffic speed reduction.

\section{REFERENCES}

1. Quinn, B. E., and S. E. Hildebrand. The Effect of Pavement Roughness on Safe Vehicle Handling Characteristics. School of Mechanical Engineering, Purdue University, Lafayette, Ind., Jan. 1972.

2. Quinn, B. E., and S. E. Hildebrand. Effect of Road Roughness on Vehicle Steering. In Highway Research Record 471, HRB, National Research Council, Washington, D.C., 1973, pp. 62-75.

3. Brickman, A. D., W. H. Park, J. C. Wambold, and J. R. Zimmerman. Road Roughness Effects on Vehicle Performance. Report 7207. Pennsylvania Transportation and Traffic Safety Center, Pennsylvania State University, University Park, Aug. 1972. 
4. Wambold, J. C., A. D. Brickman, W. H. Park, and J. Ingram. Effect of Road Roughness on Vehicle Braking. In Highway Research Record 471, HRB, National Research Council, Washington, D.C., 1973, pp. 76-82.

5. Parr, H. G. The Relation Between the Roughness of Road Surfaces and the Chance of an Accident. Conference Paper. Dutch Touring Club ANWB, Wassenaarseweg, Netherlands, 1973.

6. Hutchinson, J. W., N. G. Tsongos, R. C. Bennett, and W. J. Fogarty. Pavement Surface Information Needs in Accident Investigation: Surface Texture Versus Skidding Measurements, Friction Aspects, and Safety Features of Tire-Pavement Interactions. Published ASTM STP 583. ASTM Philadelphia, 1975, pp. 116-126.

7. Ivey, D. L., and L. Griffin, III. Driver/Vehicle Reaction to Road Surface Discontinuities and FailureThe Hidden Trigger to Accidents. Presented at 16th International Congress of International Federation of Societies of Automotive Engineers, Tokyo, May 1976.

8. Magnusson, G., and P. W. Arnberg. The Influence of Road Roughness on the Braking and Steering Performance of Cars. National Swedish Road and Traffic Research Institute, Linkoeping, Sweden, 1977.

9. Bohn, P. F., and H. D. Dunkle. Computer Simulation of the Effects of Road Roughness on TirePavement Forces in Braking and Cornering. Report FHWA-RD-77-124. FHWA, U.S. Department of Transportation, 1977. NTIS: PB 279887/AS.

10. Kuehne, C. S., and P. F. Bohn. Computer Simulation of the Effect of Road Roughness on Tire-Pavement Forces for an Articulated Vehicle Performing Braking and Cornering Maneuvers. Report FHWA/RD80/29. FHWA, U.S. Department of Transportation, 1980. NTIS: PB 81238461.

11. Burns, J. C. Roughness and Roadway Safety. In Transportation Research Record 836, TRB, National Research Council, Washington, D.C., 1981, pp. 8-14.

12. Molenaar, A. A. A., and G. T. Sweere. Rough Roughness: Its Evaluation and Effect on Riding Comfort and Pavement Life. In Transportation Research Record 836, TRB, National Research Council, Washington, D.C., 1981, pp. 41-48.

13. Cap, J. S., and J. C. Wambold. Traction Loss of a Suspended Tire on a Sinusoidal Road. In Transportation Research Record 1000, TRB, National Research Council, Washington, D.C., 1984, pp. 33-38.

14. Bester, C. J. The Effect of Road Roughness on Safety, 82nd Annual Meeting of the Transportation Research Board, Washington, D.C., 2003.

15. Lenngren, C. A., and J. Granlund. Relating Road Roughness to Human Discomfort and Health Impact, Swedish National Road Administration, Box 1200, 46228 Vanerborg, Sweden. 2002.

16. Baker, J. S. Traffic Accident Investigator's Manual 4th ed., The Traffic Institute, Northwestern University, Evanston, Ill, Jan. 1975.

17. Klein, R. H., W. A. Johnson, and H. T. Szostak. Influence of Roadway Disturbances on Vehicle Handling. Final Report. Systems Technology, Inc., Hawthorne, Calif., Oct. 1976.

18. Zimmer, R. A., and D. L. Ivey. The Influence of Roadway Surface Holes and the Potential for Vehicle Loss of Control. Res. Report 328-2F. Texas Transportation Institute, Texas A\&M University, College Station, Aug. 1983.

19. Walter, J. Style Over Substance. Tire Technology International, March 2006.

20. Ivey, D. L., W. F. McFarland, R. L. Lytton, D. D. Burke, B. M. Gallaway, and C. V. Wootan. Highway Pavements, Past Maturity and in Future Shock. Texas Transportation Institute, Texas A\&M University, College Station, Aug. 1980.

21. A Policy on Geometric Design of Highways and Streets. AASHO, Washington, D.C., 1954, 1965, 1983, and 2004.

22. Beaton, J. L., and H. A. Peterson. Final Report of Full-Scale Dynamic Tests of Bridge Curbs and Rails. Department of Public Works, California Division of Highways, Sacramento, Aug. 1957.

23. Beaton, J. L., and R. N. Field. Dynamic Full-Scale Tests of Median Barriers, Bull. 266, HRB, National Research Council, Washington, D.C., 1960, pp. 78-125.

24. HRB Special Report 81: Highway Guardrail - Determination of Need and Geometric Requirements, with Particular Reference to Beam-Type Guardrail. HRB, National Research Council, Washington, D.C.

25. Highway Design and Operational Practices Related to Highway Safety. AASHO, Washington, D.C., 1967. 
26. Michie, J. D., and L. R. Calcote. NCHRP Report 54: Location, Selection, and Maintenance of Highway Guardrails and Median Barriers. HRB, National Research Council, Washington, D.C., 1968.

27. Michie, J. D., and M. E. Bronstad. NCHRP Report 118: Location, Selection, and Maintenance of Highway Traffic Barriers. HRB, National Research Council, Washington, D.C., 1971.

28. A Policy on Design of Urban Highways and Arterial Streets. AASHO, Washington, D.C., 1973.

29. Highway Design and Operational Practices Related to Highway Safety. 2nd ed., AASHTO, Washington, D.C., 1974 .

30. Olson, R. M., G. D. Weaver, H. E. Ross, Jr., and E. R. Post. NCHRP Report 150: Effect of Curb Geometry and Location on Vehicle Behavior. TRB, National Research Council, Washington, D.C., 1974.

31. Navin, Frank. Experimental Results on the Effectiveness of Roadside Curves. TRB Committee on Roadside Safety Features, Jan. 1999.

32. Guide for Selecting, Locating and Designing Traffic Barriers. AASHTO, Washington, D.C, 1977.

33. Griffin, L. I., III. Probability of Driver Injury in Single-Vehicle Collision with Roadway Appurtenances as a Function of Passenger Car Curb Weight. Texas Transportation Institute, Texas A\&M University, College Station, Oct. 1981.

34. Kamplade, J. Analysis of Transverse Uneveness with Respect to Traffic Safety. Surface Characteristics of Roadways: International Research and Technologies, ASTM STP 1031, 1990, pp. 211-223.

35. Start, M. R., J. Kim and W. D. Berg. Development of Safety Based Guidelines for Treatment of Pavement Rutting. Proceeding of the Conference, Road Safety in Europe and Strategic Highway Research Program (SHRP) No. 4, Part 5, 1996.

36. Finley, M. D., and J. D. Miles. Exterior Noise Created by Vehicles Traveling Over Rumble Strips. Presented at the Annual Meeting of the Transportation Research Board, Washington, D.C., 2007. (See TRB 2007 Annual Meeting CD-ROM). 


\title{
Positive Effects of Road Surface Discontinuities
}

\author{
FRANCESCA LA TORRE
}

$\mathrm{W}$ hen traveling over most road surface discontinuity the effect on the driver is vibration and noise inside the vehicle that can be considered as a negative effect on driving comfort. In some instances, however, this "vibrational effect" can be achieved intentionally to alert the driver to a potential hazard or as a traffic calming intervention.

These "intentional" discontinuities can be of several types. The most common are

- Continuous shoulder rumble strips (either rolled-in or milled-in);

- Centerline rumble strips;

- Transversal in-lane rumble strips; and

- Humps.

The first two types of interventions are aimed at alerting the driver when the vehicle departs from its preferred trajectory. The third and fourth interventions are specifically aimed at reducing driving speed.

\section{CONTINUOUS SHOULDER RUMBLE STRIPS}

A shoulder rumble strip is a longitudinal design feature installed on a paved roadway shoulder near the travel lane (Figure 1). It is made of a series of indented or raised elements intended to alert inattentive drivers through vibration and sound that their vehicles have left the travel lane. On divided highways, they are typically installed on the median side of the roadway as well as on the outside (right) shoulder (1).

There are 4 different rumble strip types: milled-in, rolled-in, formed, and raised. A short description of each rumble strip type is provided here:

- Milled-in: This design is made by cutting (or grinding) the pavement surface with carbide teeth. Some of these cutting devices could be considered small roto-mills.

- Rolled-in: The rolled-in design is generally installed by using a steel wheel roller to which half sections of metal pipe or solid steel bars are welded. The compaction operation presses the shape of the pipe or bar into the hot asphalt shoulder surface.

- Formed: The formed rumble strip is added to a fresh concrete shoulder with a corrugated form which is pressed onto the surface just after the concrete placement and finishing operations.

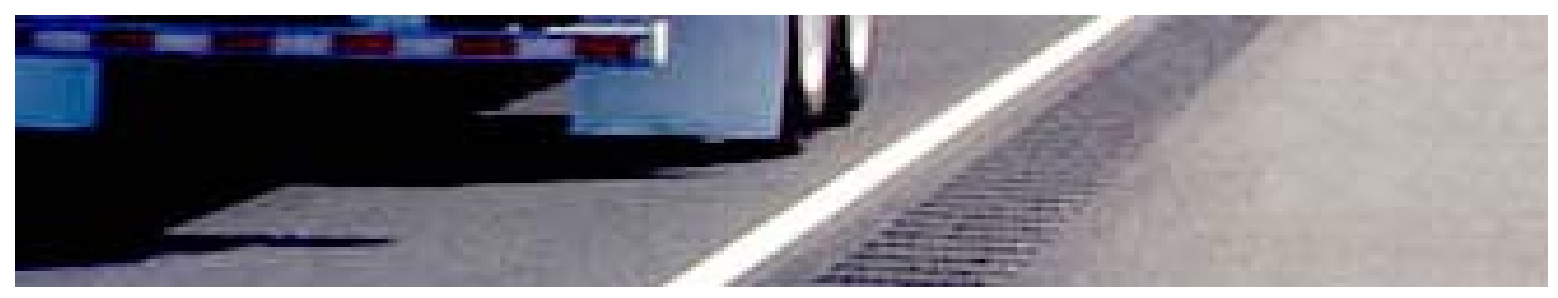

FIGURE 1 Shoulder rumble strips. 
- Raised: Raised rumble strip designs can be made from a wide variety of products and installed using several methods. The elements may consist of raised pavement markers, a marking tape affixed to the pavement surface, an extruded pavement marking material with raised portions throughout its length, or an asphalt material placed as raised bars on the shoulder surface.

The most common shoulder rumble strip types are the milled-in and the rolled-in. The difference between the two types is not only the construction technique adopted to realize them but also the resulting cross section and therefore the effects on vehicle vibrations, as shown in Figure 2.

Several studies were conducted in the 1990s to evaluate the effect of shoulder rumble strips on freeways. All lead to the conclusion that these interventions are extremely cost effective in reducing single-vehicle, run-off-road accidents. Concerning those first evaluations the studies conducted by Wood (2), Hickey (3), and Perillo (4) estimated the following:

- Wood, in 1994, reported a 70\% reduction in single-vehicle, run-off-road accidents by implementing milled-in rumble strips in the Pennsylvania Turnpike;

- Hickey, in 1997, updated Wood's results on the effects of the shoulder rumble strips in the Pennsylvania Turnpike, confirming a reduction in single-vehicle, run-off accidents by $60 \%$ over 53 test segments; and

- Perillo, in 1998, reported a reduction in single-vehicle, run-off-road accidents up to $88 \%$ after the installation of milled-in shoulder rumble strips in the New York Thruway.

It should be noted that the described studies are straightforward comparisons between the accidents occurring before and after the rumble strip installation. These are normally considered statistic-limited or naïve before-after studies.

A recent study by Griffith (6) on rolled-in rumble strips, resulted in a "medium-high" level of predictive certainty according to NCHRP Project 17-25 (7), a potential reduction in single-vehicle, run-off-road accidents by $14 \%$, considering all freeways (rural and urban); and a $21 \%$ reduction, considering only rural freeways. Even though these expected reductions

\section{5" Rolled Rumble Strips}

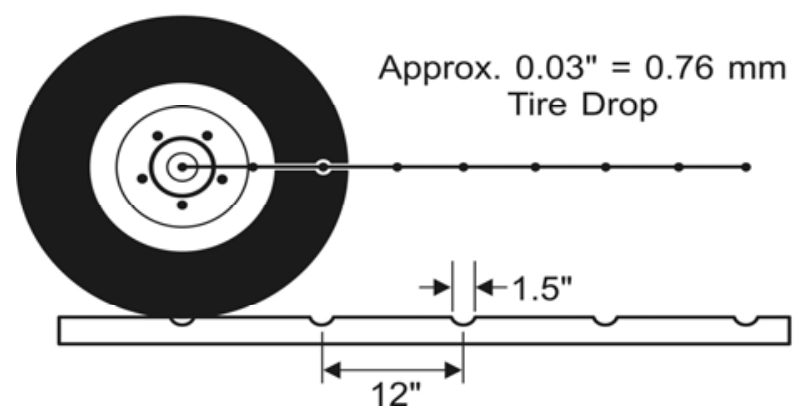

\section{7" Milled Rumble Strips}

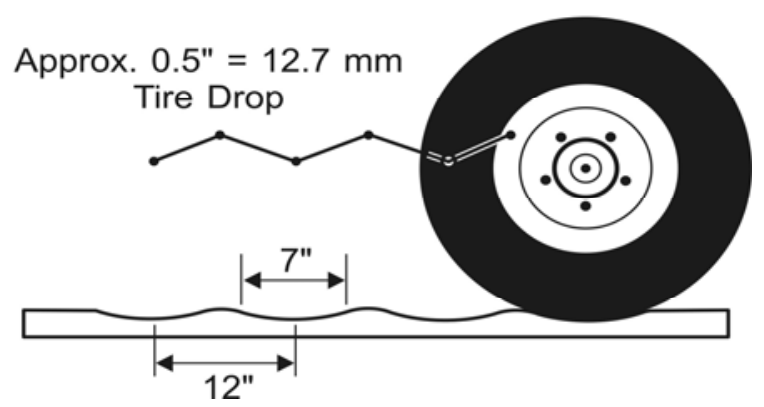

FIGURE 2 Difference in cross section between rolled (left) and milled (right) shoulder rumble strips (5). 
in accidents are much smaller than the ones estimated in the late 1990s, they confirm rumble strips are extremely effective, considering the reasonable cost of the intervention. As noted in NCHRP Project 17-25 (7) these results are not applicable to other road classes (two-lane or multilane rural highways). Similar results have been obtained, by Carrasco et al. (8) showing that the late 1990s indications on the effectiveness of shoulder rumble strips on accident reduction appear to be overestimated. The most recent estimate gives a reduction of single-vehicle, run-off accidents of $22 \%$.

Patel et al. (9) have recently analyzed the effect of this treatment on two-lane rural roads and found out that there is still a considerable positive effect with a reduction in single-vehicle, run-off-road accident of 13\% when all accidents are considered and 18\% when considering only injury accidents. It was noted that not all sites experience a crash reduction and the resulting standard deviation of the expected crash reduction is $8 \%$ for total accidents and $12 \%$ for injury accidents. This means that, considering a 95\% confidence interval, the effectiveness in terms of crash reduction can range from $13-15.7 \%$ and $13+15.7 \%$ for all accidents and $18-23.5 \%$ and $18+23.5 \%$ for injury accidents. As it can be seen, a "negative crash reduction" (which means a crash increase) can occur within the $95 \%$ confidence interval. According to Patel et al. an in depth study with a larger database should be conducted to find out the explanatory variables that lead to such a different performance in different sites (e.g., road geometry, different types of accidents, etc).

To investigate the human behavior in response to milled rumble strips a driving-simulator study has been conducted at VTI in Sweden (10) simulating the vehicle response when travelling over 4 different types of milled rumble strips. It was concluded that all tested rumble strip designs and placements had clear alerting effects and consistently induced the appropriate steering correction.

The effectiveness of permanent raised pavement markings (Figure 3) has been investigated by Bahar and others and reported in the NCHRP Report 518 (11). The major conclusion is that the effectiveness of this type of marking on road safety is limited on low volume roads. This may be due to lower design standards. Centerline raised pavement markings

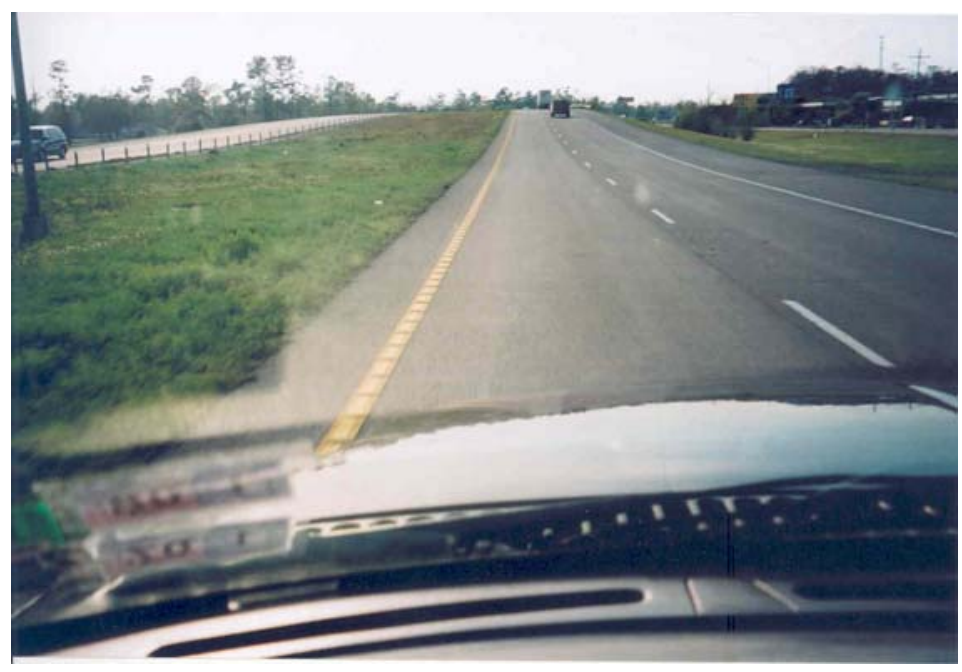

FIGURE 3 Permanent raised pavement markings. 
induce the driver to move toward the shoulder potentially increasing the run-off-road events on roads with lower design standards. It was also found under some conditions, the raised pavement markings may cause drivers to increase speed. This may be due to better visibility.

The Conference of European Director of Roads (CEDR) Task Group on Road Safety is currently preparing a report on the best practices on cost-effective road safety investments. Rumble strips are indicated as a highly cost effective measure to reduce run off accidents.

Rumble strips are also identified as a potential safety intervention for single-vehicle accidents by the PIARC Road Safety Manual (12) even though there is no specific quantification of the potential accident reduction that could be expected.

The positive effects of continuous shoulder rumbles strips on safety were shown in a recent paper by Finley and Miles (13): "Previous research findings have clearly shown that continuous shoulder rumble strips along the shoulders of freeways yield significant benefitsbetween 15 and 80 percent reductions in ROR crashes. In addition, transverse rumbles strips in the travel lane typically yield crash reductions between 20 and 30 percent. Based on these positive results, transportation agencies are continuing to install rumble strips in the travel lane and are beginning to install rumble strips on undivided roadways to reduce ROR, head-on, and opposite direction side-swipe crashes."

One of the disadvantages of shoulder rumble strips is the negative effect that these can have on bicycles. This issue has been addressed by Moeur (14) who proposes to pattern the strips in the shoulder leaving gaps without grooves to allow the cyclist to drive across the rumble strips on the smoother segments.

The Federal Highway Administration (FHWA) has established a specific website (http://safety.fhwa.dot.gov/roadway_dept/rumble/) where several good references on shoulder rumble strips including the "Synthesis of shoulder rumble strip practices and policies" (15) can be found.

\section{CENTERLINE RUMBLE STRIPS}

Centerline rumble strips are obtained by milling the centerline of two-lane, two-way rural roadways (Figure 4) in order to limit the head-on and opposite-direction sideswipes. A recent and extremely comprehensive study on this type of intervention has been conducted in 2005 leading to an NCHRP Synthesis (16).

One of the key studies identified in this area by the NCHRP Synthesis is the 2003 IIHS study (17). This study has been rated "medium-high" in terms of level of predictive certainty by NCHRP Project 17-25 (7) and has indicated a potential accident reduction of $14 \%$ with respect to all accidents and $21 \%$ when only head-on and opposite-direction sideswipes are considered. The results of this study are applicable only to two-lane rural roadways.

One of the key limitations of this intervention technique is the reduced visibility of the centerline painting due to the milled portion of the surface. To overcome this effect the NCHRP Synthesis (14) highlights the innovative solution proposed in Minnesota where 4-6 inch rumble strips have been placed 2 inches on each side of the centerline.

Based on the results if the international inquiry conducted in 2005 for the NCHRP Synthesis, and on additional literature review conducted for this report, this type of intervention seems to be currently in use only in the United States and in Canada. 


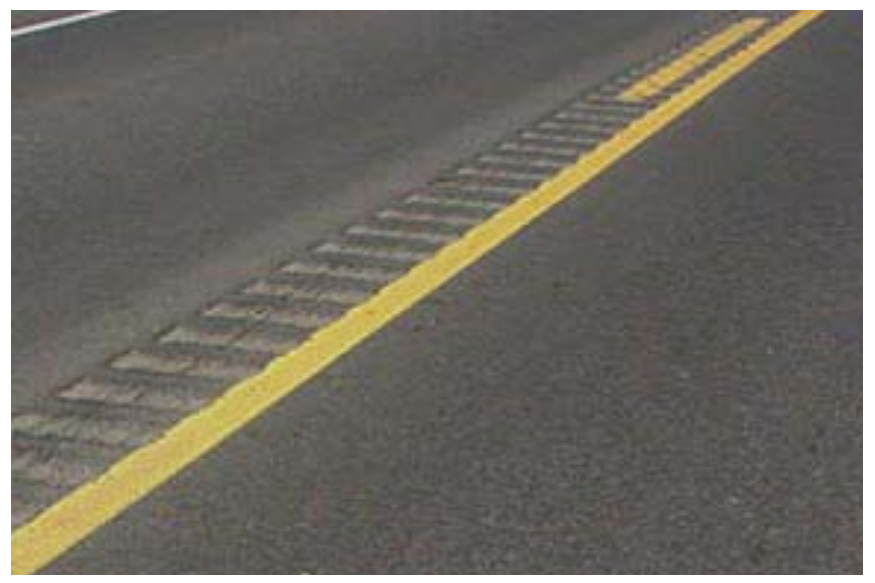

FIGURE 4 Centerline milled rumble strips.

An interesting application of milled centerline rumble strips can be observed in Austria where they have been used in the tunnel entrance areas in bidirectional tunnels. The draft new release of the Austrian standard RVS 09.01.25 requires rumble strips as a mandatory treatment at tunnel entrances.

\section{DISCONTINUOUS IN-LANE RUMBLE STRIPS}

This type of intervention consists of installing transverse strips, usually raised over the pavement (Figure 5) in order to alert the driver of an incoming potential hazard (such as a sharp curve or an intersection) to induce a speed reduction. This type of intervention is specifically recommended by the PIARC Road Safety Manual (12) as a speed reduction technique.

Elvik and Vaa (18) have estimated an average accident reduction of $33 \%$ in terms of injury accidents at intersections when applying this type of intervention. Considering a 95\% confidence interval this reduction ranges from 25 to $40 \%$. The counter effect is that traffic noise can be increased by $2-6 \mathrm{~dB}$ as a result of installing transverse rumble strips. In several countries their application is therefore limited to rural areas.

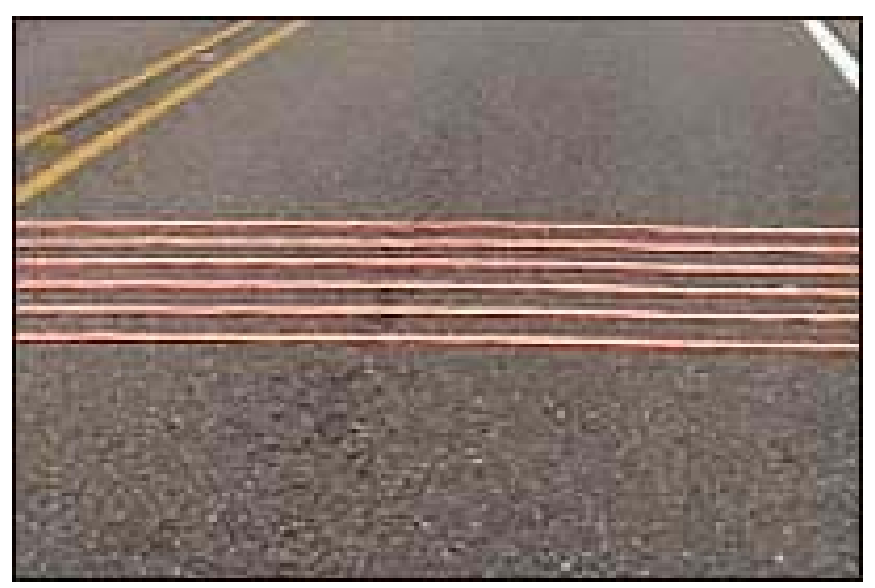

FIGURE 5 Raised transverse in-lane rumble strips. 


\section{HUMPS}

Humps are artificial elevations of the pavements (Figure 6). Often humps are designed so that they can also be used as pedestrian crossings. Elvik and Vaa (18) have estimated a 48\% reduction in accidents (42 to 54\% considering a 95\% confidence interval) when installing humps. The speed reduction that can be achieved by installing humps ranges from 24.4 to $36.4 \mathrm{~km} / \mathrm{h}$.

It should be noted that the vertical acceleration induced by speed humps is extremely high for high driving speeds. In most countries speed humps are therefore accepted only on urban roads with low design speed and with lighting to allow the driver to reduce the speed well in advance of the humps.

\section{THE EFFECT OF RUMBLE STRIPS ON EXTERIOR NOISE}

A key disadvantage of rumble strips is the noise generated outside the vehicle. This can be disturbing to the inhabitants surrounding the road infrastructures. Two studies have recently been published, (one based on a United States experience (13), and one based on a Danish experience (19)). Both investigate the influence of different rumble strip designs on exterior noise. Kragh et al. (19) shows that a change in the rumble strip design can seriously affect the noise levels measured at $25 \mathrm{~m}$ from the travelled lane. When a sinusoidal indentation is used only a $0.5-1 \mathrm{~dB}$ increase in the noise level is expected as compared to a "rectangular" indentation that can produce 3-7 dB higher noise levels.

Much higher noise level increases have been found by Finley and Miles (13). They show noise levels that increase from 4-5 dB (when using "button rumble strips") to $19 \mathrm{~dB}$ when milled rumble strips with 12-inch spacing are considered.

Noise is an issue in some urban areas. Even high macrotexture pavements are apparently an issue due to higher noise, and high textures have long been encouraged from a tire-pavement friction perspective. All noise/vibration guidance methods, generally reduce accident rates and are considered good practice where environmental issues related to increased noise are not determining factors.

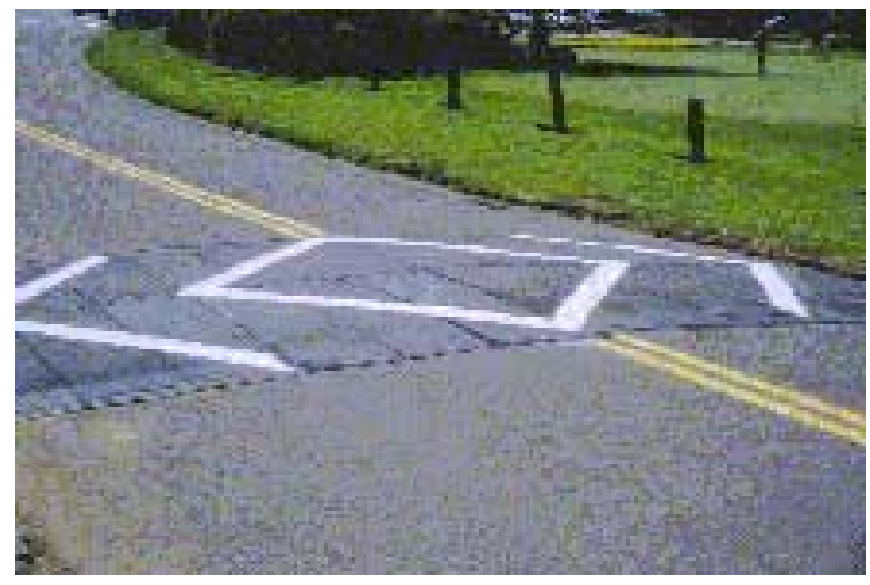

FIGURE 6 Speed hump. 


\section{REFERENCES}

1. FHWA. Technical Advisory-Roadway Shoulder Rumble Strips T5040.35, December 20, 2001.

2. Wood, N. E. Shoulder Rumble Strips: A Method to Alert "Drifting Drivers." Presented at the 73rd Annual Meeting of the Transportation Research Board, Washington, D.C., 1994.

3. Hickey, J. J., Jr. Shoulder Rumble Strip Effectiveness: Drift-off-road Accident Reductions on the Pennsylvania Turnpike. In Transportation Research Record 1573, TRB, National Research Council, Washington, D.C., 1997, pp. 105-109.

4. Perillo, K. The Effectiveness and Use of Continuous Shoulder Rumble Strips, Aug. 1998, FHWA website http://safety.fhwa.dot.gov/roadway_dept/rumble.

5. http://www.rumblestrips.com/sub_level/project_rollmilled.htm.

6. Griffith, M. S. Safety Evaluation of Rolled-in Continuous Shoulder Rumble Strips Installed on Freeways. HSIS Summary Report - FHWA-RD-00-032, December 1999.

7. NCHRP. Crash Reduction Factors for Traffic Engineering and Intelligent Transportation System (ITS) Improvements: State-of-Knowledge Report. Research Results Digest 299, November 2005.

8. Carrasco, O., J. McFadden, P. Chandhok, and R. Patel. Evaluation of Effectiveness of Shoulder Rumble Strips on Rural Multilane Highways in Minnesota. Presented at the 83rd Annual Meeting of the Transportation Research Board, Washington, D.C., 2004.

9. Patel, R. B., F. M. Council, and M. S. Griffith. Estimating Safety Benefits of Shoulder Rumble Strips on TwoLane Rural Highways in Minnesota: Empirical Bayes Observational Before-and-After Study. In Transportation Research Record: Journal of the Transportation Research Board, No. 2019, TRB, National Research Council, Washington, D.C., 2007.

10. Anund, A., M. Hjälmadahl, H. Sehammar, G. Palmqvist, and B. Thorslund. Placement and Design of Milled Rumble Strips on Centerline and Shoulder-A Driving Simulator Study, VTI Report 523A, 2005.

11. Bahar, G., C. Mollet, B. Persaud, C. Lyon, A. Smiley, T. Smahel, and H. McGee. Safety Evaluation of Permanent Raised Pavement Markers. NCHRP Report 518: 2004.

12. PIARC. Road Safety Manual. PIARC Publication \#103.03.B, Paris, 2003.

13. Finley, M. D., and J. D. Miles. Exterior Noise Created by Vehicles Traveling Over Rumble Strips. Presented at the 86th Annual Meeting of the Transportation Research Board, Washington, D.C., 2007. (See TRB 2007 Annual Meeting CD-ROM).

14. Moeur, R. C. Analysis of Gap Patterns in Longitudinal Rumble Strips to Accommodate Bicycle Travel. In Transportation Research Record: Journal of the Transportation Research Board, No. 1705, TRB, National Research Council, Washington, D.C., 2000.

15. FHWA. Synthesis of Shoulder Rumble Strip Practices and Policies. FHWA website http://safety.fhwa.dot.gov/roadway_dept/rumble.

16. Russel, E. R., and M. J. Rys. Centerline Rumble Strips-A Synthesis of Highway Practice NCHRP Synthesis of Highway Practice 339, Transportation Research Board of the National Academies, Washington, D.C., 2005.

17. Persaud, B. N., R. A. Retting, and CA. Lyon. Crash Reduction Following Installation of Centerline Rumble Strips on Rural Two-Lane Roads. Accident Analysis Prevention, Vol. 36, Issue 6, November 2004, pp. 10731079.

18. Elvik, R., and T. Vaa. The Handbook of Road Safety Measures. Elsevier, San Diego, Calif., 2005.

19. Kragh, J., B. Andersen, and S. Thomsen. Low Noise Rumble Strips on Roads-A Pilot Study. Proceeding of the Internoise 2007 Conference, Istanbul, Turkey, Aug. 28-31, 2007. 


\title{
Pavement Edges
}

\author{
DON L. IVEY \\ RICHARD A. ZIMMER \\ FRANK JULIAN \\ DEAN L. SICKING \\ WALTER A. JOHNSON \\ ERIC F. NORDLIN
}

\begin{abstract}
$\mathrm{A}^{\mathrm{n}}$ $\mathrm{n}$ abrupt difference in elevation between two adjacent riding surfaces can occur at the joining of (a) a paved traveled way and an unpaved shoulder, (b) a paved traveled way and a paved shoulder, (c) a paved shoulder and an unpaved adjacent area, or (d) two traveled lanes. If this difference in elevation reaches certain levels for certain edge shapes, safety can be affected.

Pavement edge drops can be produced when the longitudinal edges of an asphalt concrete pavement lift are not tapered to become flush with the surface of the existing paved shoulders. Edge elevation differentials are a necessary temporary situation at the edge of a pavement overlay until the adjacent overlay can be placed. Another common pavement edge drop can result from the displacement of untreated shoulder material from the edge of the traveled way caused by vehicle tire contacts or erosion from wind, rain, or other environmental conditions.

The pavement edge elevation differentials considered here range in height from less than 1 inch to 6 inches. The edge drop-offs created by trenching for the construction of pavement widening, edge sub-drainage systems and so forth are deeper and constitute more obvious traffic safety problems. Pavement edges can affect vehicle control because of inappropriate action or inaction by a driver.

The following scenario describes the elements of an edge drop loss of control
\end{abstract}

1. A vehicle is under control in a traffic lane adjacent to a pavement edge where an unpaved shoulder is lower than the pavement.

2. Through inattention, distraction, or some other reason the vehicle is allowed to move into a position with the right wheels on the unpaved shoulder and just off the paved surface.

3. The driver then carefully tries to gently steer the vehicle to gradually bring the right wheels back up onto the paved surface without reducing speed significantly.

4. The right front wheel encounters the pavement edge at an extremely flat angle and is prevented from moving back onto the pavement. The driver further increases the steer angle to make the vehicle regain the pavement. However, the vehicle continues to scrub the pavement edge and does not respond. At this time there is equilibrium between the cornering force to the left and the edge force acting to the right, as shown in Figure 1a.

5. The driver continues to increase the steer input until the critical steer angle is reached and the right front wheel finally mounts the paved surface. Suddenly, in less than one wheel revolution, the pavement edge force has disappeared and the cornering force of the right front wheel may have doubled because of increases in the available friction on the pavement and the right front wheel load caused by cornering (see Figure 1b).

6. The vehicle yaws radically to the left, pivoting about the right rear tire, until that wheel can be dragged up onto the pavement surface. The excessive left turn and yaw continues 


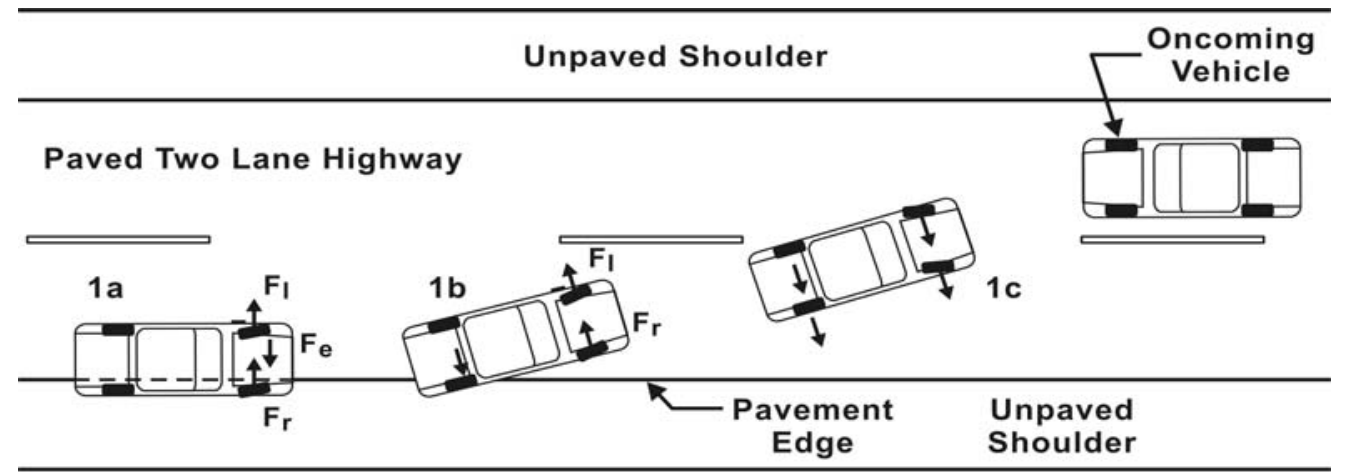

$$
F_{1}+F_{r}=F_{e} \quad \begin{aligned}
& F_{I} \text { and } F_{r} \text { are } \\
& \text { unbalanced }
\end{aligned}
$$

FIGURE 1 Illustration of the pavement edge influence on vehicle stability.

and it is too rapid in its development for the driver to prevent penetrating the oncoming traffic lane (Figure 1c).

7. A collision with oncoming vehicles or spin out and possible vehicle roll may then occur.

In many situations vehicle loss of control may not develop because the driver steers more aggressively. By moving back onto the pavement at a slightly sharper angle and increased lateral velocity, the scrubbing action on the face of the pavement drop-off can be avoided. In many cases, however, the same result — vehicle loss of control-may occur without the influence of a pavement edge drop. A loose, muddy, or low-friction shoulder can have the same effect if the driver oversteers when trying to return to the paved surface. Often it is this oversteering that is the cause of an accident when a pavement edge drop of modest height is encountered.

The qualitative effect of pavement edges, or the so-called lip drop-off, has been to some degree understood for many years. In Baker's Traffic Accident Investigator's Manual (1) published by Northwestern University, the following statement is found: "Lip Drop-off is simply a low shoulder at the edge of a hard pavement. It is important when the shoulder is more than three inches below the pavement...." Based on a telephone conversation with Baker on September 22, 1982, it was determined that this conclusion was reached by informal testing at Northwestern as early as 1959.

\section{TESTING AND ANALYSIS}

In 1974 the California Department of Transportation (Caltrans) studied several highway accident cases where pavement edge drops were cited as a contributing factor. There were contentions that a drop-off height as small as 1 to 2 inches would throw a vehicle out of control as it tried to climb back up the pavement edge, that the steering wheel would be wrenched out of the driver's hands, and that the vehicle would be forced into a path into the opposing lanes before it could be straightened out. As a result, Nordlin and Stoughton et al. $(2,3)$ conducted a number of vehicle tests under various conditions to confirm or refute some of the claims that were being made and, in general, to observe the effects of pavement edge drops on vehicle stability and controllability. Pavement edge drops from $1 \frac{1}{2}$ to $4 \frac{1}{2}$ inches did not throw the vehicles into an unstable condition or cause the driver to even come close to losing control during any of the tests. 
In 1978 Stoughton et al. (4) conducted several tests involving a broken, crumbling asphalt concrete (AC) pavement edge and a 2-inch drop, to the surface of an adjacent muddy soil shoulder. The same professional driver from the Nordlin study drove a pickup truck at $60 \mathrm{mph}$ on a trajectory with only the two right wheels dropping off and coming back up onto the AC shoulder. Because the tires sank in the mud, the overall drop-off height was 2.75 inches where the truck returned to the pavement. No problems with vehicle stability or controllability occurred in driving the test course.

In 1976 Klein et al. (5) conducted a roadway surface study that included pavement edge drops. In the study accident data and public inquiries through questionnaires were analyzed and a variety of both open- and closed-loop tests were conducted. Naïve drivers were used in the closed-loop tests. In all of the pavement edge drop-off tests, a special effort was made to achieve the tire scrubbing condition before attempting to climb up the drop-off. In edge drop tests with drop-off up to 5 inches and the scrubbing condition, losses of vehicle control were encountered at higher speed levels, generally more than $30 \mathrm{mph}$.

Klein et al. found the time between edge mounting of the front and rear tires to also be less than $0.6 \mathrm{sec}$. As shown in Figure 2 (5), they developed curves for the relationships between steering wheel angle and the vehicle steer angle required to climb various vertical pavement edge heights from the scrubbing condition. For edge heights up to 3 inches, the curve of Figure 2 curves is relatively linear. In this range the edge-climbing maneuver appears relatively safe. As the curves become more curvilinear, the maneuver becomes significantly more difficult. As the curves start a precipitous rise, again approaching a straight line, the difficulty becomes extreme.

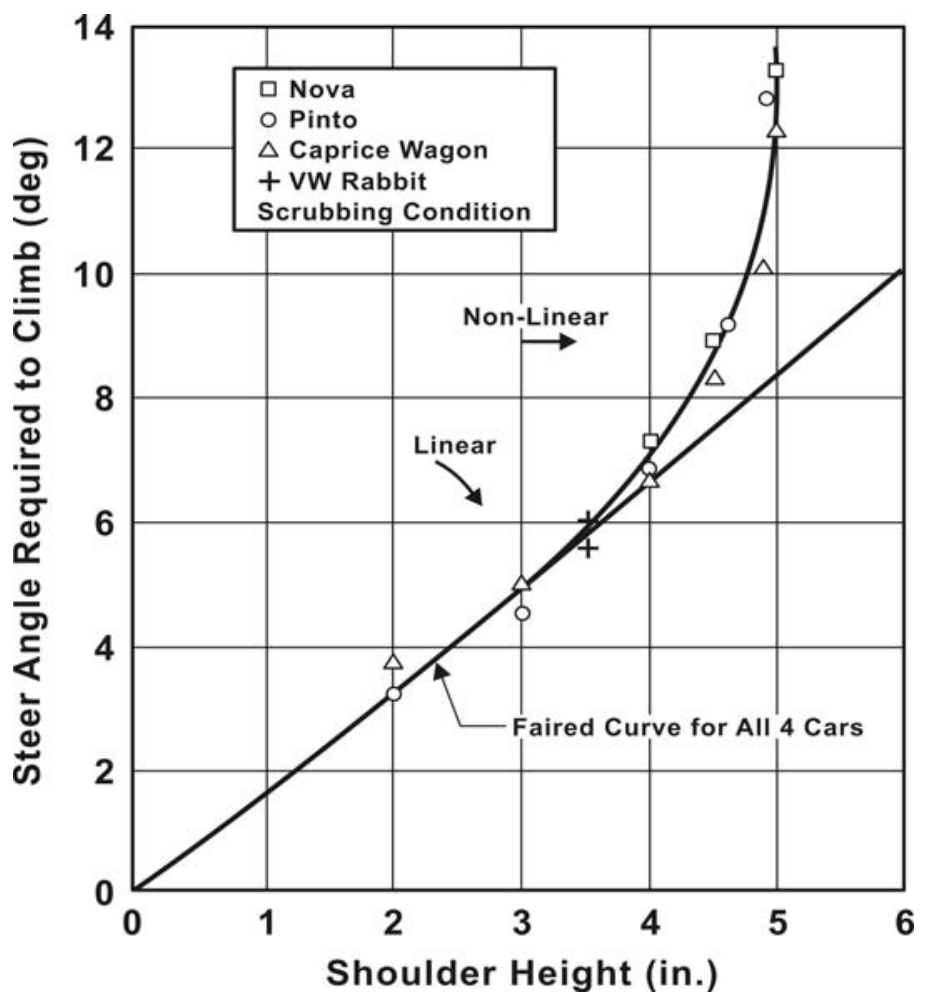

FIGURE 2 Steer angle required for different edge heights. 
The Nordlin and Stoughton studies had not included the pavement edge-scrubbing condition, and the Klein study had concentrated almost entirely on the edge-scrubbing condition and one pavement edge geometry, that is, vertical with little edge rounding. Therefore, Zimmer and Ivey (6) in 1981 undertook a new study to extend the information already developed by Nordlin, Stoughton, and Klein.

The results of the work by Zimmer and Ivey under the edge-scrubbing condition are summarized in Figure 3 (6), where the relative degree of safety, in terms of the subjective severity levels, is plotted against the longitudinal edge elevation change (drop-off).

When compared to the other published studies available in 1983 the influences of longitudinal pavement edges on vehicle safety are consistent and supplement each other. It was agreed that loss of vehicle control can develop at speeds greater than $30 \mathrm{mph}$ under certain circumstances, where inattentive or inexperienced drivers return to the traffic lane by oversteering to overcome the resistance from a continuous pavement edge and tire-scrubbing condition. This safety problem is minimized where the face has a 45-degree or lower slope. However, losses of control can occur even without any edge drop when an errant vehicle is returned to the higher cornering friction of the pavement by oversteering. Pavement edge heights more than 5 inches in height can interfere with the underneath clearance and thus create safety problems for small automobiles.

In the period subsequent to publication of SOAR 1 (1983) there have been significant changes in highway speed limits and in automobile construction. In 1983 the top speed limit was 55 and all testing had been limited to that speed. There were also no capricious styling driven changes to tire construction such as the ones required by 18 to 22 inch rim diameters. This styling change now results in rim-pavement clearances that are as little as $1 \frac{1}{2}$ inches.

The Zimmer and Ivey work was criticized for being nonrepresentative of naïve drivers. In 1986, Olson et al. (7) attempted to study the reaction of naïve drivers to edge drop situations. That work demonstrated that it was not feasible to test the "naïve" driver condition. The best that would be done was to test a larger number of randomly selected drivers after they had been coached in how to get their vehicles into an edge-scrubbing condition. The evaluation criteria in the 1983 (Zimmer/Ivey) and 1986 (Olson et al.) studies were somewhat different. A direct comparison of the two data sources was not attempted until 2004 when Zimmer and Ivey collaborated in relating the two indices for the Atlanta workshop.

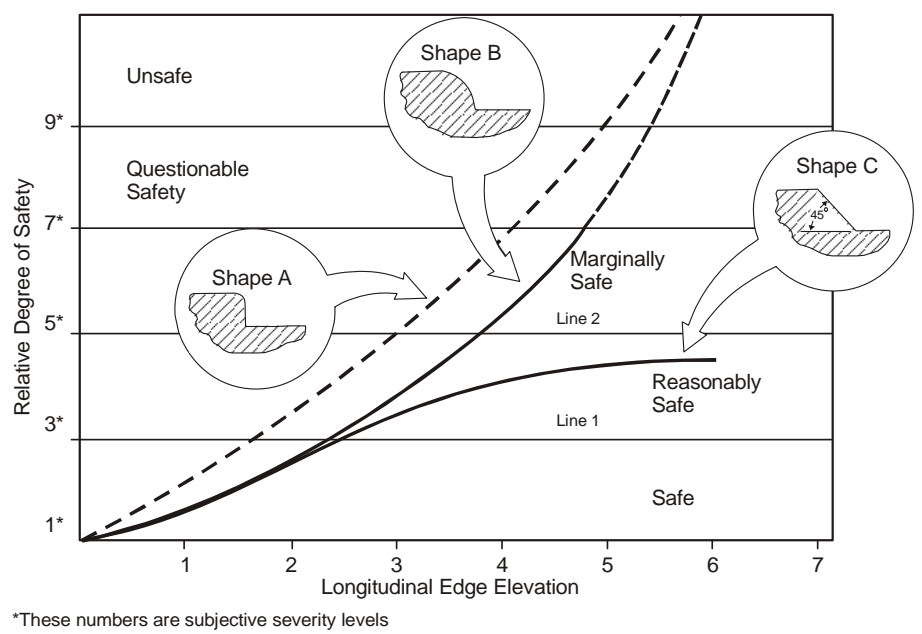

FIGURE 3 Relative degrees of safety for various edge conditions. 
The obvious difference between the 1986 Olson study and the 1983 Zimmer study was a higher variability in the performance of the 50 drivers in capability to deal with various edges compared to the four drivers used in the first work, a predictable finding. The resulting study evaluated a vertical drop-off and $45^{\circ}$ wedge drop-off with hard and soft shoulder surfaces, different passenger vehicle sizes, and front- versus rear-wheel-drive vehicles. Fifty nonprofessional drivers were used to complete 185 test runs. Speeds of 20, 30, and $40 \mathrm{mph}$ were tested for a 4.5-inch vertical face drop-off; 30, 40, and $50 \mathrm{mph}$ for a 3-inch vertical face drop-off; and various speeds up to $55 \mathrm{mph}$ for a 3 - and 4.5 -inch drop-off with a $45^{\circ}$ beveled edge. Results indicated that a vertical drop-off of 4.5 inches or deeper could not be negotiated by any of the nonprofessional drivers at any speed. They found that vehicle size was relevant and that vertical edge drop-offs around three inches could be negotiated at speeds of $30 \mathrm{mph}$ in large passenger cars.

For the speeds up to $55 \mathrm{mph}$. The authors also evaluated test runs on soft shoulders with a professional driver and concluded that the height of the drop-off, not shoulder material, was the determining factor in being able to recover safely.

In the range of Type $\mathrm{A}\left(90^{\circ}\right.$ as in PCC) edge drops from 2 to 5 inches the average values measured in the Olson study ranged from $1 / 2$ to 1 inch larger than the nominal edge height considered. Olson et al. (7) did not study the Type B (rounded as in ACP) edge and concurred with previous work on the Type $\mathrm{C}\left(45^{\circ}\right)$ safety edge. Because of data variability it was not clear that a significant difference between the 1983 and 1986 studies existed. When the two studies were finally related it was found there was a difference in the results from Type A edges between $2 \frac{1}{2}$ and 4 inches in height as shown in Figure 4. Using the same maintenance guide of key lines at the 3 and 5 relative degree of safety level, maintenance should be scheduled and performed before the edge exceeds the 2 inch level. This more conservative approach was a conclusion also reached by Hallmark et al. (8) and the advisory group acting on the project.

Ivey and Sicking further evaluated the relationship between drop-off height and the driver's ability to recover. They used simulation and analytical relationships and earlier testing by Klein et al. (5) to determine the steer angle necessary to remount a drop-off with

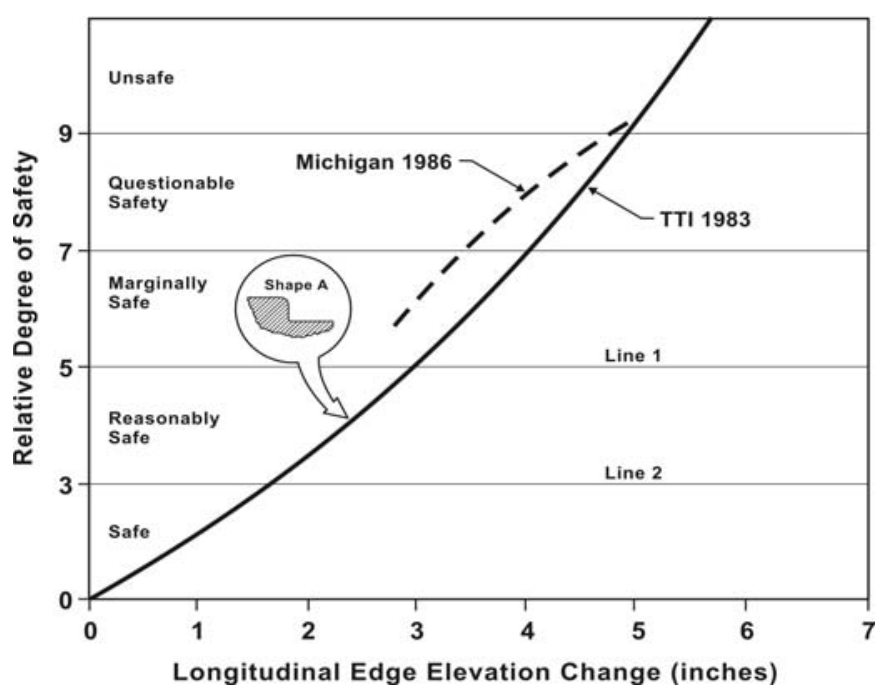

FIGURE 4 Comparison with Michigan. 
different heights and edge shapes at $50 \mathrm{mph}$. Their results reinforced and explained earlier findings that edge shape profoundly influences the driver's ability to recover. A 4-inch vertical edge resulted in loss of vehicle control. As the edge shape became flatter, less effect was noted. The authors evaluated a 2 -inch, 4 -inch, and 6-inch drop-off with a $45^{\circ}$ wedge. They found that even with a drop-off depth of six inches, recovery within the 12 -foot lane was possible with a $45^{\circ}$ wedge, which would come to be called by FHWA, the safety edge.

Until 1998, no one had reported tests at speeds above $70 \mathrm{mph}$. Zimmer and Ivey (6) had shown some degree of speed sensitivity between 35 and $55 \mathrm{mph}$, resulting in concern that previous results might not be applicable to $70 \mathrm{mph}$. Zimmer conducted tests for Texas DOT with several vehicles at $70 \mathrm{mph}$ on $90^{\circ}$ concrete edges (Type A) from one to 4 inches in height. He showed that the Type A curve needed to be altered for the $70 \mathrm{mph}$ condition. This finding was first presented at the Alabama workshop in 2004 (9). The results are compared in Figure 5.

Results are shown using 5 modern vehicles on Type A edges (right angle PCC) at speeds of 70 to $73 \mathrm{mph}$.

The somewhat more sensitive results were not inconsistent, however, with the conservative approach many state DOTs were taken by requiring signing and marking for any type A edge.

While the 1983 Zimmer and Ivey report in TRR 946 produced guidelines for the maintenance of edges and shoulders there was a need recognized for further work in signing, marking and barriers to deal with edge drop situations in construction zones. This need resulted in the 1988 TRR publication, "Safety in Construction Zones Where Pavement Edges and Dropoffs Exist" (10), where it was recommended that even less than 2 inch, $90^{\circ}$ edges were cause for signing and delineation due to unknown compaction of adjacent soil while under construction. The relatively simple guidelines developed were adopted in whole or in part by a number of state DOTs and continue in use.

The construction zone report relied on work done by Ivey and Sicking (8) which presented an analytical solution to the interaction of tires and edges of various shapes in 1986.

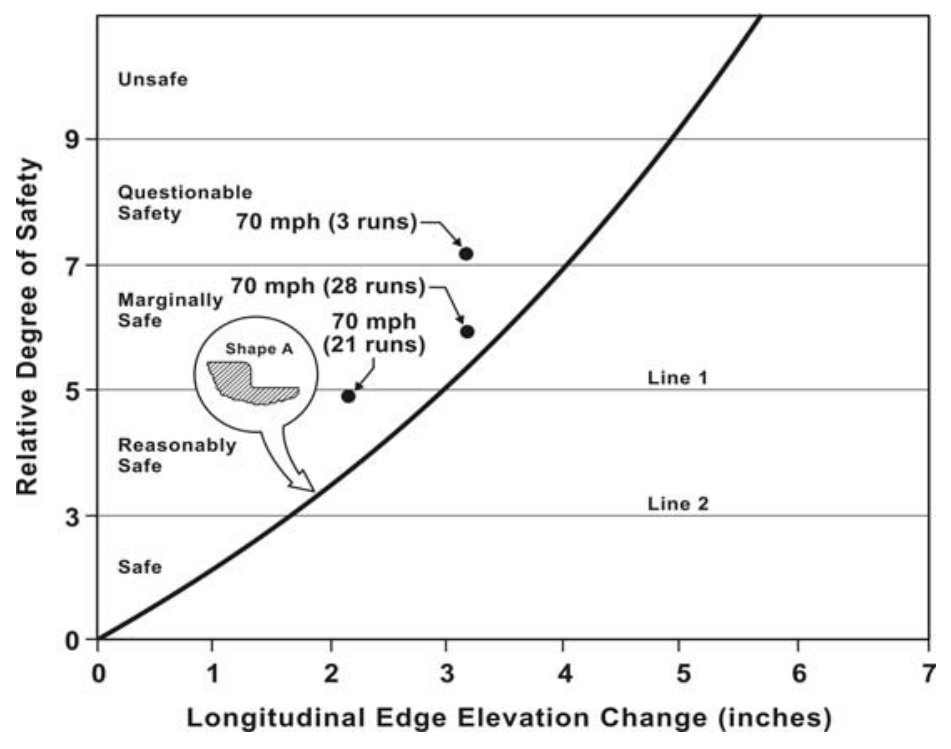

FIGURE 5 Comparison with $70 \mathrm{mph}$. 
This analytical solution made possible the simulation work presented by Ivey et al. (11) on tractor/semi-trailer interaction with edges that was done in concert with the development of the construction zone report.

Perhaps of the many influences that resulted in the current attention given to edge drop related accidents the "tipping point" was reached with Humphreys and Parham in their 1994 project for the AAA Foundation for Traffic Safety (12). They not only provided an excellent review of the literature at that time but pushed hard for the requirement of a $45^{\circ}$ beveled edge as a cure for edge drop losses of control, a finding that dated back to 1983 (6) and was reinforced in 1986 by the University of Michigan and Texas Transportation Institute researchers (13). A consensus on the advisability of such a step in construction practice seemed apparent in the FHWA sponsored Atlanta workshop in 2004 (14) where the first of two brochures promoting the safety edge was presented. The adoption of the safety edge as a standard procedure is moving rapidly. Significant efforts are underway in Georgia, New York, Indiana, Texas, and New Jersey. The Georgia experience was presented by Wagner and Kim at TRB in 2005 (15). The results are consistently positive.

The latest effort to develop a consensus on the influence of pavement edge drops on losses of control was made by Hallmark et al. (9) under sponsorship by AAA Foundation for Traffic Safety. It is a comprehensive treatment of the status of state DOT guidelines, the documentation of automobile testing and simulation and statistical relationships between edge sizes and shapes and accident frequency. That latter relationship was summarized in more detail in the chapter on accident data relationships.

The four factors or sources of new information relating to Figure 3 are

1. The Olson study interpreted by Zimmer and Ivey indicating a more severe influence of Type A, $90^{\circ}$ edge $(14,15)$;

2. The Zimmer study indicating a more severe influence of a Type A, $90^{\circ}$ edge at the speed of $70 \mathrm{mph}(6)$;

3. The emergence of the safety edge recommended by FHWA and now in use in 5 states $(12,14)$; and

4. The emergence of plus-sized tires and rims with potentially major influence on the safe boundaries of Type A $90^{\circ}$ edges.

Figure 6 illustrates these influences with the more severe placement of the Type A, $90^{\circ}$ curves labeled Olson, $70 \mathrm{mph}$, and plus-sized rims. Clearly for higher speeds and more critical tire-rim designs the Type A edges result in a more severe influence on vehicle stability.

This makes the use of paving devices and edge grinding to achieve a more forgiving edge shape of even greater importance. The placement of the curve for a shape " $\mathrm{D}$ " safety edge is considered conservative in that the transition from on-roadway surface to shoulder and back is so smooth it defies assignment of any degree of severity, except when the elevation change from pavement to shoulder causes a noticeable tilt in the vehicle.

Figure 7 shows clearly the great improvement in safety that can result from producing the safety edge, especially with an angle as low as $30^{\circ}$.

A definitive set of recommendations for constructing and maintaining safe pavement edge conditions has now been produced by William D. Lawson and M. Shabbir Hossain (13). Most authors to date have concentrated on defining the problem. Lawson and Hossain chose to develop and report extremely practical solutions. 


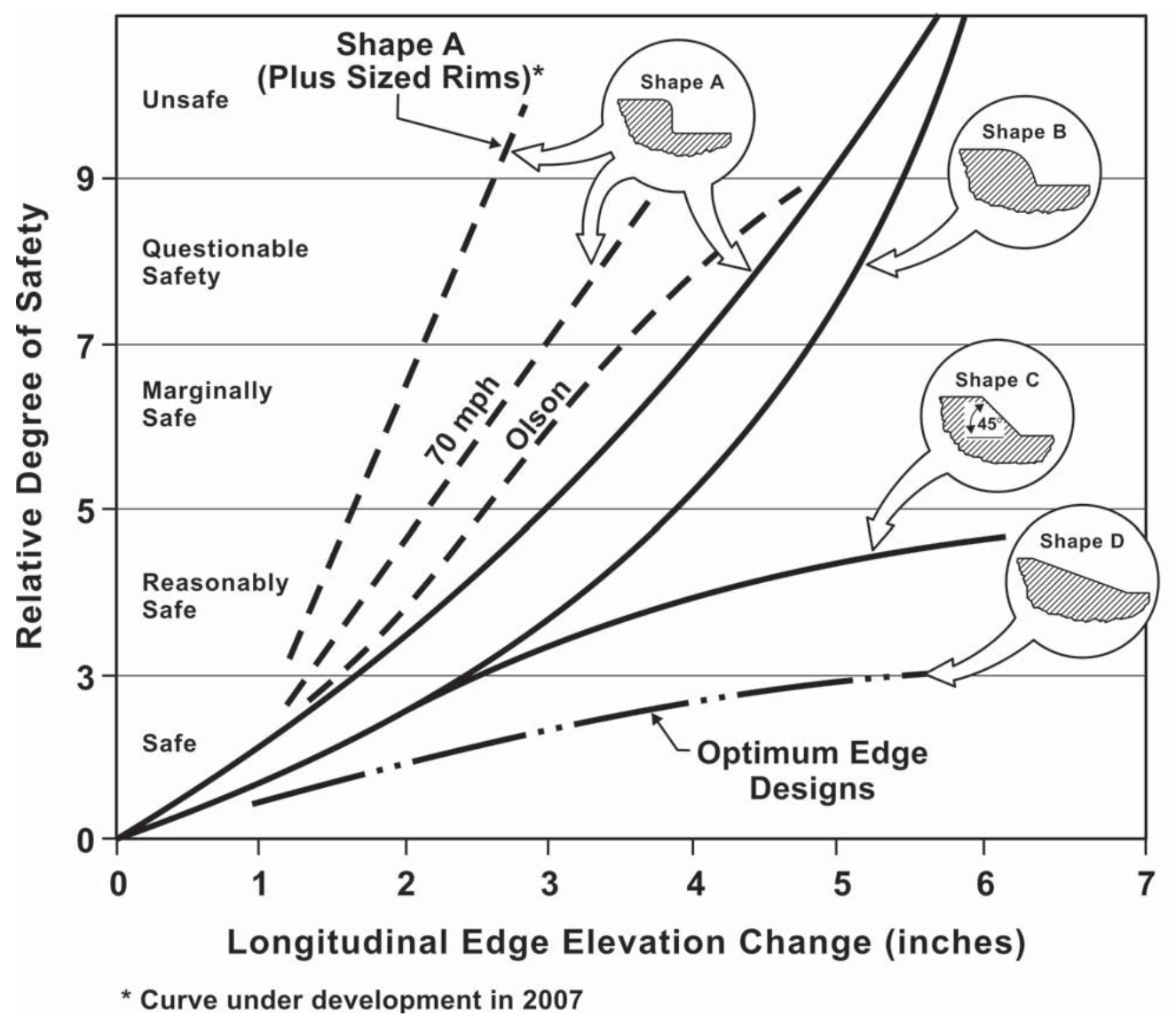

FIGURE 6 Type A edges compared with Types B, C, and D.

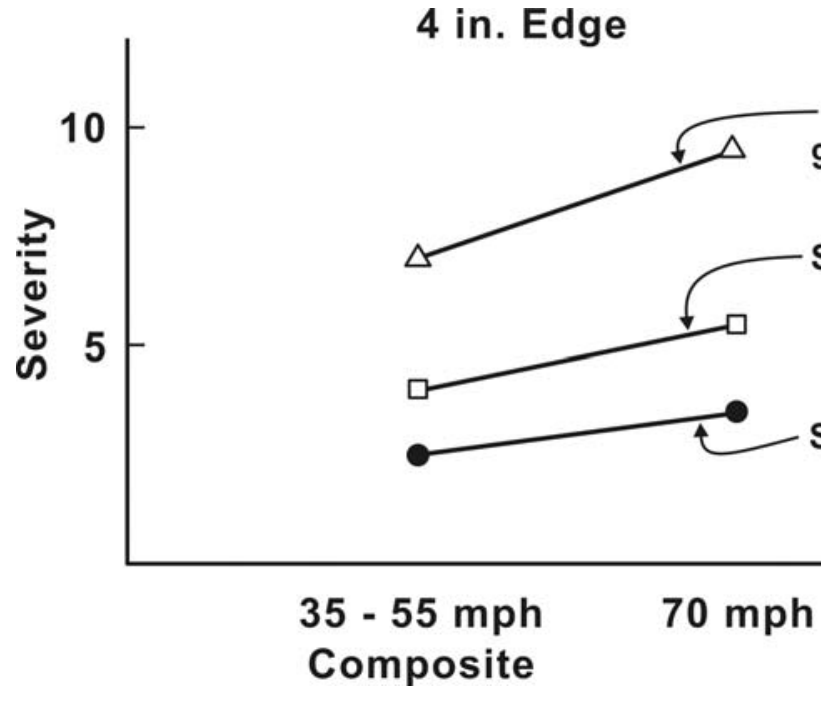

FIGURE 7 Safety improvement of safety edges. 


\section{REFERENCES}

1. Baker, J. S. Traffic Accident Investigator's Manual, 4th ed. Traffic Institute, Northwestern University, Evanston, Ill., Jan. 1975.

2. Nordlin, E. F., et al. The Effect of Longitudinal Edge of Paved Surface Drop-Off on Vehicle Stability. Report CA-DOT-TL-6783-1-76-22. California Department of Transportation, Sacramento, March 1976.

3. Stoughton, R. L., D. M. Parks, J. R. Stoker, and E. F. Nordlin. Effect of Longitudinal Edge of Paved Surface Drop-Off on Vehicle Stability. In Transportation Research Record 703, TRB, National Research Council, Washington, D.C., 1979, pp. 24-30.

4. Stoughton, R. L., et al. The Effect of a Broken AC Pavement Drop-Off Edge and Muddy Shoulder on Vehicle Stability and Controllability. Memorandum Report. California Department of Transportation, Sacramento, July 1978.

5. Klein, R. H., W. A. Johnson, and H. T. Szostak. Influence of Roadway Disturbances on Vehicle Handling. Final Report. Systems Technology, Inc., Hawthorne, Calif., Oct. 1976.

6. Zimmer, R. A., and D. L. Ivey. Pavement Edges and Vehicle Stability-A Basis for Maintenance Guidelines. In Transportation Research Record 946, TRB, National Research Council, Washington, D.C., 1983, pp. 48-56.

7. Olson, P. L., R. Koppa, and V. Pezoldt. Pavement Edge Drop UMTRI-86-33. University of Michigan Transportation Research Institute, Ann Arbor, 1986.

8. Ivey, D. L., and D. Sicking. The Influence of Pavement Edge and Shoulder Characteristics on Vehicle Handling and Stability. In Transportation Research Record 1084, TRB, National Research Council, Washington, D.C., 1986.

9. Hallmark, S. L., D. Veneziano, T. McDonald, J. Graham, K. Bauer, R. Patel, and F. Council. Safety Impacts of Pavement Edge Drop-offs. AAA Foundation for Traffic Safety, Washington D.C., 2006.

10. Ivey, D. L., K. K. Mak, H. D. Cooner, and M. A. Marek. Safety in Construction Zones Where Pavement Edges and Dropoffs Exist. In Transportation Research Record 1163, TRB, National Research Council, Washington, D.C., 1988.

11. Ivey, D. L., H. E. Ross, Jr., D. L. Sicking, and C. MacAdam. Loss of Control of Trucks Caused by Pavement Edge and Shoulder Conditions. Surface Characteristics of Roadways: International Research and Technologies, ASTM-STP-1031, 1990.

12. Humphreys, J. B., and J. A. Parham. The Elimination or Mitigation of Hazards Associated with Pavement Edge Drop-offs During Roadway Resurfacing. AAA Foundation for Traffic Safety, Washington, D.C., 1994.

13. Lawson, W. D., and M. Shabbir Hossain. Best Practices for Pavement Edge Maintenance, Research Report, TxDOT Report No. FHWA/TX-04/0-4396-1, TechMRT: Multidisciplinary Research in Transportation, Lubbock, Tex., May 2004. (Also available, Training Manual and Training Video).

14. Ivey, D. L. Summary of Research, Pavement Edges and Highway Safety: 1940-2004. Presented at FHWA workshop Managing Shoulder Edge Drop-offs to Improve Safety. Atlanta, Ga., 2004.

15. Wagner, C., and Y. S. Kim. Construction of a Safe Pavement Edge: Minimizing the Effects of Shoulder Dropoff. Presented at the 84th Annual Meeting of the Transportation Research Board, Washington, D.C., 2005. 


\title{
Friction Variations
}

\author{
JOHN C. BURNS \\ WolfGang E. MEYER \\ GORDON F. HAYHOE \\ J. J. HENRY \\ DON L. IVEY
}

\section{TRANSVERSE FRICTION}

Transverse variations of friction across a lane, sometimes called differential friction, can cause significant problems for a braking vehicle. This condition arises when the individual wheel paths on which a vehicle's tires ride have significantly different coefficients of friction. This problem may be minor or extremely serious, depending on the magnitude of the frictional difference, its relationship to the average coefficient of friction, and the speed at which a vehicle travels across the surface.

This phenomenon was first described theoretically by Zuk (1) in 1959. Zuk developed equations to predict the total yaw angle of a vehicle based on its mass, speed, and the coefficient of friction for each of the wheel paths. Zuk concluded that a difference in the friction coefficients of the wheel paths could be potentially hazardous even though the average surface friction was relatively high.

Fifteen years later Burns (2) provided further information on this subject by performing braking tests using various vehicles under highway conditions. These tests provided detailed observations of the movement of vehicles braking on split-friction surfaces, as well as indications of the relative controllability of vehicles under those conditions. An example found on the highway during Burns' study was where the left wheel path was bleeding and the right wheel path was chip-sealed. The right wheel path had a wet stopping distance number $\left(\mathrm{SDN}_{40}\right)$ of 67 and the left had a wet $\mathrm{SDN}_{40}$ of 41 . This difference of 26 represents a 63 percent braking force differential. A car braking at $40 \mathrm{mph}$ on this surface rotated 90 degrees clockwise. The same car braking at $50 \mathrm{mph}$ rotated 270 degrees clockwise.

This research also identified the most commonly found differential wheel path conditions. They are (a) differential flushing or bleeding, (b) unequal wear, (c) partial seal coating of a lane, (d) dissimilar shoulder surfaces, (e) maintenance crack patching of only one wheel path, and (f) unequal drainage properties.

In 1981 Hayhoe and Henry (3) conducted research to better determine the levels of acceptable differential friction. A simulation of the skidding behavior of cars in plane rotation on differential friction surfaces was used to develop the curves shown in Figure 1 (3). These curves are used as follows. $\mu 1$ is the higher of the two coefficients. Plot the position of the lower coefficient $(\mu 2)$ and the length of the split-coefficient surface. If the resulting point is to the left of the $\mu$ l curve, the situation is potentially unsafe; if it is to the right, a relatively safe situation is indicated.

These and other studies have confirmed that differential friction can have a significant effect on a braking vehicle. The vehicle-rotation phenomenon can occur at high as well as low friction levels and should be considered in any pavement friction evaluation. The greatest 


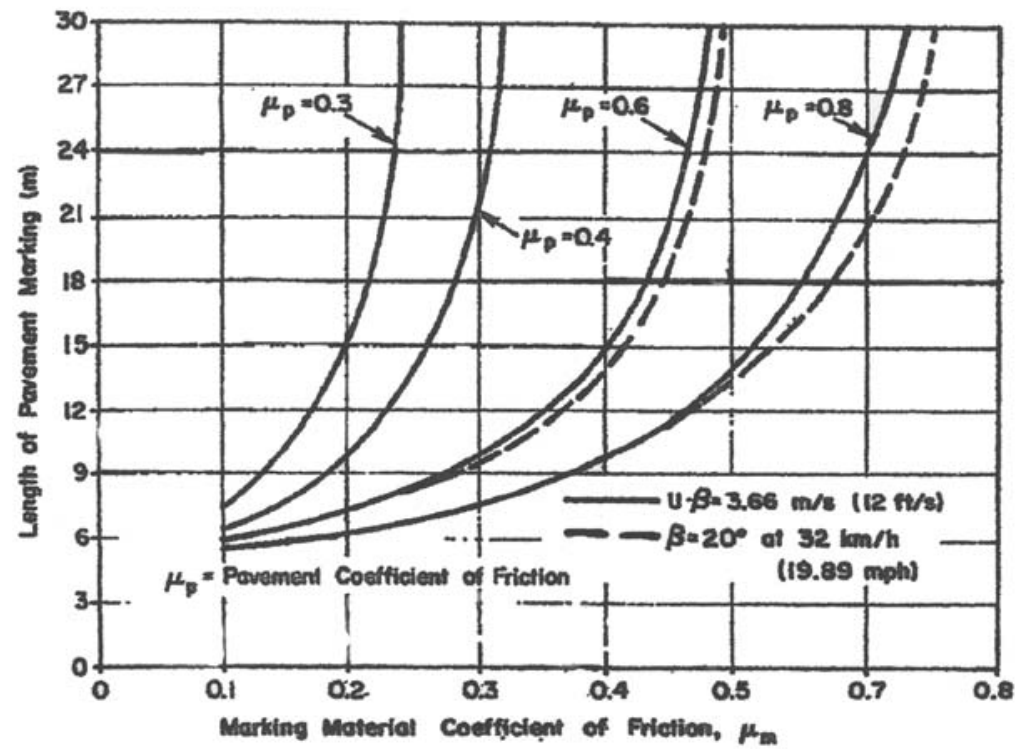

\section{FIGURE 1 Recommended maximum lengths of differential friction for safe operation of cars during hard-braking conditions (vehicle initial speed is 55 mph).}

problem arises when the driver releases his brakes after the car has begun to spin. When this is done the vehicle is propelled in the direction it is facing. This could be off the road or into oncoming traffic. Thus the greater the degree of rotation, the more probable the vehicle will be uncontrollable.

\section{LONGITUDINAL FRICTION VARIATIONS}

In the longitudinal direction variations in the friction properties of pavement surfaces occur more frequently than is commonly assumed. There are several types of such discontinuities. One type exists where one construction project adjoins another or where a surface has been repaired. In these cases the transition from one pavement to the other is often quite sharp, and usually it is recognizable by drivers. Whether drivers can and do judge correctly the related changes in friction properties, or even realize the possible existence of such changes, is debatable, as is whether they adjust their driving pattern to perceived changes. Because not all existing changes are perceived and, even if they are likely to be judged incorrectly or ignored, they can constitute a potential hazard.

Gradual transitions occur at locations where the friction demand is higher than elsewhere along a roadway, as on curves and where acceleration and deceleration occur frequently and consistently. At these locations available friction tends to be lower than on the adjacent tangents with freely flowing constant speed traffic. The friction properties of the surface are degraded by the greater rate of pavement wear and polishing that accompanies speed changes and cornering. The friction needed for these vehicle maneuvers might be available elsewhere on the same pavement, but at the maneuver sites it may eventually decrease below that demanded by a significant number of drivers. The problem of measuring skid resistance on curves has not been addressed since 1977 (4); thus no data are available for assessing the magnitude of the hazard at this and other maneuver sites. It is, however, well established that certain types of surface 
courses suffer considerable loss of friction potential under the influence of traffic, and that this loss is accelerated when the tires do more than normal amounts of scrubbing (5).

Short sections that have quite different friction properties than the adjoining pavement result from pavement markings, particularly at pedestrian crossings or where spot repairs have been made that extend across a traffic lane. In the first example the available friction is likely to be lower than that of the basic pavement, and in the second example it is likely to be higher than that of the basic pavement. Normally this is of little consequence, but it can present a hazard if an emergency maneuver must be executed at this location. The consequences will be much the same as if the front and rear brakes on a vehicle are out of balance, except that the friction imbalance is of a short duration only. The driver would have to react to two changes superimposed on an emergency maneuver, and this is at best within the capability of only the most skilled driver.

Remedies for some of the described cases of longitudinal friction variations are available. For instance, instead of repairing a few feet of pavement on a curve, overlaying the entire curve will prevent drivers from unexpectedly encountering a different friction level at a critical point. Overlaying a curve in its entirety raises the available friction on the curve, if only temporarily, above that of the adjacent tangents. This is desirable and will be cost effective if the curve was a high accident location even before the pavement needed repair. On the other hand, it is difficult to prevent variations between adjoining projects. If highly skid and polish-resistant surface courses could be used everywhere, this will not only reduce the total number of skidding accidents, but the difference in accident experience between old and new projects will be reduced. This is so because, as is generally thought, the relationship of skidding accident rate versus skid resistance is flatter at higher skid numbers than it is at low ones (6). Alternately, if surfacing projects were designed to involve long sections of roadway, the number of changes in available friction would be reduced. Because drivers appear to go through a learning period whenever they encounter a change in driving environment, uniform sections of greater length may result in disproportionately greater improvements in accident rates than might be expected from the reduction in the number of abrupt changes in surface properties.

Many aspects of the problem of longitudinal variations of friction have not been investigated. There are no applicable statistics, but the following example illustrates the potential hazard that traveling from a high friction surface to one with much poorer friction properties can present. When the latter is of such design that the combination of summer heat and heavy truck traffic pumps the asphalt to the surface of the pavement, the wheel paths get quite slippery. Bleeding pavements can have an $\mathrm{SN}_{40}$ as low as 10. If such a section is encountered on an upgrade by a vehicle coming from a surface with an $\mathrm{SN}_{40}$ of 40 , running under full power, the drive wheels may suddenly begin to spin unless the driver anticipates the change and reduces power. The transition zone may be no more than $10 \mathrm{ft}$ long, and in some cases less. At $55 \mathrm{mph}$ it takes $0.12 \mathrm{sec}$ for the vehicle to travel the $10 \mathrm{ft}$, which does not give the driver enough time to sense the impending wheel spin and prevent it. Use of cruise control in hilly country is therefore risky. The consequence can be a serious deviation from the intended path. Vehicle spin-out may occur. Similar hazards exist during braking and cornering or whenever the wheels of a vehicle suddenly encounter a drop in available friction. In the reverse case, other instabilities occur that can catch an inattentive or inexperienced driver off guard.

Thus, from the viewpoint of safety, there is little doubt that longitudinal variations in pavement properties should be avoided where possible and, if this cannot be done, these variations should be held to a minimum. Where major variations exist, warning signs may be an appropriate measure until surface conditions can be corrected. 


\section{PAVEMENT MARKINGS}

Pavement markings are primarily used to provide visual guidance for drivers and to guide traffic flow. Turn arrows, hazard warning messages, and so forth are frequently marked directly on the pavement surface. In their intended roles pavement markings are universally held to provide positive benefits, particularly under conditions of poor visibility $(7,8)$, but the degree of skid resistance that they provide is of increasing concern with the growing use of plastic materials and heavy marking in sections such as ramps and gores. Marking materials generally lower the skid resistance of a pavement and, when applied over large sections, increase wet skid stopping distances. Differential friction caused by the application of marking materials also gives rise to such hazardous conditions as excessive vehicle yaw during locked-wheel skids, loss of control during motorcycle or bicycle turning and braking maneuvers, and slipping and falling by pedestrians on crossings.

Skid-resistance requirements for marking materials have traditionally been specified in terms of low-speed wet friction measurements (7). However, high-speed skid resistance measurements made by the Massachusetts and Michigan departments of transportation $(9,10)$ have demonstrated that low speed measurements do not accurately reflect the absolute skid resistance of marking materials for vehicles traveling at highway speeds. Results for three materials field-tested in the Michigan study were as follows:

\begin{tabular}{lcc} 
Material & SN $_{\mathbf{4 0}}$ & BPN \\
\hline Fast-drying white paint (with beads) & 37 & 31 \\
Extruded hot plastic (with beads) & 23 & 35 \\
Smooth cold plastic (no beads) & 4 & 14 \\
Bare pavement substrate surface & 67 & -
\end{tabular}

In this table $\mathrm{SN}_{40}$ is the skid number at $40 \mathrm{mph}$ as measured by ASTM E274 method of test, and BPN is the British pendulum number as measured by ASTM E303 method of test. Two of the three materials had lower $\mathrm{SN}_{40}$ than BPN, with the unbeaded plastic having a friction level consistent with hydroplaning or melting ice.

In a later, more comprehensive study (11), the performance of 11 different materials applied to four different pavement surfaces was evaluated. A total of 113 combinations of material type, material formulation, and pavement surface were included in the study. Macro texture, $\mathrm{SN}_{40}$, and BPN measurements were made on each sample surface. Predictor equations relating $\mathrm{SN}_{40}$ to $\mathrm{BPN}$ and root mean square (RMS) macro texture height were then developed by linear-regression techniques. A single regression equation, which would encompass all of the materials, could not be formulated at an acceptable level of correlation, so the materials were grouped into eight categories, and a separate equation was developed for each category. Thus the results of the study may be used to estimate the high-speed skid resistance of typical marking materials from low-speed laboratory measurements. In most cases a BPN measurement is sufficient to provide the $\mathrm{SN}_{40}$ estimate, although the addition of a macro texture measurement may be beneficial in improving the correlation. The average skid resistance numbers measured on the various materials included in the study are given in Table 1 (11). 


\section{TABLE 1 Average High-Speed Skid Resistance of Five Marking Materials}

\begin{tabular}{lccc} 
Marking Material & $\begin{array}{c}\text { No of } \\
\text { Applications }\end{array}$ & $\begin{array}{c}\text { Avg. Skid } \\
\left(\mathbf{S N}_{40}\right) \\
\text { Resistance }\end{array}$ & $\begin{array}{c}\text { Standard } \\
\text { Deviation }\end{array}$ \\
\hline Traffic paint (unbeaded) & 22 & 20.7 & 8.0 \\
Traffic paint (beaded) & 41 & 26.7 & 6.8 \\
Thermoplastic (unbeaded) & 12 & 18.7 & 10.1 \\
Thermoplastic (beaded) & 26 & 24.7 & 7.5 \\
Performance plastic & 11 & 25.2 & 8.7
\end{tabular}

Specific findings of the study were as follows.

1. For all combinations of material, formulation, and pavement surface, the high-speed skid resistance of the marking material was lower than that of the bare substrate pavement surface, whereas the low-speed skid resistance in some cases was higher than that of the substrate.

2. The skid resistance of markings applied in the field did not increase significantly with time and suffered seasonal and short-term variations similar to those of the substrate pavement surface.

3. Beaded paint and plastic marking materials had significantly higher skid resistance than unbeaded materials. The use of unbeaded materials should be avoided.

4. Chlorinated rubber-based paints had significantly lower skid resistance than alkyd resin paints.

5. Spray thermoplastics had higher skid resistance than hot-extruded thermoplastics.

The effects of differential friction caused by marking materials on highway safety is difficult to determine because of a lack of accident studies specifically directed toward the problem. However, single- and double-delineation stripes do not appear to be hazardous to the operation of cars and trucks (11). When a large section of marking material is present on wet pavement, a differential friction problem could exist. In a computer simulation study of cars skidding on pavements with differential friction caused by marking materials (11), a design procedure was developed for determining the maximum allowable differential friction between pavement and material, given the length of the marking on the pavement. Boundaries of safe operation are shown in Figure 2, the same figure that gave boundaries for transverse friction variations. Safe operation is indicated if a given combination of the lower coefficient of friction $(\mu \ell)$ and if the length of differential friction surface falls to the right of the appropriate $\mu p$ curve; otherwise braking is potentially unsafe.

Pavement markings may present a wet skidding hazard to operators of motorcycles and bicycles. However, the extent of the hazard and its overall impact on highway safety cannot be determined at present, particularly in view of the acknowledged, but obviously positive, benefits of pavement marking materials.

Pedestrian safety is another concern at crossings in urban areas. Requirements for satisfactory walking traction are a static coefficient of friction of 0.5 or higher and a sliding coefficient of friction higher than the static value (12). The walking traction performance of 
marking materials in current use appears to be satisfactory, or at least (for materials with the most unsatisfactory performance) no worse than borderline.

\section{TRAVELED SURFACE TO SHOULDER}

The problem of friction variation between the paved surface and the shoulder is related to the lateral variation influence. Although it is such a special influence and such a relatively common (and critical) influence, it will be given special treatment.

The primary focus here concerns the existence of a lower friction surface on the shoulder immediately adjacent to a traveled lane. There are accidents each year that are triggered by a single-vehicle loss of control resulting from the inability of some drivers to deal with a lower friction shoulder surface. A driver, either through inattention or from some external influence, allows his vehicle to run off the paved surface, perhaps only a foot or two, so that the wheels, at least on one side of the vehicle, are on an unpaved, lower-friction surface. It may be sand, loose gravel, soil, or perhaps a muddy wet surface. The next reaction of the driver, as he becomes conscious of the situation, is critical. If the driver reacts with restraint, allowing the vehicle to slow while using modest steering inputs, the paved surface can be easily and safely regained. All too often, however, this is not the case. The driver reacts quickly with a steering input that is too large. The result is a precipitous steer force generated when the offside front wheel regains the paved surface. These actions may result in a collision with another vehicle or a roll. Figure 2 illustrates this phenomenon.

In Figure 2a the vehicle is shown with the right wheels on the shoulder (lower friction) surface just after the driver has made a left steer input that is too intense. The steering may even feel appropriate to the driver in terms of the rate at which he is regaining the appropriate lane of the roadway. The driver is not prepared, however, for the radical increase in the cornering force and thus the rate of cornering when the right front tire comes in contact with the higher friction lane surface, as shown in Figure 2b. The result is a vehicle fundamentally out of control, as shown in Figure 2c. Here the vehicle goes into adjacent lanes, may spin out, possibly resulting in a vehicle roll. The high lateral acceleration produced in the case shown further complicates the recovery problem for an unbelted driver on a bench front seat. This driver may be thrown completely out of the wheel position, precluding any further efforts of value in regaining control.

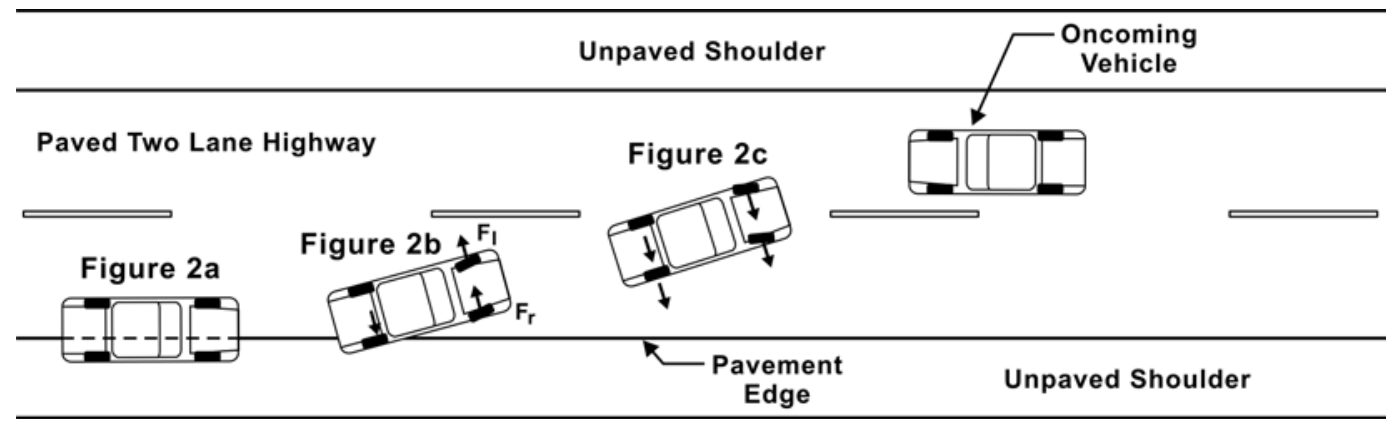

FIGURE 2 Illustration of loss of control caused by oversteering. 
One aspect of this phenomenon is that the existence of even extremely modest pavement edge height differentials, even 1 inch or less, may be blamed for the loss of control. The chapter on pavement edges illustrates the insignificance of these low values of edge differentials on loss of control. The degree to which a lower friction surface on the shoulder may influence safety is a function of the exposure to people allowing vehicles off the paved surface, perhaps related to geometrics (16), and to the degree to which the shoulder surface friction is lower than that of the paved surface. The available friction of paved surfaces both dry and wet is widely known. A major treatise on this subject was written by Kummer and Meyer (13). This work remains amazingly current and the dominant contribution. Data concerning available friction levels on surfaces covered by sand, gravel, soil, and mud are much more limited.

It appears there was much more interest in this type of surface when paved roads were rarer. Data on the values of available friction on mud, soil, gravel, sand, and sod are given in the chapter on surface contaminants. These values can range from as low as 0.2 to more than 1.0. The lowest values are found on wet clay and on wet grass. Some gravels exhibit surprisingly high values in either wet or dry conditions.

The most recent work has been provided by R. J. Koppa (Pavement Edge, Roadway Discontinuities, and Vehicle Stability, Task Report on Project 328, Texas Transportation Institute, October 1982). By using an ASTM E274 locked-wheel skid trailer, Koppa measured both the locked-wheel friction on unpaved shoulder surfaces and the friction on the pavement immediately adjacent to the shoulder. The difference in friction, as indicated by locked-wheel braking, was thus directly observed. The data in Table 2 describe the surface types and the results of Koppa's tests. In the fourth column, labeled Condition, the pavement condition is given [note that $\mathrm{D}=$ dry, $\mathrm{W}=$ wet (ASTM internal watering system), and $\mathrm{W}^{*}=$ wet (by significant natural rainfall)]. Only on sites 2,6 , and 7 were skid numbers determined after significant natural rainfall, a condition more critical than the quick coating provided by the internal watering system. The results on site 2 were somewhat surprising in that the dry skid number on the pavement was lower than the wet skid number on the shoulder (38.9 for pavement dry compared with 48.8 for shoulder wet).

A real contrast in relative values would be when both surfaces are wet: pavement wet $(\mathrm{SN}=16.3)$ and shoulder slightly wet $(\mathrm{SN}=57.8)$. This would not produce the control sequence described in Figure 2, but it could produce a problem if a rapid return was produced that resulted in a spin-out due to the low available friction on the pavement.

On sites 6 and 7 the results were more as expected. Assuming the pavement surface dries more rapidly than the adjacent shoulder, the critical situation would be when the pavement surface has just dried and the shoulder is still wet: 43.7 compared with 22.3 on site 6 , and 68.5 compared with 30.0 on site 7 .

In general, the friction values obtained on the gravel shoulders were rather high, which indicates good traction. The real problems would be expected on wet soil with a high clay content and where wet vegetation contributed to lowering available friction. On surfaces of this type little is known about the relationship between available cornering friction and braking friction. In this case it is the cornering friction that is critical, and few observations of this type are available. Braking skid numbers may not provide satisfactory estimates. 
TABLE 2 Sites Measured for Differential Skid Numbers

\begin{tabular}{|c|c|c|c|c|c|c|c|c|}
\hline \multirow[b]{2}{*}{ Site } & \multirow[b]{2}{*}{ Pavement } & \multirow[b]{2}{*}{ Shoulder or Adjacent Surface } & \multirow[b]{2}{*}{ Surface } & \multirow[b]{2}{*}{ Condition* } & \multicolumn{3}{|c|}{ Run } & \multirow{2}{*}{$\begin{array}{c}\text { Mean } \\
\text { Skid No } \\
\end{array}$} \\
\hline & & & & & 1 & 2 & 3 & \\
\hline \multirow[t]{4}{*}{1} & \multirow[t]{4}{*}{ Bituminous concrete } & \multirow{4}{*}{$\begin{array}{l}\text { Crushed limestone gravel, } 5-25 \\
\mathrm{~mm} \text {; some asphalt overspray }\end{array}$} & Pavement & $\mathrm{D}$ & 87.4 & 87.3 & 86.1 & 85.9 \\
\hline & & & Pavement & W & 34.6 & 39.8 & 34.3 & 36.2 \\
\hline & & & Shoulder & $\mathrm{D}$ & 75.6 & 81.4 & 77.1 & 78.0 \\
\hline & & & Shoulder & $\mathrm{W}$ & 72.5 & 72.7 & 74.5 & 73.2 \\
\hline \multirow[t]{5}{*}{2} & \multirow{5}{*}{$\begin{array}{l}\text { Seal coat, asphalt bleed; heavy truck } \\
\text { distress (tread impressions) }\end{array}$} & \multirow{5}{*}{$\begin{array}{l}\text { Poorly graded gravel from } 20 \mathrm{~mm} \\
\text { to silt }\end{array}$} & Pavement & $\mathrm{D}$ & 38.4 & 37.1 & 41.2 & 38.9 \\
\hline & & & Pavement & W & 22.6 & 12.3 & 13.9 & 16.3 \\
\hline & & & Shoulder & $\mathrm{D}$ & 61.3 & 61.7 & 62.8 & 61.9 \\
\hline & & & Shoulder & W & 56.3 & 57.5 & 59.7 & 57.8 \\
\hline & & & Shoulder & $\mathrm{W}^{\dagger}$ & 40.3 & 56.5 & 49.8 & 48.8 \\
\hline \multirow[t]{4}{*}{3} & \multirow{4}{*}{$\begin{array}{l}\text { Prepared rill (roadway under } \\
\text { construction) }\end{array}$} & \multirow[t]{4}{*}{ Gravel, sand, and clay mixture } & Pavement & $\mathrm{D}$ & 69.7 & 71.7 & 74.1 & 71.8 \\
\hline & & & Pavement & W & 56.3 & 50.9 & 53.1 & 53.4 \\
\hline & & & Shoulder & D & 69.8 & 68.1 & 67.4 & 68.4 \\
\hline & & & Shoulder & W & 59.9 & 63.4 & 61.6 & 61.5 \\
\hline \multirow[t]{4}{*}{4} & \multirow{4}{*}{$\begin{array}{l}\text { Bituminous concrete, some asphalt } \\
\text { bleed }\end{array}$} & \multirow[t]{4}{*}{ Gravelly sand } & Pavement & $\mathrm{D}$ & 44.2 & 42.3 & 39.5 & 42.0 \\
\hline & & & Pavement & W & 23.8 & 33.7 & 26.6 & 28.0 \\
\hline & & & Shoulder & D & 61.6 & 59.8 & 60.2 & 60.5 \\
\hline & & & Shoulder & W & 59.7 & 60.5 & 61.3 & 60.5 \\
\hline \multirow[t]{4}{*}{5} & \multirow{4}{*}{$\begin{array}{l}\text { Bituminous concrete; weathered, } \\
\text { somewhat raveled }\end{array}$} & \multirow{4}{*}{$\begin{array}{l}\text { Silty sand, course gravel, some } \\
\text { spillover bituminous concrete and } \\
\text { vegetation }\end{array}$} & Pavement & $\mathrm{D}$ & 45.5 & 46.1 & 46.5 & 46.0 \\
\hline & & & Pavement & W & 39.3 & 41.4 & 39.6 & 40.1 \\
\hline & & & Shoulder & D & 59.6 & 60.1 & 63.9 & 61.2 \\
\hline & & & Shoulder & W & 58.7 & 59.6 & 62.5 & 60.3 \\
\hline \multirow[t]{5}{*}{6} & \multirow[t]{5}{*}{ Seal coat, asphalt bleed } & \multirow[t]{5}{*}{ Peat with some gravel, vegetation } & Pavement & D & 45.7 & 44.2 & 41.3 & 43.7 \\
\hline & & & Pavement & W & 22.8 & 24.2 & 24.3 & 23.8 \\
\hline & & & Shoulder & D & 57.9 & 59.6 & 62.3 & 59.9 \\
\hline & & & Shoulder & W & 44.8 & 32.8 & 31.7 & 36.4 \\
\hline & & & Shoulder & $\mathrm{W}^{\dagger}$ & 25.5 & 22.1 & 19.3 & 22.3 \\
\hline \multirow[t]{5}{*}{7} & \multirow[t]{5}{*}{ Concrete } & \multirow[t]{5}{*}{ Silty gravel } & Pavement & D & 68.5 & - & - & 68.5 \\
\hline & & & Pavement & W & 42.4 & - & - & 42.4 \\
\hline & & & Shoulder & D & 63.0 & 61.7 & 62.4 & 62.4 \\
\hline & & & Shoulder & W & 56.6 & 55.7 & 51.8 & 54.7 \\
\hline & & & Shoulder & $\mathrm{W}^{\dagger}$ & 31.0 & 29.0 & - & 30.0 \\
\hline
\end{tabular}

$* \mathrm{D}=$ dry, $\mathrm{W}=$ wet, and $\mathrm{W}^{\dagger}=$ wet after significant natural rainfall.

\section{SEASONAL AND SHORT-TERM VARIATIONS OF FRICTION}

In the early 1980's several studies of seasonal and weather related variations of skid resistance were funded by the Pennsylvania Department of Transportation and the Federal Highway Administration (14-18). It had been recognized that the skid resistance decreased over the summer months in northern climates and recovered due to winter maintenance procedures. Also it was observed that the skid resistance increases after a period of rain. Models were developed to predict the changes over the season as well as the short term variations due to weather conditions. Variations as high as fifteen skid numbers $\left(\mathrm{SN}_{40}\right)$ were observed.

\section{REFERENCES}

1. Zuk, W. The Dynamics of Vehicle Skid Deviation as Caused by Road Conditions. Proc., International Skid Prevention Conference, Charlottesville, Va., Sept. 1958.

2. Burns, J. C. Differential Friction: A Potential Skid Hazard. In Transportation Research Record 602, TRB, National Research Council, Washington, D.C., 1976, pp. 46-53.

3. Hayhoe, G. F., and J. J. Henry. Effects of Differential Pavement Friction on the Response of Cars in Skidding Maneuvers. In Transportation Research Record 836, TRB, National Research Council, Washington, D.C., 1981, pp. 61-66. 
4. Rizenbergs, R. L., J. L. Burchett, and L. A. Warren. Relation of Accidents and Pavement Friction on Rural, Two-Lane Roads. In Transportation Research Record 633, TRB, National Research Council, Washington, D.C., 1977, pp. 21-27.

5. Dahir, S. H., W. E. Meyer, and R. R. Hegmon. Laboratory and Field Investigation of Bituminous Pavement and Aggregate Polishing. In Transportation Research Record 584, TRB, National Research Council, Washington, D.C., 1976, pp. 1-13.

6. Schlosser, L. H. M. Traffic Accidents and Road Surface Skidding Resistance. In Transportation Research Record 623, TRB, National Research Council, Washington, D.C., 1977, pp. 11-20.

7. Organization for Economic Cooperation and Development. Road Marking and Delineation. Road Research Group, Paris, Feb. 1975.

8. Bali, S. G., H. W. McGee, and J. K. Taylor. State of the Art on Roadway Delineation Systems. Report FHWARD-76-73. FHWA, U.S. Department of Transportation, May 1976.

9. Turo, M. D. Skid Testing Reflective Markings. Interoffice correspondence. Massachusetts Department of Public Works, Boston, December 23, 1974.

10. Richard, C. L. Skid Testing of Pavement Marking Materials. Final Report, Project TSD-284-76. Michigan Department of State Highways and Transportation, Lansing, April 1976.

11. Henry, J. J., D. A. Anderson, and G. F. Hayhoe. Skid Resistance of Pavement Marking Materials. Report FHWA-RD-80-199. FHWA, U.S. Department of Transportation, March 1981.

12. Brungraber, J. An Overview of Floor Slip-Resistance Research with Annotated Bibliography. NBS Technical Note 895. National Bureau of Standards, U.S. Department of Commerce, Jan. 1976.

13. Kummer, H . W., and W. E. Meyer. NCHRP Report 37: Tentative Skid-Resistance Requirements for Main Rural Highways. HRB, National Research Council, Washington, D.C., 1967.

14. Henry, J. J., and S. H. Dahir. Seasonal and Short Term Skid Resistance Variations. In Transportation Research Record 715, TRB, National Research Council, Washington, D.C., 1979, pp. 69-76.

15. Henry, J. J., and B. Hill. Short-Term Weather-Related Skid Resistance Variations. In Transportation Research Record 836, TRB, National Research Council, Washington, D.C., 1981, pp. 76-82.

16. Henry, J. J., and B. Hill. Surface Materials and Properties Related to Seasonal Variations in Skid Resistance, In Pavement Surface Characteristics and Materials, ASTM STP 763, American Society for Testing and Materials, 1982, pp. 45-60.

17. Henry, J. J., and K. Saito. Mechanistic Model for Seasonal Variations in Skid Resistance, In Transportation Research Record 946, TRB, National Research Council, Washington, D.C., 1983, pp. 29-37.

18. Henry, J. J., K. Saito, and R. R. Blackburn. Development and Application of Predictor Models for Seasonal Variations in Skid Resistance, Proceedings of the 13th Australian Road Research Board-5th Road Engineering Association of Asia and Australasia, Adelaide, Australia, Vol. 13, Part 5, Aug. 1986, pp. 34-54. 



\title{
Water Accumulations
}

\author{
THOMAS YAGER \\ BOB GALLAWAY \\ DON L. IVEY \\ JOHN M. MOUNCE
}

\section{HYDROPLANING}

Hydroplaning is the separation of the tire contact zone from the road surface by a layer of fluid. Operational conditions may involve some degree of partial hydroplaning as long as there is significant water present. Hydroplaning is a low-probability event, primarily because the high-intensity rainfalls necessary to flood a pavement are low probability events. Hydroplaning, however, is so hazardous that when it does occur, criteria for surface design have been developed to reduce the probability of hydroplaning and driver education is of critical importance.

Some of the earliest investigations and technical reports on hydroplaning came from the National Advisory Committee for Aeronautics (NACA) and its successor the National Aeronautics and Space Administration (NASA) (1). During aircraft ground operations in wet weather, a water removal or drainage problem is created at the tire-pavement interfaces. The runway surface water encountered by the moving aircraft tires must be rapidly expelled from the tire-pavement contact area or the viscous and dynamic water pressures that build up with increasing ground speed will significantly reduce tire/surface friction availability. The same is true for automobile and some truck configurations on highways.

The principal forms of these wet pavement tire friction losses, namely viscous and dynamic hydroplaning and reverted rubber skidding, are described in Figure 1. The speed regime, pavement and tire conditions, and tire operation mode that contribute to loss in tire friction are identified together with the factors that tend to alleviate their occurrence. Viscous hydroplaning or thin-film lubrication results from the inability of the tire to penetrate and disrupt the very thin residual fluid film left on the pavement after the majority of the trapped water has been displaced from the tire footprint. In this case, the pressure buildup within the tire-pavement interface is due to fluid viscous properties. Smooth tires operating on wet smooth pavements are particularly susceptible to this type of tire hydroplaning.

During dynamic hydroplaning, a buildup of hydrodynamic pressure between tire and flooded pavement is a function of the square of vehicle speed (2). When this hydrodynamic pressure exceeds the tire-pavement bearing pressure, a wedge of water penetrates the tire contact area and the tire footprint is partially or totally detached from the pavement surface. Under total dynamic hydroplaning conditions, tire friction capability is reduced to near zero because of the inability of the fluid to support significant shear forces. It should be noted that for many wet pavement operations of both aircraft and highway vehicles, reduced tire friction performance may occur from both viscous and dynamic fluid pressure buildup resulting in combined viscous/dynamic hydroplaning (3). 


\begin{tabular}{|c|c|c|c|}
\hline \multirow[b]{3}{*}{ CAUSES } & \multicolumn{2}{|c|}{ HYDROPLANING } & \multirow{2}{*}{$\begin{array}{l}\text { REVERTED RUBBER } \\
\text { SKIDDING }\end{array}$} \\
\hline & VIScous & DYNAMIC & \\
\hline & & & \\
\hline CONTRIBUTING & $\begin{array}{l}\text { DAMP OR WET PAVEMENT } \\
\text { MEDIUM TO HIGH SPEED }\end{array}$ & $\begin{array}{l}\text { FLOODED PAVEMENT } \\
\text { HIGH SPEED }\end{array}$ & $\begin{array}{l}\text { WET OR FLOODED PAVEMENT } \\
\text { HIGH SPEED }\end{array}$ \\
\hline FACTORS & $\begin{array}{l}\text { POOR PAVEMENT TEXTURE } \\
\text { WORN TIRE TREAD }\end{array}$ & $\begin{array}{l}\text { LOW TIRE PRESSURE } \\
\text { WORN TIRE TREAD }\end{array}$ & $\begin{array}{l}\text { POOR PAVEMENT TEXTURE } \\
\text { DEFICIENT BRAKE SYSTEM }\end{array}$ \\
\hline $\begin{array}{l}\text { ALLEVIATING } \\
\text { FACTORS }\end{array}$ & $\begin{array}{l}\text { PAVEMENT MICROTEXTURE } \\
\text { PAVEMENT GROOVING } \\
\text { GOOD TREAD DESIGN }\end{array}$ & $\begin{array}{l}\text { PAVEMENT MICROTEXTURE } \\
\text { PAVEMENT GROOVING } \\
\text { INCREASED TIRE PRESSURE } \\
\text { GOOD TREAD DESIGN }\end{array}$ & $\begin{array}{l}\text { GOOD PAVEMENT TEXTURE } \\
\text { PAVEMENT GROOVING } \\
\text { IMPROVED ANTISKID }\end{array}$ \\
\hline
\end{tabular}

FIGURE 1 Principal causes of wet pavement tire friction losses.

The contact pressure developed between tire tread and pavement establishes the escape velocity of bulk water drainage from beneath the tire footprint. High pressure tires can expel surface water more readily from the footprint than low pressure tires. When the aircraft ground speed equals or exceeds the escape velocity of water drainage from the footprint, "choked" water flow occurs. The tire has now reached the state of total dynamic hydroplaning. Test results $(4,5)$ indicate that the critical aircraft ground speeds required for this total hydroplaning condition to occur on flooded with an unbraked tire are approximately:

Spin-down (rotating tire) speed, knots $^{1}=9 \times$ sq. root of infl. pressure, psi and

Spin-up (nonrotating tire) speed, knots $=7.7 \times$ sq. root of infl. Pressure, psi

While these equations have proved useful to estimate hydroplaning speeds under the conditions specified. Other factors of influence have been added in more recent research efforts which will be described.

The third form of tire friction loss, reverted rubber skidding, is named for the appearance of the tire tread skid path after a prolonged locked-wheel skid. It is believed that frictiongenerated heat within the skidding tire-pavement contact area is sufficient to produce steam and cause the tire tread rubber to melt $(4,5)$. The soft, gummy reverted rubber forms a seal around the tire footprint periphery and the entrapped steam and water significantly reduce braking and cornering capability. This hypothesis would also explain the distinctive (steam cleaned) mark left on the pavement in the tire path. Evidence from several aircraft wet runway skidding accidents indicates that once started, reverted rubber skidding results in very low tire-pavement friction

\footnotetext{
${ }^{1}$ In deference to the origin of these equations the units of speed are nautical miles per hour. $(1$ naut mile $=1.15$ highway miles.)
} 
which persists down to very low speeds. With respect to highway vehicles this is probably a rare occurrence, and with well maintained antilock brake systems may never occur.

Returning to consideration of the highway a summary of the relationship among vehicle speed, tread condition, and water depth (as a function of rainfall intensity and pavement cross slope) is given by Yeager (6) and illustrated by Figure 2, for two typical examples of pavement cross slope and pavement width (drainage path length).

Figure 2 (6) shows that dynamic hydroplaning can occur with water depths as little as 0.03 inch with slick tires, under carefully controlled conditions.

Gallaway et al. (7) gave a comprehensive treatment of most factors related to dynamic hydroplaning. Those results can be summarized graphically by Figure 3 .

- In $3 a$ critical dynamic hydroplaning speed is reduced from 58 to $50 \mathrm{mph}$ as water depth (WD) is increased from 0.1 to 0.7 inches.

- Figure $3 b$ shows a tread depth (TD) variation from 12 to zero thirty seconds of an inch reduces hydroplaning speed from 54 to $47 \mathrm{mph}$.

- Figure $3 c$ shows as tire pressure $(\mathrm{P})$ is reduced from 36 to 18 psi hydroplaning speed is reduced from 58 to $46 \mathrm{mph}$.

- Figure $3 d$ shows the influence of texture depth (TXD). As TXD decreases from .15 inch to .03 inch hydroplaning speed is reduced from 64 to $52 \mathrm{mph}$.

Key elements to keep critical dynamic hydroplaning speed as high as practical, keep water depth low, tread depth high, tire pressure high, and texture depth high. Gallaway et al. give recommendations for pavement design and maintenance to achieve two of these four conditions.

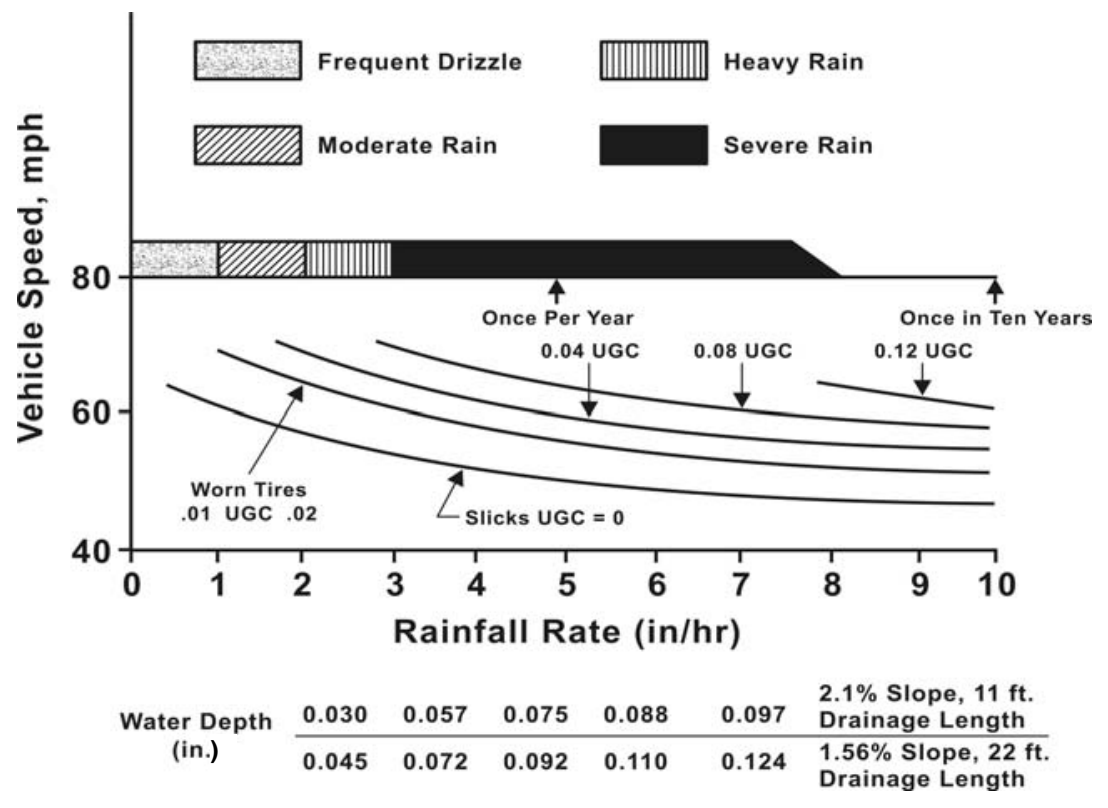

FIGURE 2 Estimated free rolling minimum full dynamic hydroplaning speed for passenger tires (conditions: relatively smooth surface, rounded footprint, and rated inflations and loads). 

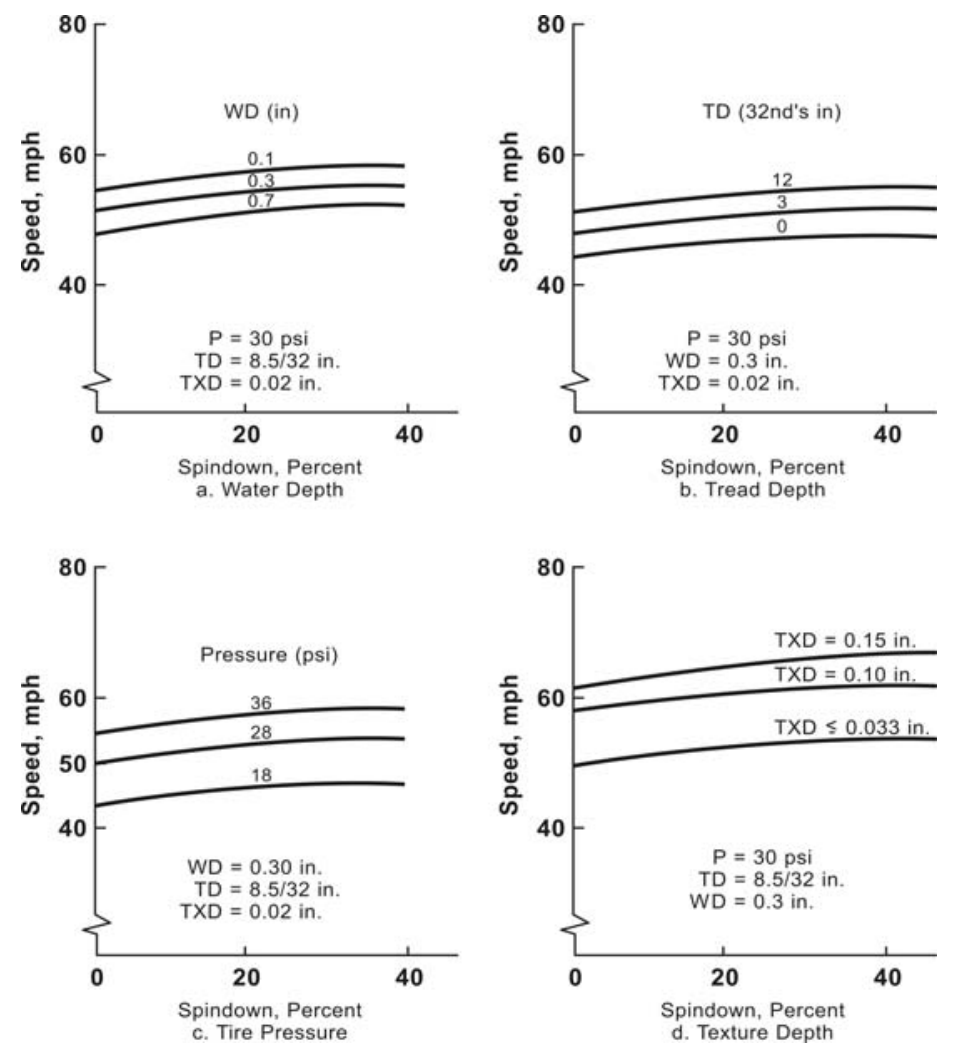

FIGURE 3 Influence of four parameters on hydroplaning speed.

Those recommendations of original construction texture depths of .040 inches or more, drainage cross slopes not less than $1 \frac{1}{2}$ percent and drainage path lengths as short as practical are still valid for conventional tire sizes even though it is recognized in periods of intense rainfall (e.g., a rate of 2 inches/hour or more) there will always be positive water depths which will allow hydroplaning if a vehicle is driven fast enough.

Increasing the probability of hydroplaning is the recent styling exercise in the automotive industry, apparently an effort to imitate race cars. These are the extremely low-profile tires accommodated by plus-sized rims. A significant disadvantage of replacing conventional tires and rims with the plus-sized tires and rims on automobiles and light trucks is a spectacular decrease in dynamic hydroplaning speed.

Walter states:

Dramatic changes occur in the shape of the tire contact patch as wheel diameter increases with a fixed tire OD. Specifically the length-to-width ratio of the footprint decreased from more than unity (long and narrow) to less than unity (short and wide). The specifics of footprint geometry control many important tire performance parameters. The plussized tires with square footprints generate appreciably "more" hydrodynamic lift compared to tires with slender footprints, leading to reductions in hydroplaning speeds of 20 percent or more in going from 15 inch to 17 inch wheels. (8) 


\section{HYDRODYNAMIC DRAG}

Observations of hydroplaning as a test trailer passed over or through a puddle showed that hydroplaning could occur with puddle lengths as short as 30 feet in concert with significant hydrodynamic drag. Hydrodynamic drag during the traversal of a road puddle in combination with loss of traction may have an influence on safety. Gengenbach (9) demonstrated that a drag as high as $25 \mathrm{lb}$ could occur in as little as 0.078 inch of water. These were steady-state drum tests, however, and much higher values were observed by Gallaway in typical roadway puddles. Gallaway found peak hydrodynamic forces encountered by a tire during puddle traversal to range from 70 to $330 \mathrm{lb}$. Hydroplaning, as indicated by loss of traction, occurred at speeds between 40 and $50 \mathrm{mph}$. If a peak longitudinal drag force were applied to one vehicle front wheel only, it could have a significant destabilizing effect. Such an event might occur in a situation in which water collects along a curb because of poor drainage. The opposite effects of hydroplaning and hydrodynamic drag require some elaboration. Although full hydroplaning destroys any capability of the tires to interact with the pavement surface, and thus no capability to provide directional stability, hydrodynamic drag does place a force on the tire surface that provides a resistance to movement, in effect a small stopping traction force.

To obtain a rough estimate of the potential real world effect, some simple computations were made by using a hypothetical vehicle weighing about $3,800 \mathrm{lb}$ with a wheel base of 112 inches and a track width of 60 inches. A conventional American automobile of this size might have a vertical load on each front wheel of about 1,000 lb. If the inertial effects were neglected and the torque produced about the center of gravity were calculated, it would take a corresponding opposing torque to maintain directional stability. Assuming that the opposite front wheel was on pavement that was only wetted, with no standing water, this opposing torque could be applied by developing a cornering slip angle by steering. Data for a typical tire on wetted pavement indicate that a front wheel slip angle of about 2 degrees would be required. For a typical steer ratio of about 20:1, this would require a steering wheel correction of about 40 degrees. If such a correction were made, and full pavement contact was suddenly regained, it could cause movement toward the opposing traffic lane before appropriate steering correction is made.

In the case in which both front wheels are fully hydroplaning, but there is variation in water depth laterally, the unequal drag forces could cause yaw instability with little or no corrective steering capability available. There is little doubt, considering these illustrations, that the drag forces generated by positive water depths could pose a hazard to some drivers.

\section{TRUCK TIRE HYDROPLANING}

Until the 1980's it had been understood in the highway accident investigation community that large truck tires do not hydroplane at highway speeds. There were several reasons why this myth developed. In the early 1960's, Horne and his fellow engineers at NASA discovered and studied the phenomenon of hydroplaning as it related to aircraft tires. Because of the way aircraft tires are constructed, the shape of the contact patch remains much the same for a fairly wide variation of tire load. The NASA group found that one could predict hydroplaning speed as a simple function of tire pressure. (See equation on page 58.) This relationship predicted hydroplaning speed of tires with 100 psi inflation pressure well above what could normally be achieved by trucks. Further work in the 1960's on automobile tires confirmed that hydroplaning speeds would 
be high at high levels of tire pressure. These studies of automobile tires, including research by Stocker and Gallaway at Texas Transportation Institute, suggested that tire loads were an unimportant variable. Those who interpreted this work to mean that truck tires could not hydroplane did not appreciate the following. While an automobile tire for a $4000 \mathrm{lb}$ vehicle may have a normal range of loads from 800 to $1200 \mathrm{lbs}$, a truck tire may be operated with loads varying from 600 to $6000 \mathrm{lbs}$. With this extremely wide load variation, the aspect ratio of a truck tire surface contact zone varies spectacularly, leading to hydroplaning conditions for a lightlyloaded, albeit normally inflated, truck tire at speeds common to highway vehicles. This footprint aspect ratio is the ratio of the surface contact zone width to length.

At the Transportation Research Board's annual meeting in January of 1984, it was suggested to Committee A2B07 (Surface Properties-Vehicle Interaction) that a task group be set up to look into the special problems of tractor/trailer loss of control. Shortly after that meeting, Horne sent Texas Transportation Institute (TTI) a copy of his forthcoming paper, scheduled for presentation a the meeting of ASTM E-17 in April. Horne's arguments, explanations, and predictions were compelling. Intrigued by the possibility of explaining why unloaded tractor/ trailers are several times more prone to loss of control during wet weather, (10) engineers at TTI constructed a test trailer suitable for truck tires. The resulting test data are summarized in Table 1 .

By gradually increasing speed, the speed was determined, at which the tire began to spin down for a particular load and pressure condition. That point was a reduction of tire speed of $2 \mathrm{mph}$. By increasing speed beyond that value, large values of spin down were observed.

Figure 4 shows how the four data points compare to Horne's predictions. Within the range of practical truck tire pressures, 60 to 120 psi, the comparison appears quite good. Horne's prediction is about four mph low $(8 \%)$ at 60 psi, correct a 75 psi and about $6 \mathrm{mph}(10 \%)$ high at $100 \mathrm{psi}$. Since there was no replication of the data achieved, this may be within the range of experimental variation if such factors as tire construction, tire tread depth, water depth, and pavement texture are considered.

A comparison of the curves achieved using the two equations is given by Figure 5 . It is conclusive that Horne's theoretical predictions are reasonably accurate and that lightly loaded truck tires do hydroplane.

TABLE 1 Tabulation of Test Conditions

\begin{tabular}{|c|c|c|c|c|c|}
\hline $\begin{array}{c}\text { Truck } \\
\text { Tire } \\
\end{array}$ & $\begin{array}{c}\text { Wear } \\
\text { Condition } \\
\end{array}$ & $\begin{array}{c}\text { Pressure, } \\
\text { psi }\end{array}$ & $\begin{array}{c}\text { Load, } \\
\text { lbs }\end{array}$ & $\mathbf{W} / \ell$ & $\begin{array}{c}\text { Hydroplaning } \\
\text { Speed, mph }\end{array}$ \\
\hline 10.00 .20 & New & 20 & 940 & 1.40 & 43 \\
\hline 10.00 .20 & Worn* & 40 & 940 & 1.40 & 51 \\
\hline 10.00 .20 & Worn* & 75 & 940 & 1.43 & 58 \\
\hline 10.00 .20 & Worn* & 100 & 940 & 1.41 & 62 \\
\hline 10.00 .20 & Worn* & 700 & 3600 & 0.95 & Over $62 * *$ \\
\hline 10.00 .20 & Worn* & 100 & 3600 & 1.10 & Over $62 * *$ \\
\hline
\end{tabular}

Water depth about $1 / 4$ in \pm 0.1 in

* Worn to approximately $2 / 32$ in tread remaining

** 62 was the speed achievable. No spin was detected at this speed. 


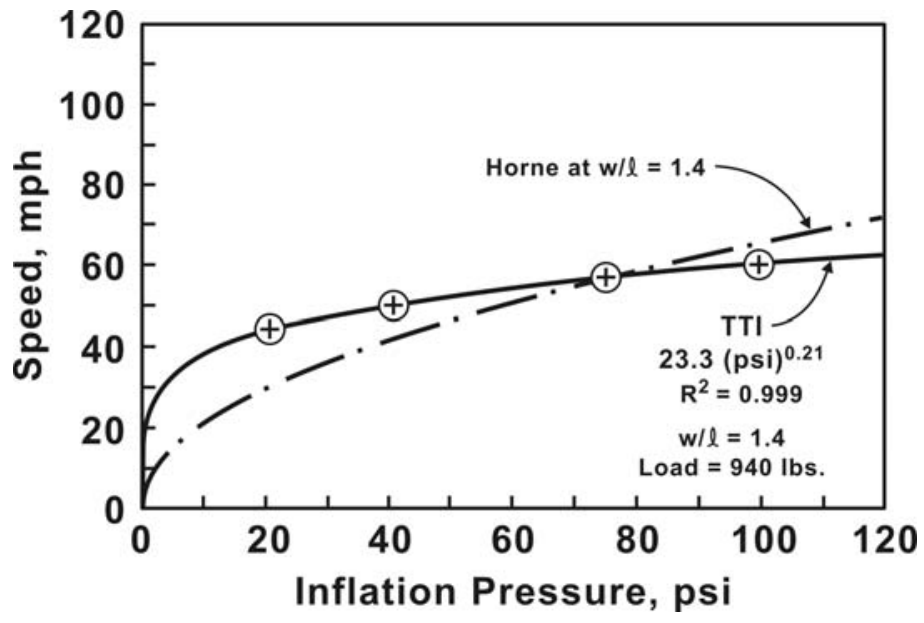

FIGURE 4 Comparison of TTI data points and Horne's predictions at w/l=1.4.

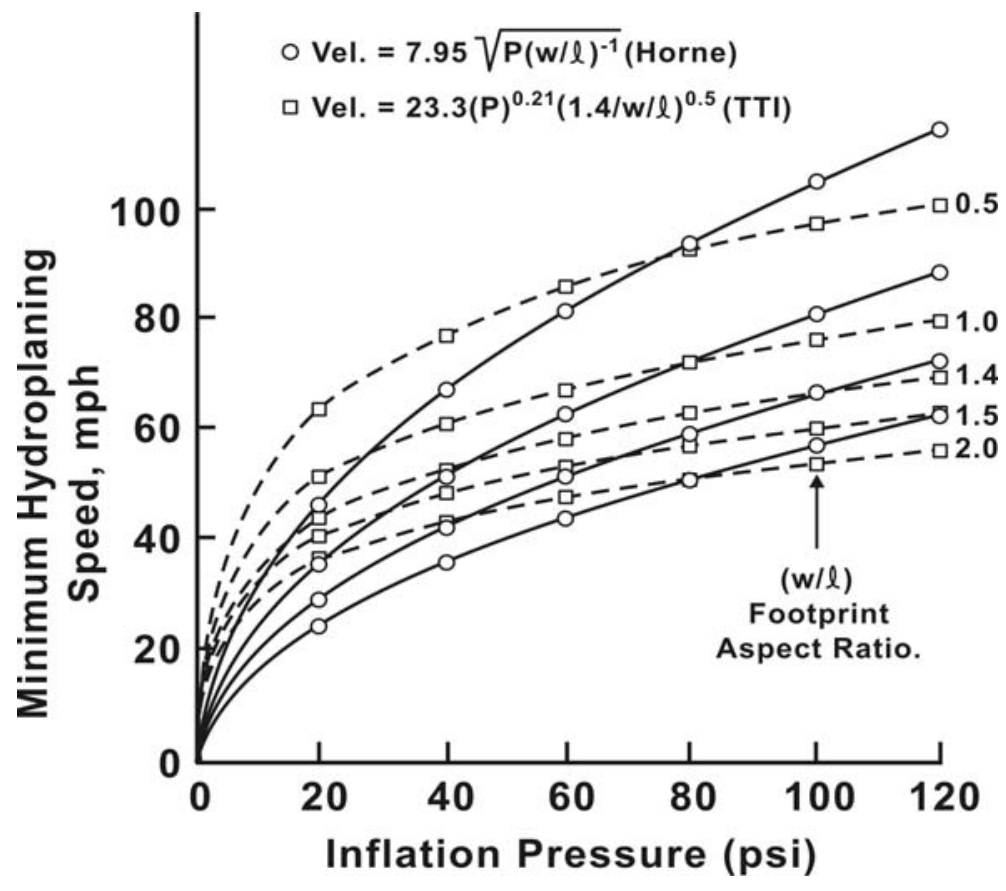

FIGURE 5 Comparison of Horne's and TTI's curves. 
Horne's equation is

$$
\text { VEL }=7.95(P)^{0.5}\left(\frac{1}{w / l}\right)^{0.5}
$$

compared to an equation based on TTI's curve fit, normalized at the test aspect ratio of 1.4 (11):

$$
\text { VEL }=23.3(P)^{0.21}\left(\frac{1.4}{w / l}\right)^{0.5}
$$

A detailed discussion and summary of other equations developed to estimate hydroplaning speed is given by Navin (12).

\section{VISIBILITY}

Research indicates that accident rates increase with the amount of annual rainfall in a roughly linear fashion. This effect was demonstrated by Ivey et al. (13) in 1977 and further substantiated by Sherretz and Farhar (14) in 1978. These findings were based on National Safety Council accident data and National Oceanic and Atmospheric Administration climatological data.

One factor that influences wet weather accident rates is the decrease in visibility caused by splash and spray. Kamm and Wray (15) state that, "passing a vehicle on a wet road requires a level of skill much higher than needed in most phases of driving. The maneuver is considerably more difficult when the driver's view is obscured by spray thrown up by the rear wheels of the adjacent vehicle." The phenomenon of splash and spray was described by Weir (16) as follows: "Splash tends to be relatively large droplets which move in ballistic trajectories and are associated with deep water or low speeds. Spray is composed of the smaller droplets, which tend to be suspended in the air and are associated with shallow water or high speeds. Formation requires a source of moisture, a hard or smooth surface, and some velocity of both vehicular movement and/or flow of air."

The degradation of visibility caused by splash and spray can be severe under dense traffic conditions when wipers do not clear the windshield effectively. The problem is described as follows (17): "Splash and spray create more or less a permanent smear which will be present on the glass, making it more difficult to see dim objects to the front of the car. Light emitted from headlights of opposing vehicles is refracted irregularly such that objects at some distance in front of the car will be considerably distorted in shape creating difficulties in recognition and judgment leading to unsafe operations."

There are many factors that interact to determine the extent and effect of splash and spray produced by water accumulations on pavement. Figure 6 illustrates the effect of splash and spray on visibility behind a large truck. Study has concentrated on tire design to remove as much water as possible from the tire-roadway contact area; however, this may have led to poorer visibility as more water is expelled to the sides and rear of the tire.

Three significant research efforts have addressed the issue of splash-and-spray reduction by pavement design. Maycock (18) conducted studies on six bituminous surfaces-four were impervious, one slightly pervious, and one very pervious (porous). The surface dressings performed slightly better than the smoother asphaltic surfaces, whereas the very porous macadam surface performed extremely well. 


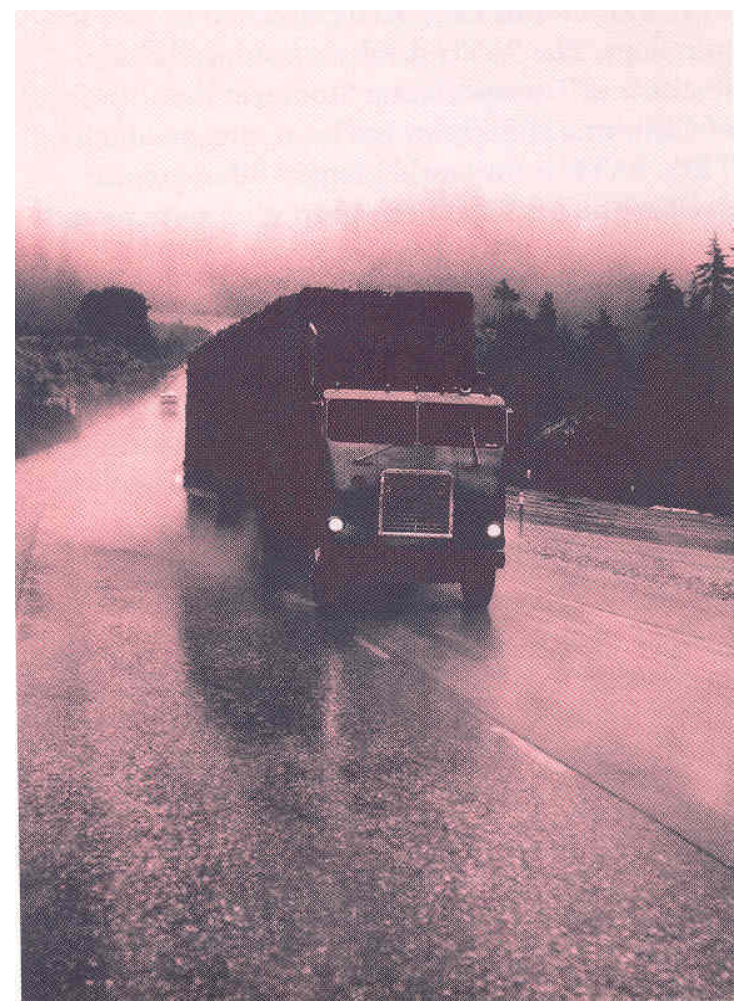

FIGURE 6 Wake of splash and spray thrown by 18 wheels.

Brown (19) investigated six experimental open textured bituminous-macadam pervious surfaces with nominal top-sized aggregates ranging from 0.40 to $0.75 \mathrm{inch}$. All experimentalsurfaces performed well in reducing spray and retained their spray-reducing properties after being subjected to heavy traffic for almost 2 years. Simoncelli (20) studied open graded bituminous mixtures developed in many countries, especially in the United Kingdom and Scandinavia. These surfaces have proved highly successful in reducing spray, improving visibility in rain, and enhancing the safety of the driver. The positive influence of open-graded pavement on surface spray reduction was also clearly demonstrated by Gallaway et al. (7).

Splash and spray can degrade driver visibility and safety. Low places in the pavement surface that hold water or flat spots that drain poorly contribute to the splash-and-spray problem. Increasing surface texture or providing porous self-draining pavements in favorable climates can contribute to better visibility. Maintaining these surfaces may prove to be difficult. Surface texture is smoothed by traffic, which may also consolidate porous pavements. Some fender systems for trucks have been devised to reduce splash and spray, but they are costly and create operational problems. Side skirts and spray-suppressant mud flaps are steps in the right direction. However, until a major breakthrough in one of these occurs, the driver must use extreme caution when environmental conditions result in reductions in visibility.

\section{REFERENCES}

1. Horne, W. B. Tire Hydroplaning and Its Effects on Tire Traction. In Highway Research Record 214, HRB, National Research Council, Washington, D.C., 1968, pp. 24-33.

2. Horne, W. B. Skidding Accidents on Runways and Highways Can be Reduced. Astronautics and Aeronautics, Vol. 5, No. 8., Aug. 1967, pp. 48-55. 
3. Leland, J. W., T. J. Yager, and U. T. Joyner. Effects of Pavement Texture on Wet-Runway Braking Performance. NASA TN-D-4323, Jan. 1968.

4. Yager, T. J. Progress in Airport Pavement Slipperiness Control. Air Line Pilots Association 18th Air Safety Forum, Dallas, Tex., July 20-22, 1971.

5. Smiley, R. F., and W. B. Horne. Mechanical Properties of Pneumatic Tires and Special Reference to Modern Aircraft Tires. NASA TR R-64, 1960. (Supersedes NACA TN 4110).

6. Yeager, R. W. Tire Hydroplaning: Testing, Analysis, and Design. In Physics of Tire Traction. (D. F. Hays and A. L. Browne, eds.) Plenum Publishing Corp., New York, 1974, pp. 25-63.

7. Gallaway, B. M., D. L. Ivey, G. G. Hayes, W. B. Ledbetter, R. M. Olson, D. L. Woods, and R. F. Schiller, Jr. Texas Transportation Institute. Pavement and Geometric Design Criteria for Minimizing Hydroplaning, Final Report. Report FHWA-RD-79-31. FHWA, U.S. Department of Transportation, December 1979.

8. Walter, J. D. Style over Substance. Tire Technology International, March 2006.

9. Gengenbach, W. The Effect of Wet Pavement on the Performance of Automobile Tires. Universitat Karlsruhe, Deutschland (translated for limited distribution by CALSPAN, Buffalo, N.Y., July 1972.)

10. Ivey, D. L., R. D. Tonda, W. B. Horne, and T. Chira-Chavala. Causes of Tractor Semi-Trailer Accidents in Wet Weather. Proceedings of the Second International Symposium on Transportation Safety, Athens, Greece, June 1985.

11. Horne, W. B, Thomas J. Yager, and D. L Ivey. Recent Studies to Investigate Effects of Tire Footprint Aspect Ratio on Dynamic Hydroplaning Speed. The Tire Pavement Interface., ASTM STP 929. (M. C. Pottinger and T. J. Yager, eds.) American Society for Testing and Materials, Philadelphia, Oct. 1986, pp. 26-46.

12. Navin, F. Hydroplaning (Theory and Applications). Institute of Police Technology and Management, University of North Florida, April 1996.

13. Ivey, D. L., et al. Development of a Wet Weather Safety Index. Report 221-1F. Texas Transportation Institute, Texas A\&M University, College Station, 1977.

14. Sherretz, L. A., and B. C. Farhar. An Analysis of the Relationship Between Rainfall and the Occurrence of Traffic Accidents. Journal of Applied Meteorology, May 1978, pp. 711-715.

15. Kamm, I. O., and G. A. Wray. Suppression on Wet Roads. Transactions of SAE, Vol. 80 (SAE Paper 710120), 1971, pp. 412-422.

16. Weir, D. H. Splash and Spray—Some Recent Results. Transactions of SAE, Vol. 89 (SAE Paper 800529), 1980, pp. $1-18$.

17. Organization for Economic Cooperation and Development. Adverse Weather, Reduced Visibility, and Road Safety. Road Research Group, Paris, 1976.

18. Maycock, G. The Problem of Water Thrown Up by Vehicles on Wet Roads. Report 4. Road Research Laboratory, Crowthorne, Berkshire, United Kingdom, 1966.

19. Brown, J. R. Previous Bitumen-Macadam Surfacings Laid to Reduce Splash and Spray at Stonebridge, Warwickshire. Report LR 536. Road Research Laboratory, Crowthorne, Berkshire, United Kingdom, 1973.

20. Simoncelli, J. P. Effects of Textures and the Aggregates That Produce Them on the Performance of Bituminous Surfaces. In Transportation Research Record 712, TRB, National Research Council, Washington, D.C., 1979, pp. 44-50. 


\title{
Surface Contaminants
}

\author{
E. A. Whitehurst \\ DON L. IVEY \\ J. J. HENRY
}

\section{ICE AND SNOW}

Whitehurst provided a detailed discussion of the influence of snow and ice on available friction in the 1983 SOAR No. 1. His observations are still timely and are included here in a more concise form.

In any consideration of ice and snow as a surface contaminant, attention must be given to the manner in which ice and snow differ from other roadway surface contaminants. Three such differences should be fully understood.

The first consideration is that of loss of traction. Although many roadway surface contaminants result in a loss of traction, the magnitude of the loss experienced when traveling on packed snow or ice probably exceeds that of most other contaminants. Dry pavements may exhibit skid numbers as low as 25 and still provide adequate surfaces for normal traffic operations where traction demands are modest. When the surface is covered with ice and the temperature is near the freezing point, the skid number will be on the order of 5 to 7 . (Skid Number is roughly equal to friction times 100.)

The second consideration is temperature effect. In most cases variations in temperature do not result in large changes in the traction available at the tire-pavement interface. It has been reported that in normal wet skid testing, wet skid number variations of 1 to 2 skid numbers per $10^{\circ} \mathrm{F}$ temperature change occur. Such changes would rarely be noticed by a vehicle operator. In the case of traction on an ice-covered surface, however, the available traction, although always low, changes drastically with temperature relative to the general level of available traction. The colder the ice on which the vehicle is traveling, the greater are the traction capabilities of the vehicle. In fact, in extremely cold weather, when the ice surface temperature is approximately $0^{\circ} \mathrm{F}$, the traction level of the surface will be more than twice that of a surface on which the ice is just at the freezing point. The driver is operating under the greatest hazard when the ice is barely adhering to the pavement surface. Figure 1 illustrates this ice temperature dependency. For example, at temperature of $0^{\circ} \mathrm{F}$ stopping distance from $50 \mathrm{mph}$ is about $900 \mathrm{ft}$. At $32^{\circ} \mathrm{F}$ stopping distance from $50 \mathrm{mph}$ may be $1700 \mathrm{ft}$.

The third consideration is that of the effect of vehicle gross weight. On ice stopping distance is seriously affected by vehicle weight. The heavier vehicle will require a greater distance in locked-wheel stopping from a given speed than will the lighter vehicle. In tests conducted by the Committee on Winter Driving Hazards involving locked-wheel stops from an initial speed of $20 \mathrm{mph}$ on ice and at an ice surface temperature of $25^{\circ} \mathrm{F}$, stopping distances averaged $247 \mathrm{ft}$ for a 16,500-lb truck, $257 \mathrm{ft}$ for a 28,360-lb truck, and $333 \mathrm{ft}$ for a 70,880-lb tractor/trailer combination (1). During the same test program the average locked-wheel stopping distance of a passenger vehicle from $20 \mathrm{mph}$ on ice at $25^{\circ} \mathrm{F}$ was $154 \mathrm{ft}$. Thus the heavily loaded 


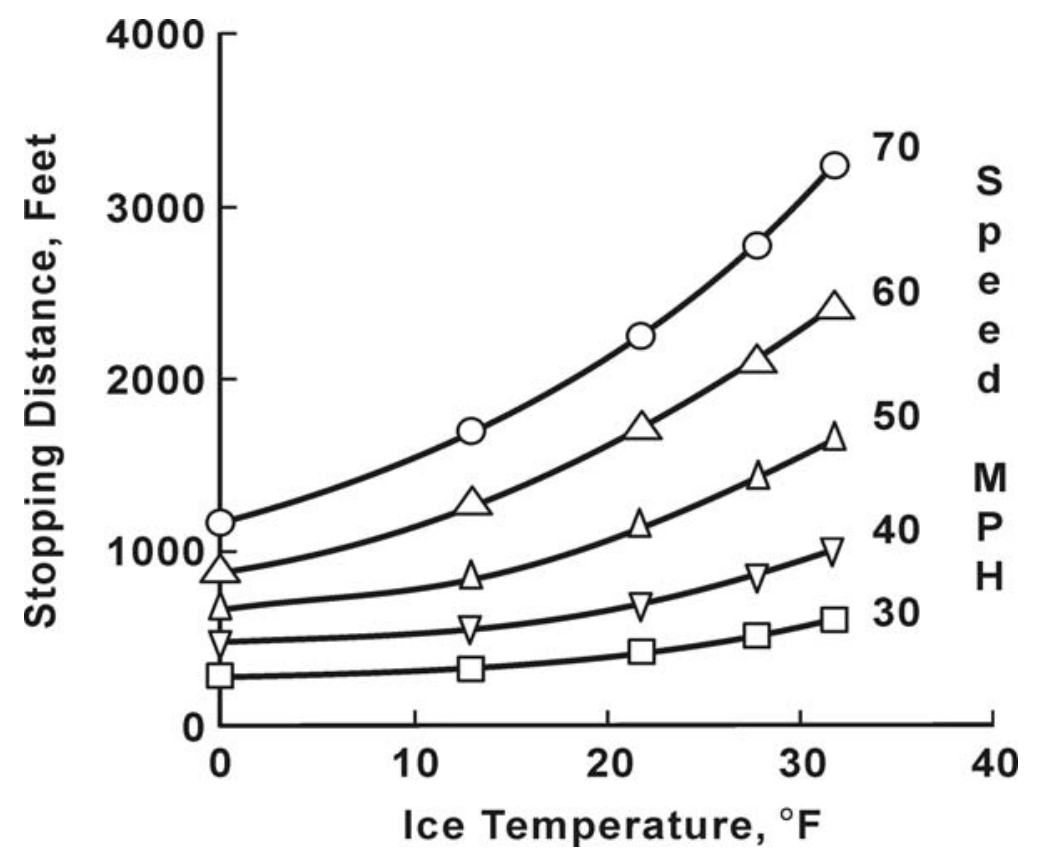

FIGURE 1 Variation of stopping distance with speed and ice temperature.

tractor/trailer required more than twice the locked-wheel stopping distance of the passenger vehicle. It is not completely clear that the weight was the only influence here. Differences in braking systems of the different trucks are a complicating factor. Similar relationships for vehicles on wet pavement have been reported by Dijks (2).

The reason for this phenomenon is not currently understood. It has been hypothesized that some melting always occurs under the wheels of a vehicle sliding on ice and that the vehicle is, therefore, always sliding on wet ice. This hypothesis suggests that more melting would occur under wheels with higher contact pressures than under those with lower contact pressures. In this case the heavier vehicle would be sliding on wetter ice and would, hence, require a longer distance to stop from a given speed.

The basic relationships have not changed. Major points made by Whitehurst are

1. The National Safety Council summarizes a number of years of tests to indicate that on glare ice at $25^{\circ} \mathrm{F}$ the locked-wheel stopping distance at $20 \mathrm{mph}$ for a passenger vehicle equipped with conventional highway tread tires averages $150 \mathrm{ft}$. When snow tires are used on the rear wheels of the vehicle, the distance is about the same. Repeated tests have indicated that in stopping on ice, snow tires provide no advantage, usually performing essentially the same as or slightly ( 1 to 5 percent) poorer than conventional highway tread tires. The use of studded snow tires. The use of reinforced tire chains on the rear wheels reduces the average stopping distance to $75 \mathrm{ft}$, an improvement of 50 percent.

On loosely packed snow a passenger vehicle equipped with conventional highway tread tires stops in about $60 \mathrm{ft}$ from $20 \mathrm{mph}$. The use of snow tires on the rear wheels provides some improvement under this condition-about 13 percent - and reduces the stopping distance, on average, to $52 \mathrm{ft}$. When reinforced tire chains are used on the rear wheels, the stopping distance is further reduced to $38 \mathrm{ft}$, an improvement of 37 percent.

2. Much attention has been given over the years to the development of appropriate braking techniques when operating a vehicle over ice-covered surfaces. For many years the 
advice given by the National Safety Council and others was to apply the brakes in a series of sharp applications and releases, a procedure generally referred to as pumping. The purpose of this procedure was to obtain deceleration through braking without reaching a sustained condition of brake lockup, thus retaining steering capability while braking was being accomplished. This advice is still sound if the operated vehicle is equipped with drum brakes.

Most modern automobiles, however, are now equipped with disc brakes on the front wheels. Disc brakes do not release as quickly as drum brakes, and if pumped rapidly they may not release at all, thus causing a condition of continuous lockup. For vehicles with disc brakes, the brakes should be squeezed with a slow, steady pressure until they are close to the point of lockup and maintained in that status. If lockup occurs the brakes should be released and, once the wheels are rolling again, the procedure should be repeated.

3. The maintenance of steering capability under adverse roadway surface conditions is obviously an important matter. Its importance becomes even greater if the driving capability of the vehicle under such circumstances is increased while the maneuvering capability is not. Testing of lateral friction involved a circular track on which the test vehicle gradually increased speed.

The circular course has a radius to the inner edge of the ice of $200 \mathrm{ft}$ and a path width of $50 \mathrm{ft}$. A $12 \mathrm{ft}$ lane is delineated on the ice surface by using rubber traffic cones; it has a known radius somewhere between 200 and $250 \mathrm{ft}$. The test vehicle is driven onto the delineated 12-ft width and the driver then accelerates until he is maintaining the highest speed possible around the course without continually slipping. When such tests were performed on a passenger car that has new highway tread tires on front and rear wheels, the average developed lateral coefficient was 0.071 . When the test was repeated with new highway tread tires on the front wheels and new snow tread tires on the rear wheels, the average developed lateral coefficient was 0.072 .

If this value of lateral acceleration is compared to the allowable AASHTO curve design lateral acceleration (or developed friction) it is seen vehicles cannot be driven at advisory speed levels when snow or ice are present. See Figure 2.

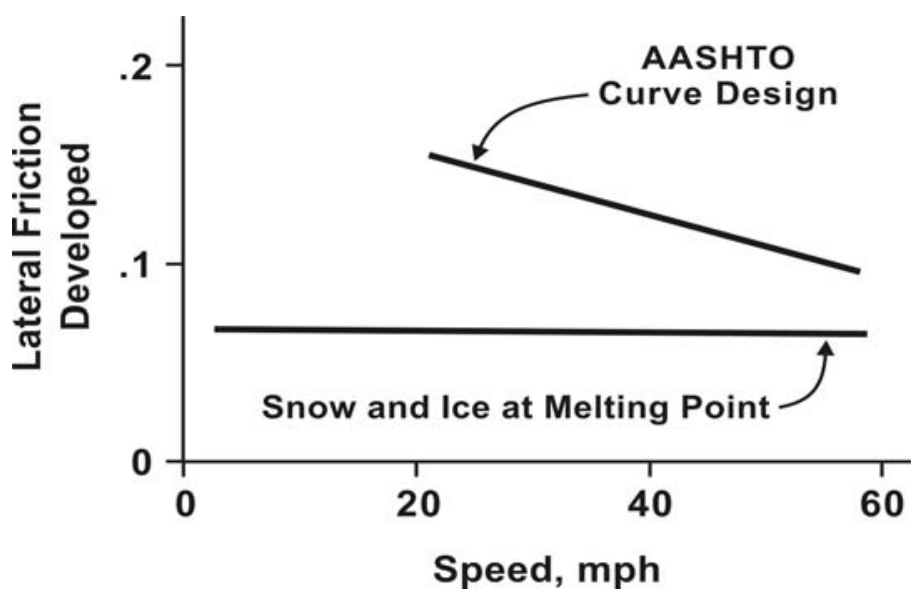

FIGURE 2 Comparison of available lateral friction on ice at melting point with AASHTO curve design allowable values. 
In summary, it may be stated that a driver operating an automobile over ice- or packedsnow-covered highways is operating under what is probably the most hostile and least-forgiving environment that he is likely to encounter. His primary concern must be to avoid breakaway between the vehicle tires and the surface over which it is traveling. Such breakaway can occur quickly as a result of excessive cornering. All such maneuvers should be avoided, and the best avoidance technique in general is to drastically reduce the speed of operation.

When breakaway does occur, as it almost inevitably will from time to time under such conditions, the driver will find that vastly greater distances are required to complete a desired maneuver or to recover control of the vehicle than is the case when operating over bare pavements. He should, therefore, greatly increase his following distance from the vehicle ahead of him - by a factor of 8 to 10 times that which he would maintain on a dry bare pavement surface. The heavier the vehicle that he is operating, the greater should be the following distance that he maintains.

Traction aids such as snow tires and tire chains can be helpful to the driver. He should, however, be thoroughly familiar with what kind of assistance and the magnitude of the assistance they provide. He should not count on more than they can deliver.

Finally, the driver should be continually mindful that, even with the best traction aids, the total traction available to him to propel his vehicle, stop his vehicle, and perform turning maneuvers is drastically less than that available to him when traveling over even a relatively poor quality rain-slick highway.

\section{EARTH, SAND, GRAVEL, AND MUD}

Mud, sand, or gravel on a paved surface can result in losses of control if significant maneuversstopping, accelerating, or cornering - are attempted. Loose sand or gravel on turns is a critical hazard to motorcyclists, constituting a common cause of loss of control. It is of lesser significance to automobiles, but is still of importance. Under certain circumstances a loose gravel surface can contribute to a full loss of control. Mud can have much the same effect.

In 1981 Ivey and Zimmer conducted a series of locked-wheel stopping-distance tests by using a 1976 Ford custom pickup. The road surface was a rounded gravel chip seal with a texture of approximately 0.04 inches This surface was coated with about 1 inch of east Texas silty clay and thoroughly wet. The results of the tests of stopping distance are shown in Figure 3. By observing the position of the test curve and comparing that position with the calculated curves of $\mathrm{f}=0.3,0.4$, and 0.6 , it can be seen that the average stopping coefficient decreases with speed, from 0.6 at $20 \mathrm{mph}$ to 0.3 at $50 \mathrm{mph}$. Because of the relatively high texture of the paved surface, these coefficients may be high compared to what mud would normally allow. At speeds up to 50 mph, a nonprofessional test driver used abrupt steering maneuvers and made lane changes without losing control. In only one of the stopping-distance tests did the vehicle spin-out. The spin was approximately 90 degrees.

Extensive data was presented in a paper published in 1924 by Agg (8). Agg gives values of locked-wheel friction on gravel, natural soil, and sandy soil. The values vary from 0.26 to 0.34. Further work by Professor Agg (9) was presented in 1928.

R. A. Moyer extended Agg's work through the 1930s. From a definitive work by Moyer (10), the findings are shown in Figure 3. 


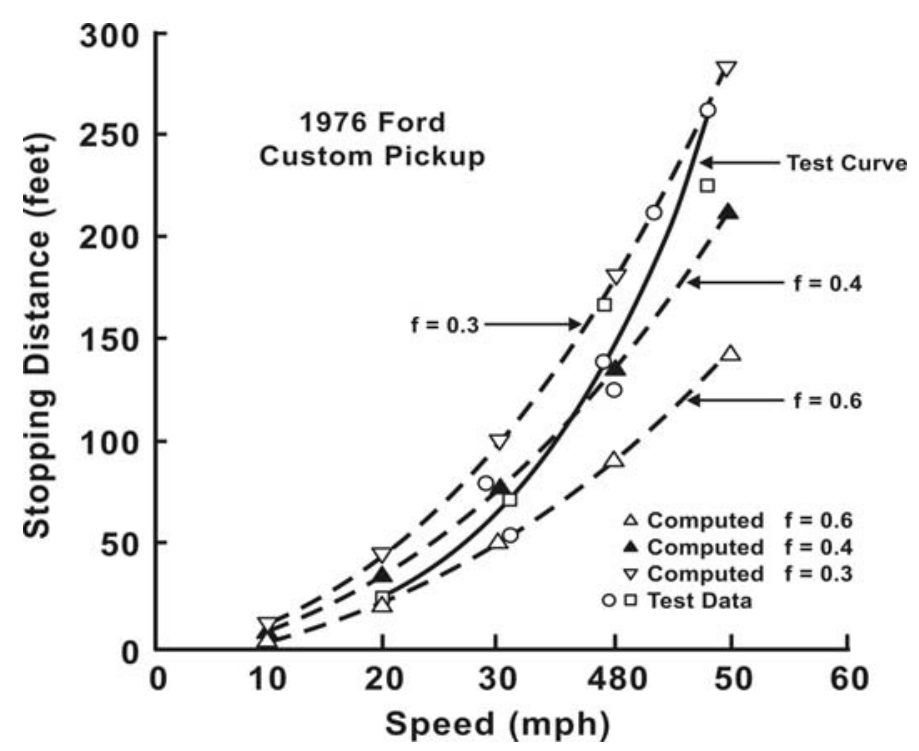

FIGURE 3 Stopping distance on wet clay-coated surface.

\section{MUD ON PAVEMENTS}

Tests on a mud-covered pavement clearly indicate how slippery such surfaces can be, the coefficients ranging from 0.2 to 0.3 . These coefficients are only slightly higher than those obtained on ice, which is an indication that muddy pavements may be considered practically as hazardous as ice. The placing of gravel, shale, cinders, or crushed rock on the shoulders and at the approaches to all pavements would not only correct a dangerous skidding condition, but would provide greater road widths for use in an emergency.

It should be understood that simply the classification mud will not suffice to estimate available friction. Although it has not been experimentally verified, many things influence the available friction on a muddy paved surface. The most obvious are (a) the mineral constituents of the soil, (b) the degree of wetness and compaction, and (c) the texture of the underlying paved surface. One thing almost all have in common is that the available friction is reduced, and thus the potential for accidents by imprudent drivers is increased.

More recent work by Koppa is given in Friction Variations. In Table 2, page 48 Koppa measured locked wheel friction on unpaved shoulders and compared them to friction on the adjacent pavements. His test sections included shoulders of limestone, gravel/sand/clay, silty sand and peat/gravel. SN values ranged from low 20 s wet to the 80 s dry. The friction values determined on gravel shoulders were surprisingly high. Problems might be expected on wet soil with a high clay content and on wet vegetation.

\section{LIME}

In 1998 there were reports of lime deposited or tracked inadvertently on an asphaltic concrete surface in areas associated with wet weather accidents. A state DOT had taken steps to remove lime deposits and the owners of the lime plant initiated washing of the $18 \mathrm{~W}$ lime transports before they entered the highway surface. It was initially suggested that the lime itself created slipperiness during periods of rainfall. Since either hydrated lime or quicklime is chemically 
much less active than clay it was unlikely that lime deposited on open highway surfaces would cause friction losses of the same order as clay. What those that investigated the highway expected was to find the lime deposits reduced the surface macro texture, thus decreasing critical hydroplaning speeds. While this would seem to be the case on surfaces that began with significant macro texture it was not the case in the area associated with accidents since the "before lime" macro texture seemed to be so low (e.g., less than 10/1000th's inch) that hydroplaning speed was affected only modestly.

ASTM E 274 skid numbers were in the low 30s. This means lime is not as influential as clay in reducing wet weather friction.

\section{DIESEL FUEL}

A relatively uncommon but extremely dangerous road surface contaminant is diesel fuel. This section relates specifically to this product, although many types of petrochemicals are at times deposited in small amounts on highway surfaces.

Even small amounts of diesel fuel on a wet surface can cause a precipitous loss of available friction. Based on the extrapolation of British pendulum numbers to account for speed sensitivity, B. M. Gallaway conducted tests on wet road surfaces contaminated by diesel fuel. Four different asphalt concrete (AC) pavements were included in the testing. These tests showed available friction may be reduced from 48 to 92 percent when diesel fuel is placed on a wet pavement. In the case of the worn pavement, the resulting friction is on the same order as wet ice.

On the Calcasieu River Bridge over Lake Charles, a 26 car and truck accident took place on August 27, 1981 (11), when 75 gallons of diesel fuel spilled from a ruptured tractor/trailer fuel tank. The spill occurred on the downhill eastbound side of the bridge, thus maximizing the need for friction by oncoming vehicles. Statements of the drivers involved in the accident verify the extreme slipperiness of the road surface in this condition. Although spills of this magnitude are rare, this event emphasizes the extremely hazardous nature of pavement so contaminated.

\section{REFERENCES}

1. 1974 Winter Test Report. Committee on Winter Driving Hazards, Traffic Conference, National Safety Council, Chicago, 1974.

2. Dijks, A. Wet Skid Resistance of Car and Truck Tires, Tire Science and Technology, Vol. 2, No. 2, May 1974, pp. 102-106.

3. 1967 Winter Test Report. Committee on Winter Driving Hazards, Traffic Conference, National Safety Council, Chicago, 1967.

4. Whitehurst, E. A. The Cornering Capacity of Studded Tires, Special Tech. Publ. 456. ASTM, Philadelphia, 1969.

5. 1973 Winter Test Report, Committee on Winter Driving Hazards, Traffic Conference, National Safety Council, Chicago, 1973.

6. 1968 Winter Test Report, Committee on Winter Driving Hazards, Traffic Conference, National Safety Council, Chicago, 1968.

7. 1971 Winter Test Report, Committee on Winter Driving Hazards, Traffic Conference, National Safety Council, Chicago, 1971.

8. Agg, T. R. Tractive Resistance of Automobiles and Characteristics of Roadway Surfaces, Bull. 67, Engineering Experiment Station, Iowa State College, Ames, Feb. 6, 1924.

9. Agg, T. R. Tractive Resistance of Automobiles and Coefficients of Friction of Pneumatic Tires. Bull. 88, Engineering Experiment Station, Iowa State College, Ames, May 2, 1928. 
10. Moyer, R. A. Skidding Characteristics of Automobile Tires on Roadway Surfaces and Their Relation to Highway Safety, Bull. 120, Iowa State University, Ames, Aug. 1934.

11. Truck Engine Fuel Tank Puncture by Bridge Repair Plate, Diesel Spill, and Multiple Vehicle Skidding Collisions, Interstate Route 10, Lake Charles, Louisiana, Aug. 27, 1981. Highway Accident Report NTSBHAR-82-4. National Transportation Safety Board, Washington, D.C., 1981. 



\title{
Small and Large Vehicles
}

\author{
LINDSAY I. GRIFFIN III \\ ThOMAS D. GILLESPIE
}

\section{SPECIAL CONSIDERATIONS FOR SMALL VEHICLES}

An increased sensitivity of the small automobile to road surface discontinuities is indicated from accident data and increased probability of injury to the occupants of such vehicles. A recent study by Griffin (1) indicates that lighter-weight cars may be more likely to be involved in curb accidents than are heavier cars. In a study on tire defects, Campbell (2) presents data that suggest that small cars may be disadvantaged by roadway discontinuities and disturbances. In his article, Campbell demonstrates that accident-involved subcompact cars are far more apt to be cited for tire defects than are accident involved large cars. Furthermore, this phenomenon is upheld when controlling simultaneously for vehicle age and driver age. Whether this phenomenon results from higher rates of rotation for smaller tires or from greater abuse suffered by smaller tires when striking ruts, potholes, edge drops, foreign objects, and so forth remains to be seen. Simply concluding that small vehicles are more sensitive to all surface problems does not appear to be warranted. In the chapters on positive effects of road surface discontinuities and pavement edges $(3,4)$ it was demonstrated by tests that a small vehicle could handle pothole traverses less effectively than a large car, but that it was no more sensitive to pavement edges than some larger vehicles.

Stewart and Carroll (5) have noted that crash involvement rates for smaller cars are greater than for larger cars. Why this disparity in rates exists is not commented on. Perhaps smaller cars are driven by younger drivers, at higher speeds, or in different circumstances; or perhaps roadway disturbances (e.g., inadequate friction) pose more severe problems for smaller cars than they do for larger cars.

A recent analysis by L. I. Griffin (unpublished data) suggests that smaller, lighter-weight cars may be more susceptible to skidding accidents than larger cars (see Figure 1). In this analysis single-vehicle accidents involving passenger cars of known curb weight were coded 1 if they resulted from skidding and 0 otherwise. Logistic regression procedures were then applied to estimate the influence of curb weight on the probability of an accident being classified as a skidding accident. A logistic regression equation of the following form was built:

$y=\exp (a+b x) /[1+\exp (a+b x)]$

where $y=$ probability of an accident being coded as a skidding accident,

$x=$ vehicle curb weight, and

$a, b=$ regression coefficients.

The maximum likelihood estimates of $a$ and $b$ are $\mathrm{a}=2.17760701$ and $b=0.00024691$. A chi-square test was carried out to determine if the two variables ( $x$ and $y$ ) are independent. The resulting chi square was $59.34(p<0.0001)$, which indicates they are not.

Whether the relationship depicted in Figure 1 results from the simple physical interaction of road surface characteristics and passenger car curb weight or other spurious factors that vary with vehicle weight (e.g., driver age, speed) will require further research. The fact that vehicle 


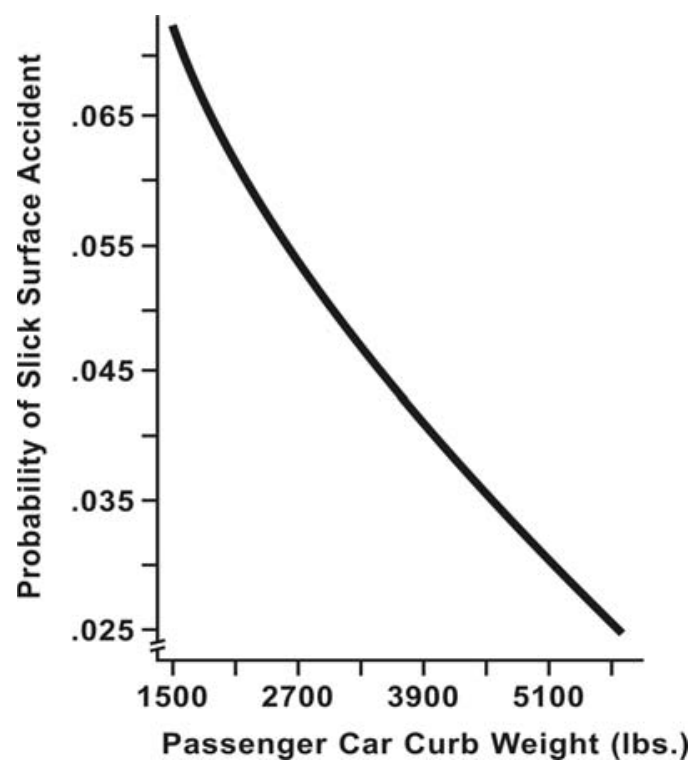

\section{FIGURE 1 Probability of involvement in slick surface accidents as a function of passenger car weight.}

wheelbase and track width are smaller with the lighter vehicles implies reduced directional stability, which provides a relatively direct explanation of the apparent susceptibility of these smaller vehicles to slick surface accidents.

\section{SPECIAL CONSIDERATIONS FOR LARGE VEHICLES}

Thus far the geometry of the roadway surface has been discussed largely from the perspective of how it influences safety of passenger cars. In this section the attention turns to the larger vehicles used for commercial transportation. Commercial vehicles range from the two-axle medium truck with a gross vehicle weight of 15,000 lb to the heavy-class articulated tractor-trailer combinations that may have from 3 to 11 axles and may operate at gross combination weights of 72,000 to more than $150,000 \mathrm{lb}$. Likewise, the commercial vehicle class includes buses used for transporting passengers that fall in the midrange of the sizes just described. In total, commercial vehicles represent about 20 percent of the vehicles on the highway; of these, approximately onehalf are the common tractor/semi-trailers, which are the primary focus in the following discussion.

Accidents involving commercial vehicles risk injury or death not only to their own occupants but especially to other motorists. Because of their weight disparity with other vehicles on the road, occupants of other vehicles are more frequently killed in collisions with combination vehicles. Perhaps this disparity in survivability is the source of the myth that big trucks are the primary problem in traffic safety.

AASHTO's strategic highway safety plan states the following:

Yet drivers of heavy trucks appear to engage in fewer unsafe driving practices than do drivers in general. Analysis of driver-related factors in crashes between large trucks and passenger vehicles indicates that passenger vehicle driver errors or other driver factors are cited in more than two-thirds of these crashes, whereas truck driver errors are cited in less than one-third (FHWA, 1999c; Blower, 1999). Studies of vehicle highway speeds in 
North America indicate that drivers of heavy vehicles generally exceed posted speed limits less often, and by smaller margins, than drivers of light vehicles (Tardif, 2003; NTSA, 1991). In addition, crash-involved truck drivers are much less likely than passenger vehicle drivers to drive under the influence of alcohol. In crashes involving a heavy truck and a passenger vehicle ( 80 percent of all fatal truck crashes), it appears that the principal culpability most often lies with the driver of the other vehicle. (6)

In 1998, Blower analyzed more than 5,400 fatal car-crashes from 1994-95, examining Fatality Analysis Reporting System (FARS) records of driver-related factors, pre-crash movements, and vehicle positions. According to this analysis the car driver's behavior was more than three times as likely to contribute to the fatal crash than was solely responsible for 70 percent of the fatal crashes, compared to 16 percent for the truck drivers. (7)

Because of their size and design, large commercial vehicles have characteristics that are uniquely different from passenger cars, which affects their sensitivity to roadway discontinuities. Those differences are seen in the roadway characteristics relating to the response to roughness discontinuities in the roadway and to tire-road friction coupling.

Discontinuities in the surface of a road that would fall in the classes of generalized roughness, potholes, edge drops, or other special features will affect commercial vehicles differently than passenger cars. Because of the larger tires used on these vehicles, the abrupt features are normally not as significant as an input to large vehicles. That is, a truck tire running through a pothole or over a curb edge, because of its size, is able to negotiate the feature with less disturbance to the vehicle. Such discontinuities impose a vertical and a longitudinal force on the wheel, the relative magnitude of which is inversely proportional to tire size. This relationship holds because trucks have larger tires that tend to smooth out the abrupt discontinuities, and they have more deflection distance available within the tire to absorb the disturbance.

Counterbalancing the advantage gained from the larger size of truck tires is the reduced isolation provided by their typical suspension systems, stiffer springs, and higher tire pressures. In order to maintain appropriate vehicle positions over a broad range of load conditions, the more common suspension types must have a high effective stiffness. As a consequence, those disturbances imposed through the tire are more directly transmitted to the vehicle chassis.

No definitive research has been done to quantify the sensitivity of large vehicles to the more abrupt features in the nature of potholes, curbs, or pavement edge drops. From the knowledge of truck dynamic properties, it may be expected that certain types of these road features can create a greater vibration disturbance to trucks than to cars. In addition, there exists the concern that such road features may produce a steering disturbance, with potentially greater consequence to a truck.

Perhaps the one area of possible influence that has not been well addressed in the literature is the significance of special wavelengths of road roughness to which trucks may be sensitive. It is known among experienced truck drivers that certain long wave road undulations, as typified by pavement settlements in bridge approach areas, may be peculiarly difficult to negotiate with commercial vehicles, particularly tractor-semitrailers. These features tune to the low-frequency rigid-body bounce and pitch modes of these vehicles. Because the drivers are located near the extremities of the vehicle (far from the center of gravity), large displacement vertical and fore-aft motions can be imposed on the driver, thus complicating the task of maintaining control when negotiating these road features. There is anecdotal evidence that truck drivers have experienced control problems reflecting on safety due to these effects, but there has been no known effort to compile statistics quantifying the magnitude of this particular problem. 
Unfortunately, available accident data are not specific enough in their recorded detail to provide that answer.

It must be concluded that the knowledge is deficient to state with confidence which road features constitute peculiar safety problems for large vehicles. Relying on the general knowledge of such vehicles, however, points to the need to better understand certain long wavelength roughness qualities in roads as potentially unique problems for such vehicles.

One area recently studied is the sensitivity of unloaded or lightly loaded commercial vehicles to hydroplaning. As noted in the chapter on roughness, holes, and bumps and explained in the chapter on water accumulations, the unloaded commercial vehicle has a short contact patch resulting in critical speeds of the 50 to $70 \mathrm{mph}$ range. The fact that unloaded rigs are often capable of higher speeds and possibly that truckers are not making money while "dead heading" may be part of the extreme over representation of unloaded commercial vehicles in wet weather loss-of-control accidents.

Commercial vehicles achieve their greater load carrying capacity not only by the use of more axles but also by the use of larger tires operated at higher inflation pressures. The higher road-tire contact stresses thus obtained are also cause for the use of tread rubber compounds that differ from those commonly used on passenger-car tires. Thus it is not surprising to find that truck tires exhibit traction qualities distinctively different from passenger-car tires. Quantitatively, truck tires exhibit lower peak tractive force coefficients of friction on a given surface $(8)$, the sliding coefficient of friction is proportionately even lower $(8,9)$, and truck tire traction qualities are more linear with load (10).

The traction differences of truck tires, either on dry or wet roads, do not appear to have a major safety significance because the vehicles' accident avoidance capabilities are not as uniquely traction limited as with passenger cars. Intuitively, it would seem that commercial vehicle safety would be linked to emergency braking capability and to limited cornering capability.

Studies of the safety benefits accrued from higher performance airbrake systems (11), however, fail to demonstrate any benefit from improved stopping-distance performance. Thus it would be inferred that the nominal traction limits of current truck tires on the road are not significant to safety in braking situations. Although this conclusion has broad implications, it can be rationalized for some situations, but not others. On dry pavements truck braking capability is normally more limited by vehicle design than by road friction characteristics. On lightly wetted roads truck tire traction is not severely disparate from that of passenger-car tires, and in the case of heavy water accumulations, the higher contact pressures under truck tires undoubtedly result in greater resistance to hydroplaning, except in the case of lightly loaded tires.

Ice- and snow-contaminated conditions are most critical for commercial vehicles (12). The more critical nature arises from several key differences: articulated vehicles have unique modes of instability (e.g., capability to jackknife), accidents are more severe because of greater size and mass, and these vehicles are more prone to rollover, even in the absence of a collision.

The higher tire contact pressures that resist hydroplaning on wet roads for heavier loaded commercial vehicles can be a detriment on ice- or snow-covered roads. Except at extremely low temperatures, the low friction coupling on ice-covered roads is dominated by the water film developed on the surface caused by frictional heating (13) and the contact pressure of the tire. Inasmuch as truck tires have higher loads and contact pressures, the low friction level is likely to prevail over a much wider temperature range than occurs with 
passenger-car tires. The combination of all these factors is then cause for greater concern for the safe operation of large commercial vehicles on snow- and ice-covered roads.

The cornering performance limits of commercial vehicles are established by two predominant modes - rollover and yaw instability (13). Rollover, in and of itself, is not an accident-causation factor that is aggravated by deficient road surface conditions. The rollover limit has a first-order relationship to the ratio of center-of-gravity height to track width, thus making it specific to the vehicle. Road friction is only significant in the sense that its nominal level will determine whether rollover is possible while the vehicle remains on the road. That is, the rollover limits for many commercial vehicles are low enough that rollover (rather than simple spin-out) is possible with loss of control on dry roads, although not as certainly on wet roads. At the same time the risks of loss of control are also greater on wet roads. Of course, once a combination vehicle has left the road, the probability of rollover is greatly increased by roadside cross slopes and soft soil conditions.

The second limit mode - yaw instability — is a technical term describing the onset of jackknife with articulated vehicles or spin-out with straight trucks (13). By the nature of the way in which the load is carried, and the way in which the roll resistance is shared among axles on commercial vehicles, their turning performance is most often limited by loss of cornering force on the rear axles of a truck or tractor. When this occurs, spin-out follows, with a subsequent risk of rollover. The loss of cornering force is, in part, a function of the road surface and its friction level. In pure cornering maneuvers, the threshold of instability occurs at rather moderate slip conditions ( 3 to 5 degrees of slip angle), where the cornering force properties are much more dependent on the stiffness of the tire carcass than on the tire-road coefficient of friction. However, when braking is also combined with cornering, brake slip at the rear wheels will contribute to loss of cornering force and subsequent jackknife. Consequently, the potential for this type of accident is greatest when the vehicle is unloaded or when the tire-road coefficient of friction is low.

From the standpoint of tire-road friction the safety performance of large commercial vehicles is uniquely critical on roads contaminated with water, ice, or snow. The threat to large vehicles under these conditions arises from the potential for loss of control, thus leading to more severe accidents; even at relatively low speeds, jackknife or rollover accidents are possible.

In 1983 the subcompact seemed destined to become the dominant vehicle size, perhaps due to the consideration of aid availability and fuel prices. That did not occur. 2002 sales data, shown by Figure 2, illustrates the dominance of mid-sized vehicles. A major contributor to that dominance is the light truck category. Figure 3 shows light trucks, which include TUVs, SUVs and vans reaching a parity in sales with passenger cars.

In 2001 of the 2.8 trillion total vehicle miles traveled, passenger cars accounted for 1.6 trillion (57\%). Other two-axle, four-wheeled vehicles accounted for 943 billion (34\%). Automobiles and light trucks accounted for 2.54 trillion vehicle miles. Heavy trucks, including 18-wheelers, accounted for 137 billion.

With these major changes occurring, which influence both the creation of road surface discontinuities and the sensitivity of vehicles to them, far more effort may be warranted to determine the interactions between vehicle size and the roadway surface problems that influence traffic accidents. 


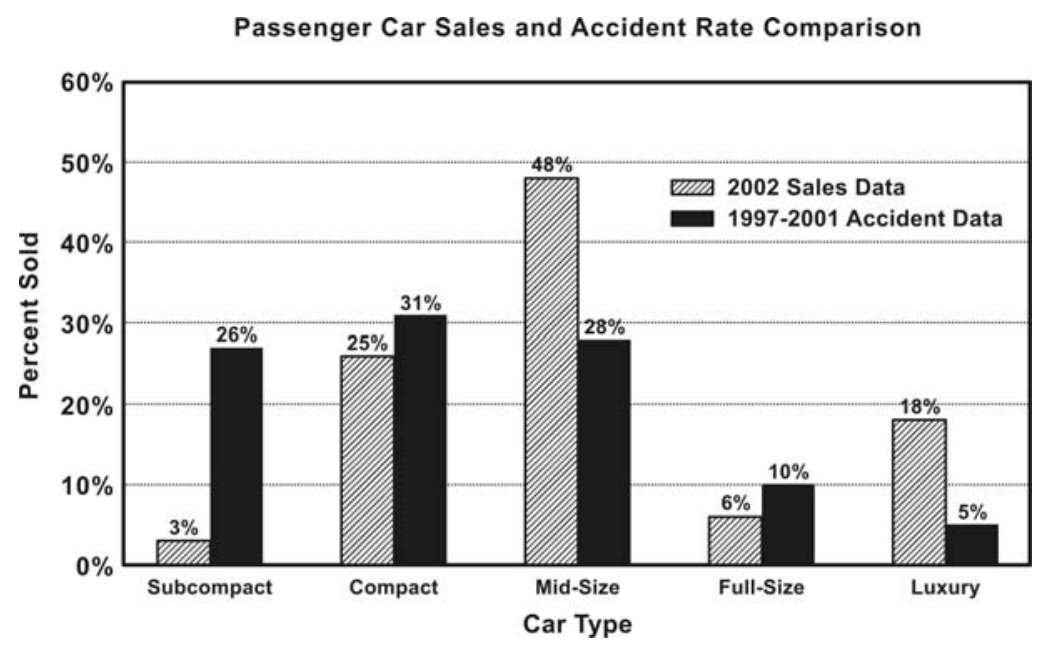

FIGURE 2 Automobile size distribution.

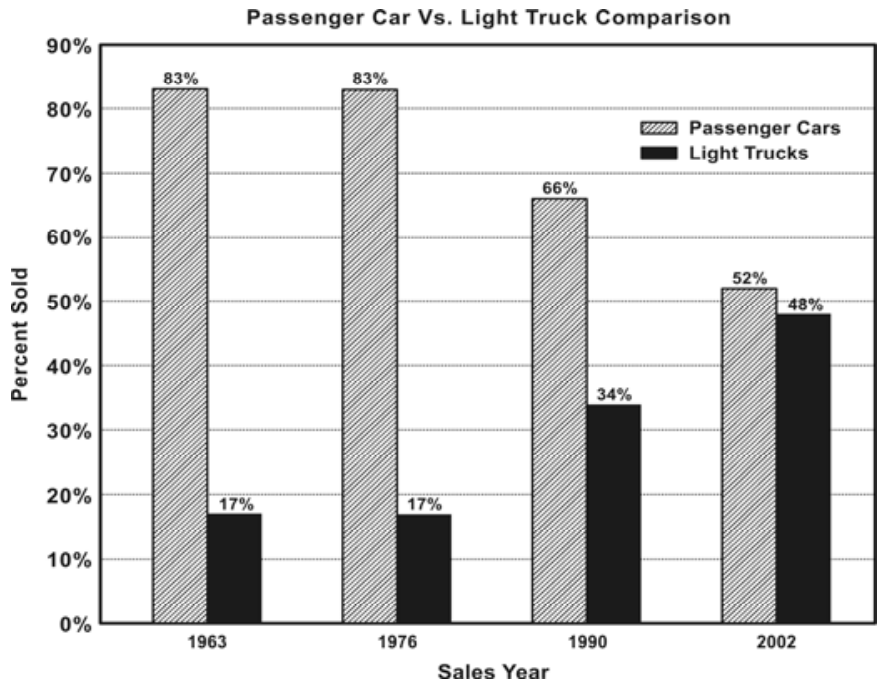

FIGURE 3 Shift in population distribution between trucks and passenger cars.

\section{REFERENCES}

1. Griffin, L. I. Probability of Driver Injury in Single-Vehicle Collision with Roadway Appurtenances as a Function of Passenger Car Curb Weight. Texas Transportation Institute, Texas A\&M University, College Station, Oct. 1981.

2. Campbell, B. J. An Analysis of Reported Tire Defects in North Carolina Accidents. Highway Safety Research Center, University of North Carolina, Chapel Hill, 1981.

3. Zimmer, R. A., and D. L. Ivey. The Influence of Roadway Surface Holes and the Potential for Vehicle Loss of Control. Research Report 328-2P. Texas Transportation Institute, Texas A\&M University, College Station, Aug. 1983.

4. Zimmer, R. A., and D. L. Ivey. Pavement Edges and Vehicle Stability-A Basis for Maintenance Guidelines. In Transportation Research Record 946, TRB, National Research Council, Washington, D.C., 1983, pp. 48-56. 
5. Stewart, R. S., and C. L. Carroll. Annual Mileage Comparisons and Accident and Injury Rates by Make, Model (Technical Summary). Highway Safety Research Center, University of North Carolina, Chapel Hill, 1980.

6. Knipling, R. R., et al. Vol. 13: A Guide for Reducing Collisions Involving Heavy Trucks, Guidance for Implementation of the AASHTO Strategic Highway Safety Plan, Transportation Research Board, Washington, D.C., 2004.

7. Council, F. M., D. L. Harkey, et al. An Examination of Fault, Unsafe Driving Acts, and Total Harm in CarTruck Collisions, Summary Report, FHWA-HRT-04-085, 2004.

8. Dijks, A. Wet Skid Resistance of Car and Truck Tires. Tire Science and Technology, Vol. 2, No. 2, May 1974, pp. 102-106.

9. Boyd, P. L., A. H. Neill, and J. A. Hinch. Truck Tire Cornering and Braking Traction Study. Report DOT-HS804-732. NHTSA, U.S. Department of Transportation, March 1979.

10. Thurman, G. R., and W. A. Leasure, eds. Noise and Traction Characteristics of Bias-Ply and Radial Tires for Heavy Duty Trucks. Report DOT-TST-78-2. U.S. Department of Transportation, Oct. 1977.

11. Campbell, K. L., and O. Carsten. Fleet Accident Evaluation of FMVSS 121. Report UM-HSRI-79-79. University of Michigan, Ann Arbor. Oct. 1979.

12. Hayhoe, G. F., and P. A. Kopac. Evaluation of Winter Driving Traction Aids. Draft Report PTI 7711. Pennsylvania Transportation Institute, Pennsylvania State University, University Park, June 1981.

13. Ervin, R. D., et al. The Yaw Stability of Tractor-Semitrailers During Cornering. Report UM-HSRI-21-1,2,3. University of Michigan, Ann Arbor, June 1979. 



\section{Summary}

\section{FORREST M. COUNCIL DON L. IVEY}

$\mathrm{T}$ he analysis of 15,968 single-vehicle accidents in North Carolina conducted in 1974 yielded the first statistical indication of the influence of road surface discontinuities on highway safety. Narratives containing 1 of 19 key words (e.g., dip, rocks, rut, edge) were examined and reviewed to determine if an accident resulted from, or was aggravated by, a roadway discontinuity. Some 566 (3.5 percent) of the 15,968 accidents were associated with roadway irregularities. Other reviews of accident data from three sources - California accident data (police reports), collision performance and injury report (CPIR) data provided by the Highway Safety Research Institute of the University of Michigan, and Indiana accident data (levels II and III) provided by Indiana University - indicated that the roadway disturbances shoulder drop off and loose material on roadway had a significant influence on safety. Other irregularities such as potholes, rough roads, and dips have been identified as potential problems.

In the opinion of the authors, a summary of the main points from the task group revision efforts to SOAR 1, concerning specific types of roadway surface discontinuities, are as follows:

\section{TIRE-PAVEMENT FRICTION}

- The influence of surface friction has been a favorite subject of researchers for many years. To assume that traffic accidents, or a given subset of traffic accidents (e.g., accidents that result from inadequate surface friction), can be accurately predicted on the basis of one condition (such as skid number) is wishful thinking. It should be recognized that the frictional properties of a road surface are not inherently adequate or inadequate, but can only be so classified in terms of specific vehicle maneuvers - stopping, turning, or accelerating (i.e., vehicle demand for friction). This fact has been recognized directly or indirectly in a number of studies.

- Variations in friction coefficients within and between wheel paths may produce difficulties in controlling a vehicle when brakes are applied. This phenomenon was first described theoretically in 1959. It was concluded that a difference in the friction coefficients of the wheel paths could be potentially hazardous, even though the average surface friction is relatively high. Severe vehicle response may occur when a driver releases his brakes after his vehicle has begun to spin. The rotating vehicle may run off the pavement or into other vehicles.

- Variations in the friction properties of pavement surfaces in the direction of travel occur frequently. Whether drivers judge changes in friction properties correctly, or even realize the existence of such changes, is debatable, as is whether they adjust their driving pattern to perceived changes. Because all changes are not perceived, and others are likely to be judged incorrectly or ignored, they can constitute a potential hazard.

- Marking materials generally lower the skid resistance of a pavement. When applied over large sections, skid stopping distances are increased. Differential friction caused by the application of marking materials may also give rise to hazardous situations, such as excessive vehicle yaw during locked-wheel skids, loss of control during motorcycle or bicycle turning and braking maneuvers, and slipping and falling by pedestrians on crossings. Single and double delineation stripes do not appear to be a problem. 
- Single-vehicle loss of control resulting from the inability of some drivers to deal with a lower friction shoulder surface causes some accidents. After running off the paved surface, if a driver reacts quickly with too much steering input, a large steering force may result when the offside front wheel strikes the paved surface. Collision or rollover may result. The high lateral acceleration produced by this maneuver further complicates recovery by an unbelted driver, who may be thrown out of position to properly control the vehicle.

\section{ROUGHNESS, HOLES, AND BUMPS}

- It is apparent that a hole must be relatively large to constitute a significant safety influence. At common highway speeds a hole must be in excess of 60 inches long and 3 inches deep to constitute a threat to the smallest automobile. On urban streets, with traffic speeds as low as $20 \mathrm{mph}$, holes must be 30 inches long and 3 inches deep to have the potential of damaging tires and rims. Damage to tires and rims, with the potential for an air-out, is the significant safety-related influence of holes identified in vehicle handling studies. It is highly probable recent styling trends toward plus-sized rims for automobiles and light trucks have rendered tirerim combinations significantly more vulnerable to damage. Problems can arise if a driver reacts to the hole inappropriately. For example, it is usually counterproductive to react with braking or extreme cornering to a hole in a vehicle's path.

- A prudent driver recognizes the problem of a rough road and adjusts his speed to meet the conditions encountered. Consistent roughness is not necessarily a negative influence on safety. Violation of driver expectancy by precipitously going from a smooth surface condition to extremely rough conditions may constitute an unsafe condition.

- Under certain conditions curbs may have a negative influence on safety.

Recommendations have been made regarding barrier height as a function of barrier setback from the curb. Highway Research Board Special Report 81, published in 1964, alluded to possible problems if high curbs are used in front of guardrails. A subsequent study (NCHRP Report 150, 1974) states: "It has been found that curbs offer no safety benefit on high-speed highways from the standpoint of vehicle behavior following impact." The AASHTO Barrier Guide of 1977 recommended that a curb should not be used as a redirective device, and if used with a barrier the face of the curb should be no closer to the traveled way than the face of the barrier.

- Smaller cars are more likely to be involved in curb accidents than are larger cars. Handling and stability problems associated with car-curb involvements are probably inversely related to car size.

\section{POSTIVE EFFECTS OF ROAD SURFACE DISCONTINUITIES}

- Surface discontinuities intentionally placed such as continuous shoulder rumble strips, centerline rumble strips, transverse in lane rumble strips and bumps provide valuable vibrational and noise notice of either a need to change vehicle lateral position or a need to stop or slow.

- These intentional discontinuities normally result in positive effects on the order of $20 \%$ reductions in run of road crashes for shoulder treatments and similar improvements in headon and side swipes due to centerline treatments. 


\section{WATER ACCUMULATIONS}

- Hydroplaning is a low-probability event, primarily because high intensity rainfalls necessary to flood a pavement are low-probability events. When hydroplaning does occur, it can result in loss of steering and directional instability. Criteria for surface design to further reduce the probability of hydroplaning have been developed and are cited. The main change in hydroplaning speed predictive equations since 1983 has been inclusion of the tire contact patch aspect ratio, w/ $/$. This consideration derived from Horne's observation that in large trucks this value varies greatly from the unloaded to loaded condition. A predictive equation suitable for trucks is now included. Unloaded tractor semi-trailers can hydroplane at speeds between 50 and $70 \mathrm{mph}$ when significant water depth is encountered.

- Splash and spray can affect driver visibility and thus safety. Low places in the pavement surface that hold water or flat spots that drain poorly contribute to the splash and spray problem. Increasing surface texture or providing porous self-draining pavements (in favorable climates) can contribute to better visibility; but maintaining these surfaces may be difficult. Some fender systems for trucks have been devised to reduce splash and spray, but these can be costly and can create operational problems. Side skirts and spray-suppressant mud flaps are steps in the right direction. However, until a major breakthrough occurs, the driver must use extreme caution when environmental conditions result in visibility reduction.

\section{SURFACE CONTAMINANTS}

- The primary influence of ice and snow is loss of traction. Although many roadway surface contaminants result in reduced tire-pavement friction, the magnitude of the loss experienced when traveling on packed snow or ice exceeds that of most other contaminants. Most dry pavements will exhibit friction coefficients in excess of 0.7 . The same pavements when wet may exhibit friction values as low as 0.25 and still provide adequate surfaces for normal traffic operations where traction demands are modest. When the surface is covered with ice and the temperature is near the freezing point, the available friction may be as low as 0.05 . The capability of the vehicle to move, corner, or stop is greatly reduced. A driver operating an automobile on highways covered with ice or packed snow is operating under a most hostile and least-forgiving environment. His primary concern must be to avoid breakaway between the vehicle tires and the surface over which he is traveling. Such breakaway can occur quickly as a result of modest braking or cornering, which should be avoided. Prudent drivers familiar with ice and snow conditions reduce speed radically.

- Mud, sand, or gravel on the paved surface can produce loss of control if significant maneuvers involving stopping, accelerating, or cornering are attempted. Loose sand or gravel on turns is a critical hazard to motorcyclists, perhaps constituting the most common cause of control loss. It is of lesser significance to automobiles, but it is still of importance.

\section{PAVEMENT EDGES}

- Studies consistently reveal a significant influence of longitudinal pavement edges on vehicle safety. Loss of vehicle control may occur at speeds greater than $30 \mathrm{mph}$ under certain circumstances, where inattentive or inexperienced drivers return to the traffic lane by oversteering. This safety problem is minimized where the pavement edge drop does not exceed 2 inches in height or the edge is sloped. FHWA now recommends a safety bevel slope of about 
2 to 1 to prevent an unsafe interaction between the tire and the edge. Testing since 1983 has shown that type A $\left(90^{\circ}\right)$ edges higher than 3 inches deemed "reasonably safe" originally may actually be only "marginally safe" for a small percentage of drivers and for vehicle speeds in the $70 \mathrm{mph}$ range. Pavement edges 5 inches or more in height can interfere with the underneath clearance and thus create safety problems for small automobiles. The safety edge recommended by FHWA is rapidly gaining acceptance.

\section{SMALL AND LARGE VEHICLES}

- Vulnerability of small automobiles to road surface discontinuities is indicated by accident data. The probability of injury during a collision is also increased for small vehicles. Crash involvement rates for smaller cars are greater than for larger cars. Smaller cars may be driven by younger drivers, at higher speeds, or in different circumstances, or roadway disturbances may pose more severe problems for smaller cars than for larger cars.

- Large commercial vehicles, because of their size and design, may be more sensitive than passenger cars to some surface discontinuities. Those differences are seen in roughness response and sensitivity to low tire-road surface friction.

- No definitive research has been done to quantify the sensitivity of large vehicles to more abrupt features such as potholes, curbs, or pavement edges. From the knowledge of truck dynamic properties, it may be expected that certain of these road features can create a greater vibration disturbance to trucks than to cars.

- Ice and snow on road surfaces are more critical for certain commercial vehicles. The critical nature arises from several differences between commercial vehicles and passenger cars: articulated vehicles have unique modes of instability (e.g., capability to jackknife), accidents are more severe because of greater size and mass, and these vehicles are more prone to rollover, even in the absence of a collision.

Most drivers are capable of adapting to adverse circumstances. Because of this capability, many potentially dangerous surface problems never cause a serious accident. The danger, however, is sometimes critical with respect to the unwary, the impaired, the distracted, or the imprudent driver. Engineers have traditionally constructed and maintained reasonably safe highways, and most drivers expect satisfactory surface conditions. Road conditions that were acceptable when the U.S. highway transportation system was developing are not acceptable to the public today because of this driver expectancy. Complicating the problem is the fact that responsible government entities do not have the funds available to maintain all highways in asconstructed condition. There is a need for highway engineers to assess their maintenance policies as the best information becomes available, and prioritize limited funds cost effectively. The task group trusts that this report provides much of the required information. 


\section{THE NATIONAL ACADEMIES Advisers to the Nation on Science, Engineering, and Medicine}

The National Academy of Sciences is a private, nonprofit, self-perpetuating society of distinguished scholars engaged in scientific and engineering research, dedicated to the furtherance of science and technology and to their use for the general welfare. On the authority of the charter granted to it by the Congress in 1863, the Academy has a mandate that requires it to advise the federal government on scientific and technical matters. Dr. Ralph J. Cicerone is president of the National Academy of Sciences.

The National Academy of Engineering was established in 1964, under the charter of the National Academy of Sciences, as a parallel organization of outstanding engineers. It is autonomous in its administration and in the selection of its members, sharing with the National Academy of Sciences the responsibility for advising the federal government. The National Academy of Engineering also sponsors engineering programs aimed at meeting national needs, encourages education and research, and recognizes the superior achievements of engineers. Dr. Charles M. Vest is president of the National Academy of Engineering.

The Institute of Medicine was established in 1970 by the National Academy of Sciences to secure the services of eminent members of appropriate professions in the examination of policy matters pertaining to the health of the public. The Institute acts under the responsibility given to the National Academy of Sciences by its congressional charter to be an adviser to the federal government and, on its own initiative, to identify issues of medical care, research, and education. Dr. Harvey V. Fineberg is president of the Institute of Medicine.

The National Research Council was organized by the National Academy of Sciences in 1916 to associate the broad community of science and technology with the Academy's purposes of furthering knowledge and advising the federal government. Functioning in accordance with general policies determined by the Academy, the Council has become the principal operating agency of both the National Academy of Sciences and the National Academy of Engineering in providing services to the government, the public, and the scientific and engineering communities. The Council is administered jointly by both the Academies and the Institute of Medicine. Dr. Ralph J. Cicerone and Dr. Charles M. Vest are chair and vice chair, respectively, of the National Research Council.

The Transportation Research Board is one of six major divisions of the National Research Council. The mission of the Transportation Research Board is to provide leadership in transportation innovation and progress through research and information exchange, conducted within a setting that is objective, interdisciplinary, and multimodal. The Board's varied activities annually engage about 7,000 engineers, scientists, and other transportation researchers and practitioners from the public and private sectors and academia, all of whom contribute their expertise in the public interest. The program is supported by state transportation departments, federal agencies including the component administrations of the U.S. Department of Transportation, and other organizations and individuals interested in the development of transportation. www.TRB.org

www.national-academies.org 
TRANSPORTATION RESEARCH BOARD

500 Fifth Street, NW

Washington, DC 20001

\section{THE NATIONAL ACADEMIES}

Advisers to the Nation on Science, Engineering, and Medicine

The nation turns to the National Academies—National Academy of Sciences, National Academy of Engineering, Institute of Medicine, and National Research Councilfor independent, objective advice on issues that affect people's lives worldwide.

www.national-academies.org 